Cochrane Database of Systematic Reviews

\title{
Laparoscopy for diagnosing resectability of disease in women with advanced ovarian cancer (Review)
}

van de Vrie R, Rutten MJ, Asseler JD, Leeflang MMG, Kenter GG, Mol BWJ, Buist M

van de Vrie R, Rutten MJ, Asseler JD, Leeflang MMG, Kenter GG, Mol BWJ, Buist M.

Laparoscopy for diagnosing resectability of disease in women with advanced ovarian cancer.

Cochrane Database of Systematic Reviews 2019, Issue 3. Art. No.: CD009786.

DOI: 10.1002/14651858.CD009786.pub3.

www.cochranelibrary.com 
TABLE OF CONTENTS

ABSTRACT 1

PLAIN LANGUAGE SUMMARY

SUMMARY OF FINDINGS

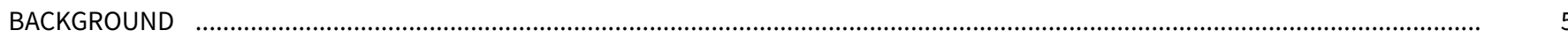

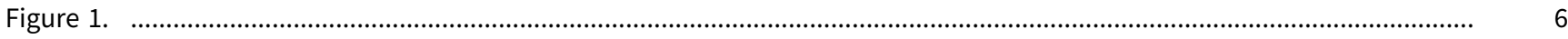

OBJECTIVES

METHODS

Figure 2.

RESULTS

Figure 3.

Figure 4.

Figure 5.

Figure 6.

Figure 7.

Figure 8.

Figure 9.

Figure 10.

Figure 11.

Figure 12.

DISCUSSION

AUTHORS' CONCLUSIONS

ACKNOWLEDGEMENTS

REFERENCES

CHARACTERISTICS OF STUDIES

DATA

Test 1. Laparoscopy.

Test 2. PIV $\geq 8$ to diagnose unresectable disease with $>1 \mathrm{~cm}$ residual disease.

Test 4. Modified fagotti PIV $>4$ to diagnose unresectable disease with $>1 \mathrm{~cm}$ residual disease.

APPENDICES

WHAT'S NEW

CONTRIBUTIONS OF AUTHORS

DECLARATIONS OF INTEREST

SOURCES OF SUPPORT

DIFFERENCES BETWEEN PROTOCOL AND REVIEW

INDEX TERMS 


\section{Laparoscopy for diagnosing resectability of disease in women with advanced ovarian cancer}

Roelien van de Vrie ${ }^{1}$, Marianne J Rutten ${ }^{1}$, Joyce Danielle Asseler 1 , Mariska MG Leeflang 2 , Gemma G Kenter ${ }^{3}$, Ben Willem J Mol${ }^{4}$, Marrije Buist ${ }^{3}$

1Department of Obstetrics and Gynaecology, Academic Medical Center, Amsterdam, Netherlands. 2Department of Clinical Epidemiology, Biostatistics and Bioinformatics, Academic Medical Center, University of Amsterdam, Amsterdam, Netherlands. ${ }^{3}$ Gynaecology, Academic Medical Center Amsterdam, Amsterdam, Netherlands. ${ }^{4}$ Department of Obstetrics and Gynaecology, Monash University, Clayton, Australia

Contact: Roelien van de Vrie, Department of Obstetrics and Gynaecology, Academic Medical Center, Meibergdreef 9, Amsterdam, 1105 AZ, Netherlands.r.vandevrie@amc.nl.

Editorial group: Cochrane Gynaecological, Neuro-oncology and Orphan Cancer Group.

Publication status and date: New search for studies and content updated (no change to conclusions), published in Issue 3, 2019.

Citation: van de Vrie R, Rutten MJ, Asseler JD, Leeflang MMG, Kenter GG, Mol BWJ, Buist M. Laparoscopy for diagnosing resectability of disease in women with advanced ovarian cancer. Cochrane Database of Systematic Reviews 2019, Issue 3. Art. No.: CD009786. DOI: 10.1002/14651858.CD009786.pub3.

Copyright @ 2019 The Cochrane Collaboration. Published by John Wiley \& Sons, Ltd.

\section{A B S T R A C T}

\section{Background}

This is an update of a Cochrane Review that was originally published in 2014, Issue 2.

The presence of residual disease after primary debulking surgery is a highly significant prognostic factor in women with advanced ovarian cancer. In up to $60 \%$ of women, residual tumour of $>1 \mathrm{~cm}$ is left behind after primary debulking surgery (defined as suboptimal debulking). These women might have benefited from neoadjuvant chemotherapy (NACT) prior to interval debulking surgery instead of primary debulking surgery followed by chemotherapy. It is therefore important to select accurately those women who would best be treated with primary debulking surgery followed by chemotherapy from those who would benefit from NACT prior to surgery.

\section{Objectives}

To determine if performing a laparoscopy, in addition to conventional diagnostic work-up, in women suspected of advanced ovarian cancer is accurate in predicting the resectability of disease.

\section{Search methods}

We searched the Cochrane Central Register of Controlled Trials (CENTRAL; 2018, Issue 6) in the Cochrane Library; MEDLINE via Ovid, Embase via Ovid, MEDION and Science Citation Index and Conference Proceedings Citation Index (ISI Web of Science) to July 2018. We also checked references of identified primary studies and review articles.

\section{Selection criteria}

We included studies that evaluated the diagnostic accuracy of laparoscopy to determine the resectability of disease in women who are suspected of advanced ovarian cancer and planned to receive primary debulking surgery.

\section{Data collection and analysis}

Pairs of review authors independently assessed the quality of included studies using QUADAS-2 and extracted data on study and participant characteristics, index test, target condition and reference standard. We extracted data for two-by-two tables and summarised these graphically. We calculated sensitivity and specificity and negative predictive values. 


\section{Main results}

We included 18 studies, reporting on 14 cohorts of women (including 1563 participants), of which one was a randomised controlled trial (RCT). Laparoscopic assessment suggested that disease was suitable for optimal debulking surgery (no macroscopic residual disease or residual disease $<1 \mathrm{~cm}$ (negative predictive values)) in 54\% to $96 \%$ of women who had macroscopic complete debulking surgery (no visible disease at end of laparotomy) and in $69 \%$ to $100 \%$ of women who had optimal debulking surgery (residual tumour $<1 \mathrm{~cm}$ at end of laparotomy).

Only two studies avoided partial verification bias by operating on all women independent of laparoscopic findings, and provided data to calculate sensitivity and specificity. These two studies had no false positive laparoscopies (i.e. no women had a laparoscopy indicating unresectable disease and then went on to have optimal debulking surgery (no disease $>1 \mathrm{~cm}$ remaining)).

Due to the large heterogeneity pooling of the data was not possible for meta-analysis.

\section{Authors' conclusions}

Laparoscopy may be a useful tool to identify those women who have unresectable disease, as no women were inappropriately unexplored. However, some women had suboptimal primary debulking surgery, despite laparoscopy predicting optimal debulking and data are at high risk of verification bias as only two studies performed the reference standard (debulking laparotomy) in test (laparoscopy)-positive women. Using a prediction model does not increase the sensitivity and will result in more unnecessarily explored women, due to a lower specificity.

\section{PLAIN LANGUAGE SUMMARY}

\section{Laparoscopy in diagnosing extensiveness of ovarian cancer}

\section{Why is improving the diagnosis of extensiveness of ovarian cancer important?}

Ovarian cancer is a disease with a high-mortality (death) rate. Many women (75\%) are diagnosed when their disease is already at an advanced stage and 140,000 women die of this disease each year worldwide. Treatment consist of debulking surgery (removal of as much of the tumour as possible during an operation called a laparotomy - normally through a long vertical cut on the abdomen) and six cycles of chemotherapy. The order in which these two treatments are given depends on the extensiveness of disease (how widespread) and on the general health of the patient. The goal of debulking surgery is to remove all visible tumour or at least to leave no residual tumour deposit bigger than $1 \mathrm{~cm}$ in diameter. When the diagnostic evaluation suggests that the goal of debulking surgery could not be achieved, initial treatment may be three cycles of chemotherapy to first shrink the tumour, followed by debulking surgery and then further chemotherapy to complete the course of six cycles of chemotherapy.

To diagnose the extensiveness of disease by physical examination, ultrasonography, abdominal computed tomography (CT scan), and measurement of serum tumour(blood) markers are performed. An incorrect diagnosis could result in women having unsuccessful primary debulking surgery.

\section{What is the aim of this review?}

The aim of this review was to investigate if laparoscopy (keyhole surgery to look inside the abdominal cavity) is accurate in predicting whether a women can be successfully operated to remove of all visible tumour or at least to leave no tumour deposits larger than $1 \mathrm{~cm}$. If so, this could help to avoid operating on those women who would be better treated with chemotherapy first.

\section{What are the main results in this review?}

The review included a total of 18 relevant studies, 11 of which were added for this update, and looked at 14 groups of women. In total 1563 women underwent a laparoscopy to evaluate the extensiveness of disease in the abdomen. Two studies concluded that laparoscopy was good at identifying those women in whom optimal debulking surgery was not feasible (with tumour deposits $>1 \mathrm{~cm}$ left after surgery) (low false positive rate for laparoscopy) and in all women the diagnosis was correct. However, even after a laparoscopy had suggested that optimal debulking surgery was feasible, some women had suboptimal primary debulking surgery where tumour deposits of $>1 \mathrm{~cm}$ were left). For every 100 women referred for primary debulking surgery after laparoscopy, between four and 46 will be left with visible residual tumour.

\section{How reliable are the results of the studies in this review?}

A limitation of this review is that only two studies performed diagnostic laparoscopy and then went on to attempt debulking laparotomy in all women. The other studies only performed a laparotomy when laparoscopy suggested that debulking to $<1 \mathrm{~cm}$ tumour residue was feasible. The correct diagnosis at laparoscopy is thereby not confirmed when $>1 \mathrm{~cm}$ tumour residue was predicted, this is called verification bias.

\section{Who do the results of this review apply to?}

Some studies used for this review also included women who underwent debulking surgery after chemotherapy or for recurrence. But mainly women were only included who were planned for primary debulking surgery. Therefore, the results presented in this review are applicable for all women who are scheduled for primary debulking surgery.

\section{What are the implications of this review?}


The studies in this review suggest that laparoscopy can accurately diagnose the extensiveness of disease. When performed after standard diagnostic work-up less women had unsuccessful debulking surgery and therefore resulting in less morbidity, Yet, there will still be women undergoing a laparotomy resulting in residual tumour of $>1 \mathrm{~cm}$ after surgery.

\section{How up to date is this review?}

The review authors searched for and used studies published from inception of databases until July 2018. 


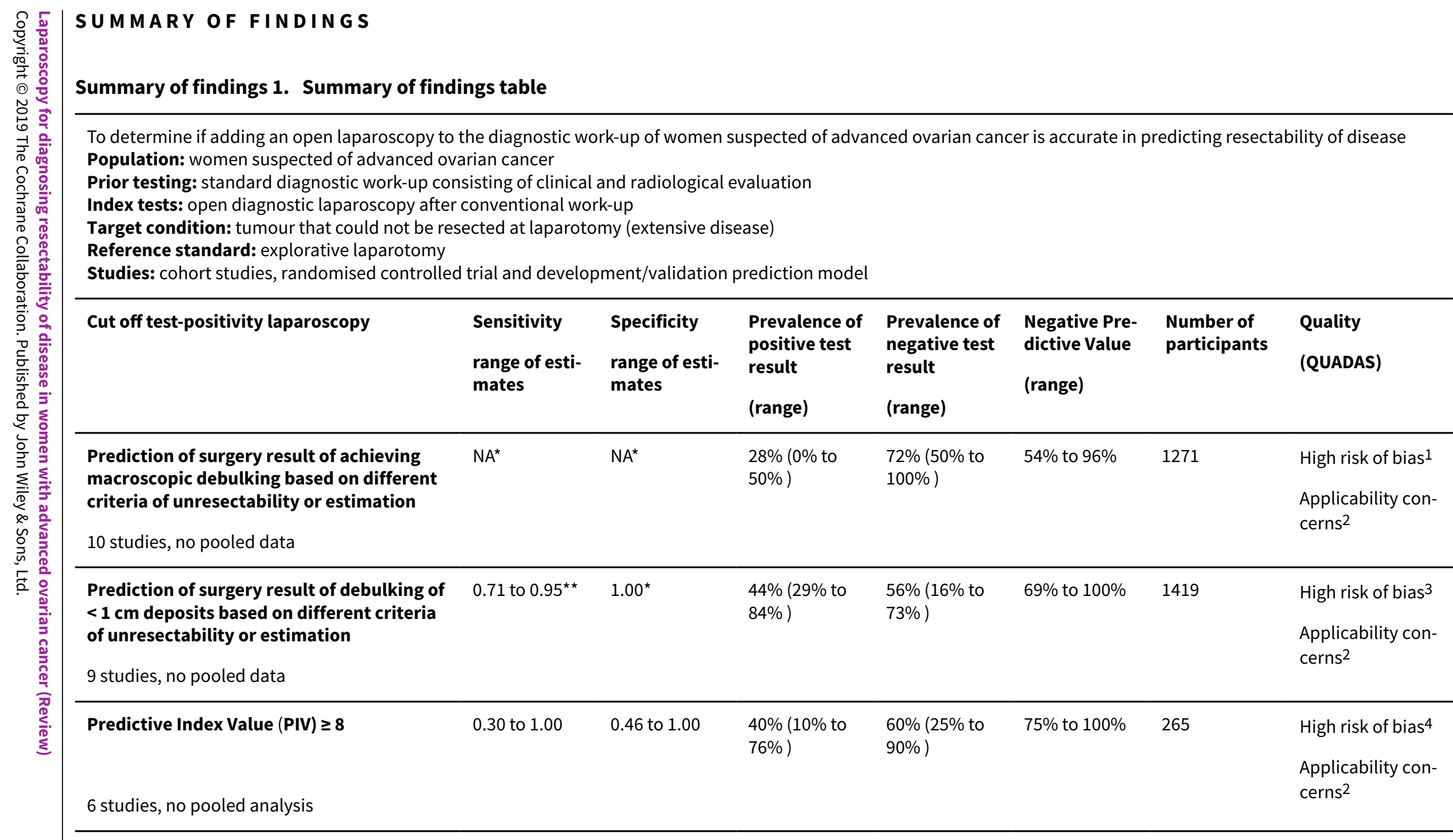

* No studies reported outcome of surgery of no residual macroscopic disease and performed the reference standard in all women

** Only two studies performed the reference standard in all women, sensitivity and specificity are based on these two studies

1 Non of the studies performed the reference standard in test-positive women

2 Applicability concerns based on inclusion of not only women planned for primary debulking surgery or conventional diagnostic work-up not conclusive

3Only 2 studies performed the reference standard in test-positive women

4 Three studies did not perform the reference standard in test-positive women 


\section{B A C K G R O U N D}

Epithelial ovarian cancer is one of the leading causes of death from gynaecological malignancies in the world (Globocan 2012). Women are commonly diagnosed with the disease at an advanced stage (Siegel 2012). This is mostly due to an early spread throughout the peritoneal (abdominal) cavity (Gallardo-Rincón 2016). Advanced stage ovarian cancer is associated with a five-year overall survival rate of $30 \%$ to $40 \%$ (Globocan 2012). Despite an initial response to treatment of $80 \%$, recurrence occurs in $70 \%$ of women, and the median survival for women with advanced disease is two to four years (Munkarah 2004).

Standard treatment of women with advanced ovarian cancer is a combination of debulking surgery and chemotherapy (carboplatin with or without the addition of paclitaxel) (Makar 2016; Vergote 2013). Debulking surgery normally involves a major operation through a long mid-line incision on the abdomen, called a laparotomy. The aim of debulking surgery is remove the womb, tubes and ovaries and all of the visible tumour deposits to leave no (macroscopic) visible tumour. If this cannot be achieved, the diameter of individual residual tumour deposits should be as small as possible, ideally $<1 \mathrm{~cm}$ in diameter, as survival is related to the size of the residual tumour (Bristow 2002; Du Bois 2009; Eisenkop 1998; Elattar 2011). Debulking surgery leaving the largest residual tumour deposits of $>1 \mathrm{~cm}$ in diameter is regarded as a suboptimal result from surgery.

An alternative strategy to primary debulking surgery followed by chemotherapy is treatment with chemotherapy first (called neoadjuvant chemotherapy (NACT)), with interval debulking surgery after three cycles of chemotherapy, followed by a further three cycles (Kehoe 2015; Vergote 2010). NACT is given in women with co-morbidities or, if primary surgery is likely to leave large residual tumour deposits (Wright 2016). Also, if the first surgery was not a maximal attempt by an experienced gynaecological oncologist, an attempt at interval debulking surgery may improve survival. These women can be offered further surgery after three courses of chemotherapy, followed by another three courses of chemotherapy (Wright 2016). In these cases, primary debulking surgery might lead to surgical morbidity without gain of survival (Vergote 2010). Ideally, primary debulking surgery leaving residual tumour of $>1 \mathrm{~cm}$ should be avoided and women with disease which is not debulkable initially, should be treated with NACT (Wright 2016).

\section{Clinical pathway \\ Prior test(s)}

Standard work-up consists of a physical and gynaecological examination, ultrasonography, serum cancer antigen 125 (CA-125) sometimes in combination with human epididymis protein 4 (HE4) and computed tomography (CT) scan or magnetic resonance imaging (MRI) scan of the pelvic area, the abdomen and the thorax. Positron emission tomography (PET) can also be performed (Hoogendam 2017). When women are thought to have operable disease after standard work-up, primary debulking surgery is offered to those fit enough to consider major surgery.

\section{Role of index test(s)}

The ability of the standard diagnostic work-up to predict accurately who might benefit from primary surgery is low, resulting in suboptimal debulking (>1 cm residual tumour) in $10 \%$ to $60 \%$ of women (Gerestein 2009; Wright 2016). This suggests that current diagnostic work-up is not sufficiently accurate and could be improved. Staging laparotomy is the most accurate way to determine if the amount of tumour in the abdomen is too extensive to achieve macroscopic debulking. Yet, a laparotomy is a very invasive intervention for diagnostic purposes.

Diagnostic laparoscopy is a less invasive surgical option to determine surgical resectability. During laparoscopy a small telescope is inserted into the abdominal cavity through a small incision. The entire abdominal cavity is systematically examined; inspecting the ovaries, fallopian tubes, uterus, pelvic peritoneum, omentum, serosa and mesentery of the large and small bowel, spleen, liver surface, paracolic gutters and diaphragm. In some institutions, a diagnostic laparoscopy is included in the standard diagnostic work-up, and in others laparoscopy is only performed when there is doubt on the resectability of disease. This surgical diagnostic procedure, under general anaesthesia, is an additional intervention with both a risk of complications and increased costs. The overall risk of complications of a diagnostic laparoscopy is between $1 \%$ and $5 \%$ depending on the type of procedure and study population (Chi 2004). If we are able to identify, prior to surgery, those women with ovarian cancer who have metastatic disease that is likely to be too extensive to be resected at primary debulking surgery, these women could avoid primary surgery. Women who are diagnosed with too extensive disease to be removed during primary debulking surgery could be treated first with NACT (Figure 1), with a later attempt at interval debulking surgery. This strategy could improve the rate of optimal surgery, limiting unnecessary morbidity and costs. 
Figure 1. Laparoscopy is used as a triage test. If laparoscopy is positive indicating that the target condition is present (i.e. a direct debulking operation would be unsuccessful: residual cancer $>1 \mathrm{~cm}$ is left behind). For these women a primary debulking could be avoided and they will be treated with neoadjuvant chemotherapy. The existing pathway would be that every patient will receive an explorative laparotomy where in this flow diagram the laparoscopy is placed.

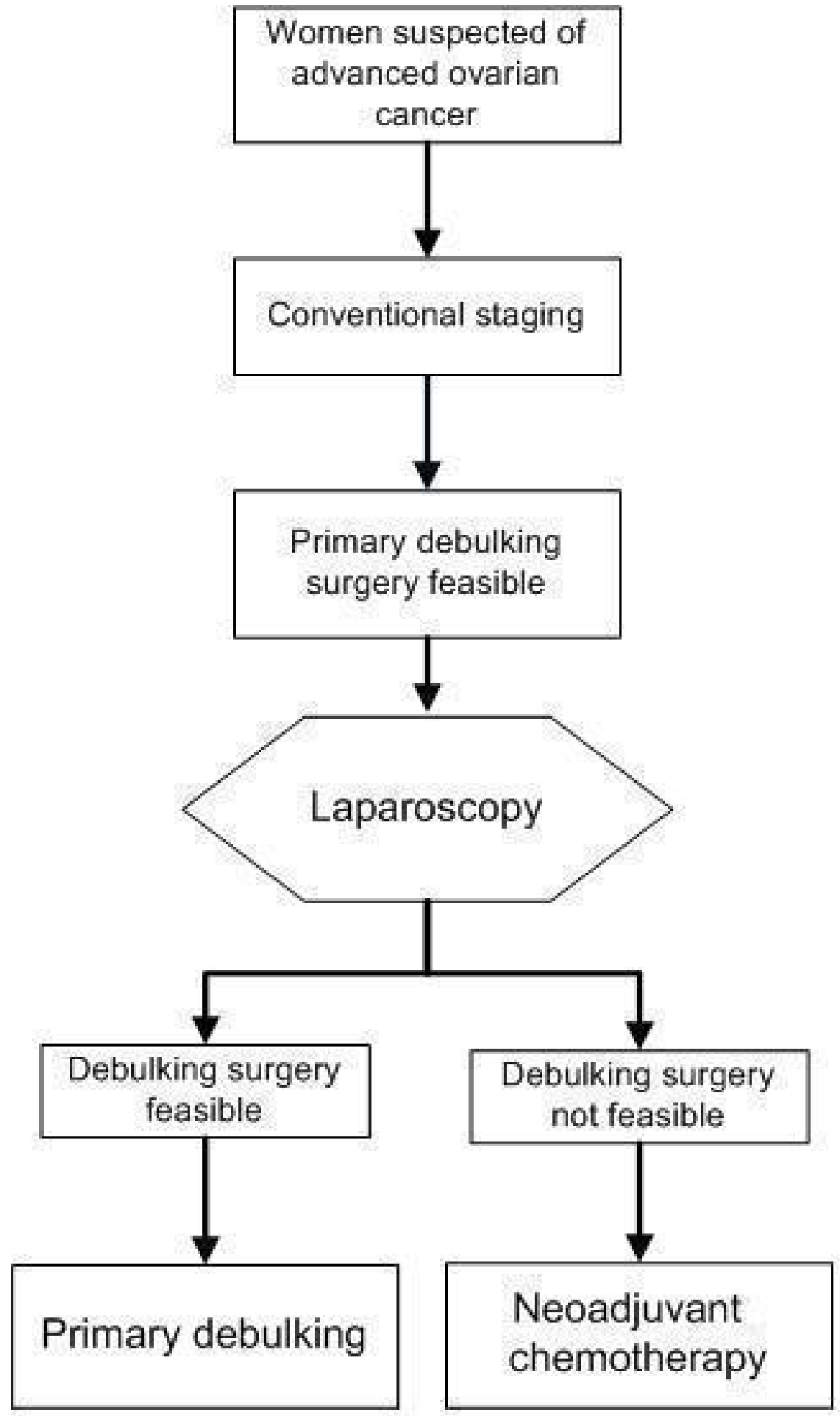




\section{Alternative test(s)}

Diffusion-weighted magnetic resonance imaging (DW-MRI) is added as an extra diagnostic test to predict outcome of primary debulking surgery ( Espada 2013; Michielsen 2017).

\section{Rationale}

As standard staging tends to underestimate disease extent, potentially exposing patients to unsuccessful or more complicated surgery than expected pre-operatively, accurate prediction of surgery result is necessary. Since the initial publication of this review new evidence has become available regarding the subject, therefore the original review was updated.

\section{O B JE C T IVES}

To determine if performing a laparoscopy, in addition to conventional diagnostic work-up, in women suspected of advanced ovarian cancer is accurate in predicting the resectability of disease.

\section{METHODS}

\section{Criteria for considering studies for this review \\ Types of studies}

We included studies that evaluated laparoscopy as a diagnostic test to determine resectability of disease in women suspected of advanced ovarian cancer who were scheduled for primary debulking surgery after conventional staging. In these studies the extensiveness of disease diagnosed with a laparoscopy was compared with the diagnosis at laparotomy. Case-control studies were excluded from the review because of the risk of bias in this study design. We presumed that there would be studies in which not all women had undergone reference standard (i.e. laparotomy) when the index test was positive (i.e. unsuitable for primary debulking surgery as likely to lead to suboptimal result). Therefore, we also included studies in which only the participants who had a negative result of the index test (meaning the tumour was thought to be not too extensively spread to obtain optimal debulking result) underwent the reference standard (laparotomy).

\section{Participants}

Participants included women suspected of having advanced stage ovarian cancer (FIGO stage IIB, IIC, IIIA-C and IVA-B), who were scheduled for primary debulking surgery, without any contraindications for laparoscopy, laparotomy, or both.

\section{Index tests}

The evaluated test was an additional diagnostic laparoscopy, performed when a woman was recommended to have primary debulking surgery after standard diagnostic work-up. Standard work-up usually consisted of full physical and gynaecological examination, ultrasonography, serum cancer antigen 125 (CA-125) and computed tomography (CT) scan or magnetic resonance imaging (MRI) scan of the pelvic area, the abdomen and the thorax. A positive index test result means that the tumour was judged to be too extensively spread to be operated upon; a negative index test result means that the tumour, according to the laparoscopy, was not too extensive to be resected (Figure 2).

Figure 2. Two by two table of index test results by reference standard outcomes. $T P=$ True Positive, $T N=$ True Negative, FP = False Positive, FN = False Negative

\begin{tabular}{|l|l|l|}
\hline & $\begin{array}{l}\text { Index test positive } \\
\text { (At laparoscopy tumour too } \\
\text { extensively spread to be } \\
\text { operated upon) }\end{array}$ & $\begin{array}{l}\text { Index test negative } \\
\text { (At laparoscopy tumour not } \\
\text { too extensively spread to be } \\
\text { resected) }\end{array}$ \\
\hline $\begin{array}{l}\text { Reference test positive } \\
\text { (At laparotomy tumour too } \\
\text { extensively spread to be } \\
\text { operated upon) }\end{array}$ & $\begin{array}{l}\text { TP: patients who had } \\
\text { residual tumour after PDS } \\
\text { who were correctly identified } \\
\text { as having too extensive } \\
\text { disease to resect }\end{array}$ & $\begin{array}{l}\text { FN: patients with seemingly } \\
\text { not too extensive disease by } \\
\text { laparoscopy, but who turned } \\
\text { out to have too extensive } \\
\text { disease to resect }\end{array}$ \\
\hline $\begin{array}{l}\text { Reference test negative } \\
\text { (At laparotomy tumour not } \\
\text { too extensively spread to } \\
\text { resect) }\end{array}$ & $\begin{array}{l}\text { FP: patients who were } \\
\text { identified by laparoscopy to } \\
\text { have too extensive disease } \\
\text { but had no macroscopic or } \\
\text { less than one centimetre of } \\
\text { residual tumour deposits }\end{array}$ & $\begin{array}{l}\text { TN: patients with not too } \\
\text { extensive disease by } \\
\text { laparoscopy and who indeed } \\
\text { had no macroscopic } \\
\text { residuals after debulking. }\end{array}$ \\
\hline
\end{tabular}

\section{Target conditions}

The target condition was deposits of ovarian cancer that could not be resected to at least $<1 \mathrm{~cm}$ (maximum diameter) at laparotomy and therefore making women unsuitable for primary debulking surgery. Examples of ovarian cancer deposits that cannot be resected include extensive peritoneal and mesenteric carcinomatoses (> 100 spots) or extensive metastases in the upper abdomen, such as bulky disease on the diaphragm or liver 
surfaces. The definition of ovarian cancer deposits that could not be resected at laparotomy was extracted from each study. Ideally, no macroscopic residual tumour is left after surgery $(0 \mathrm{~cm})$ to obtain the best survival, yet in the literature different cut-off values are used for residual tumour $(>0 \mathrm{~cm}$ or $>1 \mathrm{~cm})$, therefore we report both outcome values.

\section{Reference standards}

Laparotomy was the reference standard and allows complete exploration of the entire abdominal cavity and to locate all tumour deposits. The goal at laparotomy is to remove all macroscopic (visible) tumour, therefore representing a true impression of the resectability of ovarian cancer deposits in the abdominal cavity.

\section{Search methods for identification of studies}

\section{Electronic searches}

To identify eligible studies, searches were run up to 5 July 2018 in the following electronic databases:

- the Cochrane Central Register of Controlled Trials (CENTRAL; 2018, Issue 6) in the Cochrane Library;

- MEDLINE via Ovid (to June week 4 2018);

- Embase via Ovid (to 2018 week 27).

We also searched MEDION and Science Citation Index and Conference Proceedings Citation Index (ISI Web of Science). The search strategies can be found in Appendix 1; Appendix 2; Appendix 3; Appendix 4; Appendix 5. No language restrictions were made.

\section{Searching other resources}

Manually searching references from articles retrieved from the computerised databases and searching relevant review articles did identify one additional reference (Chéreau 2010). This article was not found in our electronic database search.

\section{Data collection and analysis}

We followed the guidelines provided in the Cochrane Handbook for Systematic Reviews of Diagnostic Test Accuracy (Handbook for DTA Reviews).

\section{Selection of studies}

In pairs (MR and MB for the first version or RV and JA for the update), we independently reviewed all citations identified by the search strategies. First by title and abstract and when necessary by review of full text to determine eligibility. To be eligible, we assessed each study to determine if participants met the inclusion and exclusion criteria as described above. We included studies if sufficient information was provided to apply the selection criteria and if they included data for analysis.

\section{Data extraction and management}

We developed a data extraction form and piloted it using a subset of the articles included in the previous Cochrane review (Rutten 2014). We completed a data extraction form for all included studies. We resolved discrepancies by discussion. We retrieved the following data.

- General information: title, journal, year, publication status and study design.
- Sample size: number of participants meeting the criteria and total number of participants included in the analysis.

- Baseline characteristics: age, FIGO stage.

- Inclusion and exclusion criteria.

- The index test: technique of laparoscopy and cut-off for test positivity.

- Reference standard test: reference standard used. If not all women received a reference standard, how many and what proportion of the total did not; definition of complete, optimal and suboptimal result at laparotomy.

- Whether or not the laparoscopy or laparotomy was performed by a gynaecological-oncologist or a general gynaecologist.

- Number of true positives (TP): women who had residual tumour after primary debulking surgery who were correctly identified as having too extensive disease to resect.

- Number of true negatives (TN): women with not too extensive disease by laparoscopy and who had a complete (no residual tumour) or optimal ( $<1 \mathrm{~cm}$ residual tumour) debulking result.

- Number of false positives (FP): women who were identified by laparoscopy to have too extensive disease but had a complete or optimal ( $<1 \mathrm{~cm}$ residual tumour) debulking result.

- Number of false negatives (FN): women with seemingly not too extensive disease by laparoscopy, but who turned out to have too extensive disease to resect.

- Number of missing, uninterpretable or doubtful results. Number of complete, optimal and suboptimal resections.

- Side effects or complications due to laparoscopy.

\section{Assessment of methodological quality}

Methodological quality of the eligible studies was assessed by using QUADAS-2 (Quality Assessment of Diagnostic Accuracy Studies), a tool for the assessment of quality in systematic reviews of diagnostic accuracy studies (Whiting 2006; Whiting 2011). The tool is based on items that cover a wide range of methodological issues in diagnostic test studies. Quadas-2 comprises four domains: patient selection, index test, reference test and flow and timing. Each domain is assessed in terms of risk of bias and the first three domains are also assessed in terms of concerns regarding applicability. Signaling questions are included to help judge bias. The QUADAS-2 tool is applied in four phases: summarise the review question (Appendix 6), tailor the tool and produce review-specific guidance (Appendix 7), construct a flow diagram for the primary study, and judge bias and applicability.

We independently piloted the tool on two primary studies and no refinements were needed. After testing, the tool was used to rate all included studies. We independently (MR and MB or RV and $\mathrm{JA}$ ) assessed the quality of the studies and any disagreement was resolved by consensus.

\section{Statistical analysis and data synthesis}

We summarised data from each study in a two-by-two table of TP, FP, FN, TN, and this was used to calculate sensitivity and specificity. Studies providing insufficient data to construct two-by-two tables were used to present data on negative predictive values (NPV). NPV is defined as the number of women with no residual disease who were correctly defined (TN), divided by the total number of women who were thought to have no residual disease after primary debulking surgery (TN+FN) (Figure 2). 
We presented Individual study results graphically by plotting the estimates of sensitivity and specificity, if possible, and NPVs and their 95\% confidence intervals (Cls). All plots were done using Review Manager 5.3 and Excel. Analyses were done in Excel and SAS/STAT Software.

\section{Investigations of heterogeneity}

We expected the main sources of heterogeneity in diagnostic accuracy encountered were likely to be related to differences in the disease stage of women included in the study or to the surgeon performing the laparoscopy or laparotomy, or differences in conventional staging. However, we did not investigate sources of heterogeneity for sensitivity or specificity because only two studies reporting sufficient data to analyse sensitivity and specificity were retrieved.

We did perform investigation for heterogeneity among estimates of NPV and among estimates of test positivity. The main source of variation in NPV is expected to be the percentage of people with unresectable tumour tissue (i.e. prevalence). We used Cochran's Q-test and used the $1^{2}$ to estimate the amount of heterogeneity (Higgins 2002) and decided not to pool data if the Cochrane's Q-test turned out to be statistically significant $(P<0.05)$. The Q-statistic was based on the weight (1/variance) and the logit of the NPV of each study, estimated in a univariate model (only test negatives counted), because for most of these studies there were not enough data to do this in a bivariate model.

\section{Sensitivity analyses}

We expected the most important form of bias encountered would be (both partial and differential) verification bias, when a laparotomy was not performed in all women. However, we could not perform sensitivity analyses because too few studies were retrieved.

\section{Assessment of reporting bias}

Tests to detect publication bias are currently used for systematic reviews of clinical trials. However, similar tests have not been designed for reviews of diagnostic studies and in the absence of appropriate methodology, therefore we could not explore publication bias in our review.

\section{RE S U L T S}

\section{Results of the search}

We identified 7237 citations from the electronic searches (138 CENTRAL, 2624 in MEDLINE and 4475 in Embase). Searching MEDION, the science Citation Index and Conference Proceedings Citation Index did not lead to finding any additional citations. We checked the references of relevant reviews and primary diagnostic studies and this revealed one extra reference. After initial evaluation, we retrieved 54 full papers, 18 of which we finally considered eligible for inclusion of this review. We did not have any disagreements on studies eligible for review. A summary of the search results, including the main reason for exclusion is presented in Figure 3. Our main reasons for exclusion were if abstracts were conference abstracts and subsequently the full articles were available and included in the review or if studies did not report data about evaluation of resectability of disease (see Characteristics of excluded studies). Our search found one casecontrol study which was excluded (Bresson 2016). We identified six studies reporting on two cohorts (Brun 2008; Brun 2009; Fagotti 2013; Petrillo 2015 and Vizzielli 2014; Vizzielli 2016). Details of all included studies on the design, setting, study population, target condition and reference standard of each included new study can be found in Characteristics of included studies. 
Figure 3. Study flow diagram: Results of the search for studies evaluating the diagnostic accuracy of laparoscopy to determine resectability of disease in women who are suspected of advanced ovarian cancer and planned for primary debulking surgery after conventional staging.

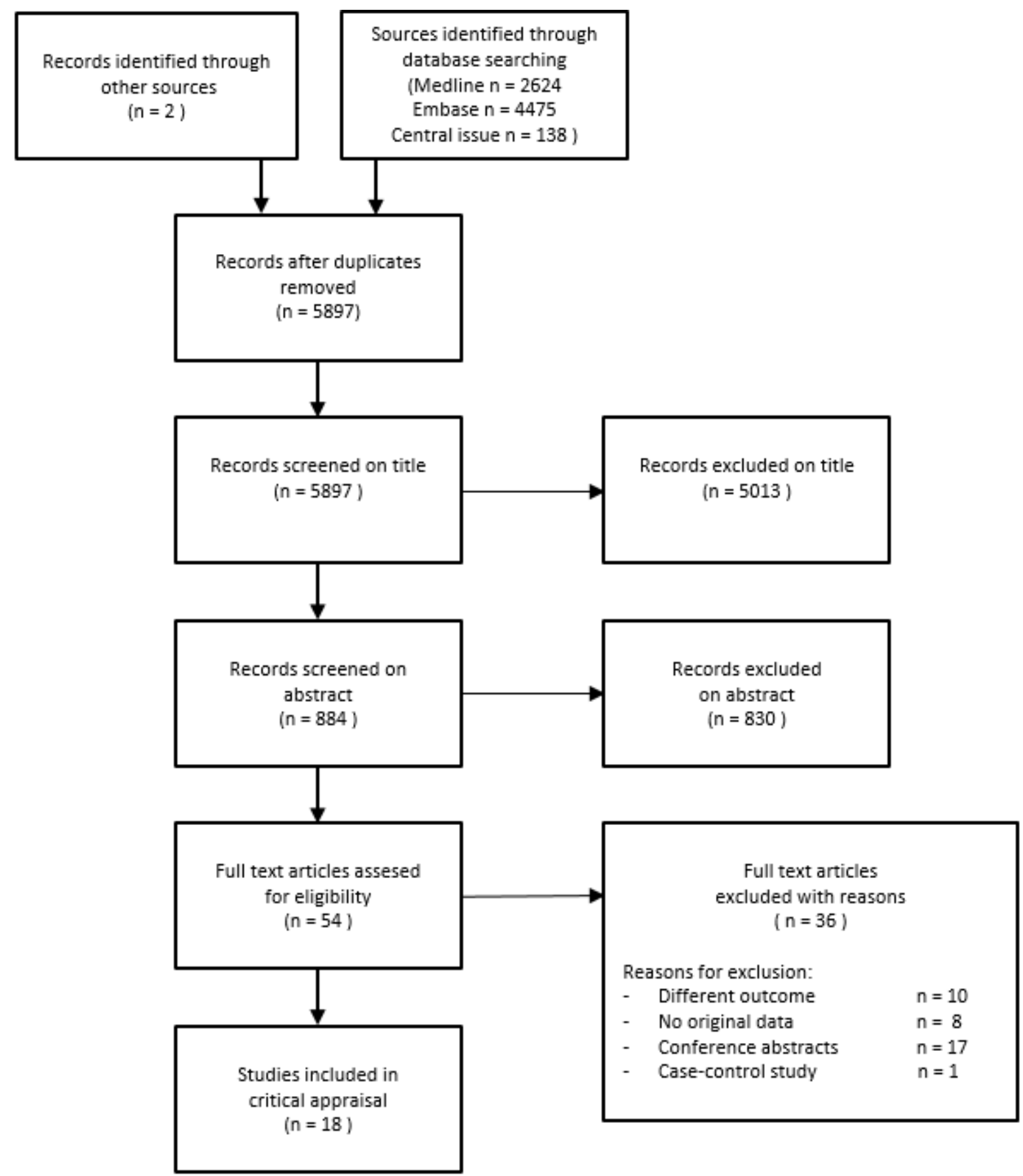

\section{Methodological quality of included studies}

We present the results of the quality assessment using QUADAS- 2 in Figure 4 and Figure 5 for all included studies. We judged one study as low risk of bias and low concern regarding applicability in all domains (Vizzielli 2016). We judged all other studies for at least one domain to be either unclear or high risk of bias or having concerns regarding applicability. We judged two studies at high risk of bias or high concern for applicability on more than one domain (Varnoux 2013; Vergote 1998).

In seven studies, the threshold for test positivity of the index test was based on a clinical estimation by the gynaecological oncologist, rather than presence of predefined criteria, therefore, we judged these studies as unclear or high in risk of bias for index test. Although in all studies the result of the reference standard 
(laparotomy) was interpreted with the knowledge of the result of the index test (laparoscopy), the risk of bias concerning the reference standard we still scored as low. An explorative laparotomy was performed in all index test-negative women to judge the extensiveness of disease, furthermore all the women judged as operable underwent debulking surgery. Therefore, we can only draw a true conclusion about the resectability of the tumour deposits at the end of the surgical intervention. Because a primary debulking surgery leaving none or $<1 \mathrm{~cm}$ of residual tumour is associated with a better prognosis, it is likely that all women, who were thought at laparoscopy to be operable, underwent an attempt at primary debulking surgery, provided that they were still fit enough for major surgery.

Figure 4. 'Risk of bias' and applicability concerns graph: review authors' judgements about each domain presented as percentages across included studies

\begin{tabular}{|c|c|c|c|c|c|c|c|c|c|c|}
\hline \multirow{2}{*}{$\begin{array}{r}\text { Patient Selection } \\
\text { Index Test }\end{array}$} & & 6 & \multicolumn{3}{|c|}{12} & & \multicolumn{4}{|c|}{14} \\
\hline & & 6 & & \multicolumn{2}{|l|}{11} & \multicolumn{5}{|c|}{17} \\
\hline \multirow{4}{*}{$\begin{array}{r}\text { Reference Standard } \\
\text { Flow and Timing }\end{array}$} & \multicolumn{5}{|c|}{18} & \multicolumn{5}{|c|}{18} \\
\hline & & & 4 & & 4 & & & & & \\
\hline & $0 \%$ & $25 \%$ & $50 \%$ & $75 \%$ & $100 \%$ & $0 \%$ & $25 \%$ & $50 \%$ & $75 \%$ & $100 \%$ \\
\hline & \multicolumn{5}{|c|}{ Risk of Bias } & \multicolumn{5}{|c|}{ Applicability Concerns } \\
\hline High & & & Juno & & & & Low & & & \\
\hline
\end{tabular}


Figure 5. 'Risk of bias' and applicability concerns summary: review authors' judgements about each domain for each included study

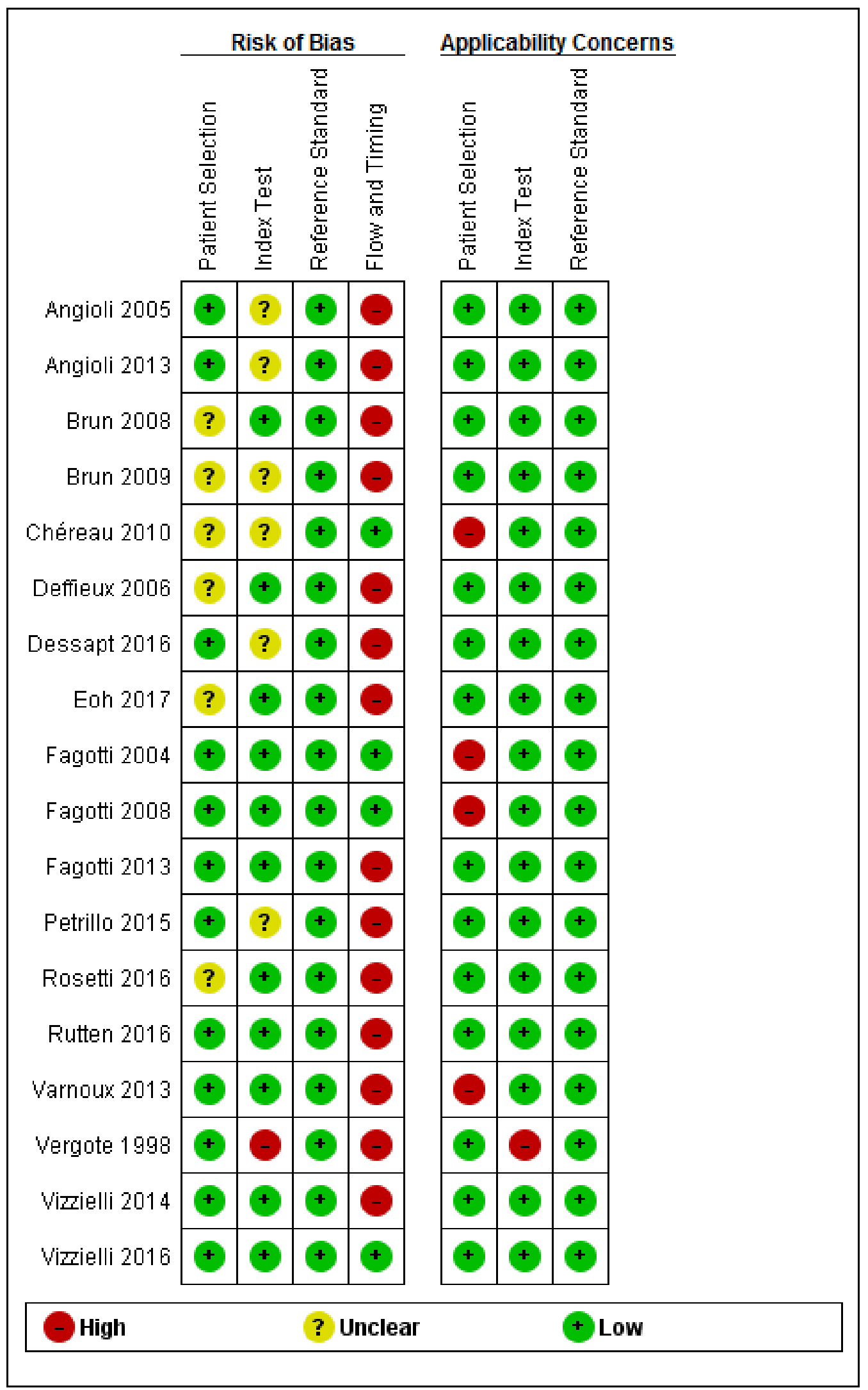

Laparoscopy for diagnosing resectability of disease in women with advanced ovarian cancer (Review) 


\section{Findings}

We identified 18 studies, describing 14 cohorts of women, evaluating laparoscopy as a diagnostic test for extensiveness of disease in women with advanced ovarian cancer, of which one randomised controlled trial (RCT). Eleven articles were added in the updated version of this review. Of the articles describing similar cohorts, data of that cohort were included only once.

In the 18 studies we included there were 1563 women who were suspected to have primary advanced ovarian cancer after conventional work-up (range 15 to 785 women) and who were evaluated by diagnostic laparoscopy for the possibility of primary debulking surgery. Of these, 1104 women actually received a primary debulking surgery after laparoscopy. In all studies, 510 women were diagnosed with unresectable disease at laparoscopy, meaning, these women were thought to have too extensive disease to achieve a residual tumour tissue $<1 \mathrm{~cm}$ in diameter.

Four studies also included women who received laparoscopy prior to an interval debulking surgery or surgery for recurrence (range three to 73 women) (Chéreau 2010; Fagotti 2004; Fagotti 2008; Varnoux 2013). In these studies data on the women receiving primary debulking surgery, were not available separately.

Only two studies performed a laparoscopy and laparotomy in all included women (Fagotti 2004; Fagotti 2008); the indexpositive women received the reference standard (laparotomy). In the other studies, these women were treated with neoadjuvant chemotherapy (NACT), thus leaving 444 women unverified. In the two studies where all women had the index test, all of those who were diagnosed at laparoscopy with disease that was too extensive to be resected during debulking surgery were confirmed as having unresectable disease at laparotomy (Fagotti 2004; Fagotti 2008). These women could have been treated with NACT as shown in Figure 1. The specificity of laparoscopy in both studies was therefore 1. Sensitivity of laparoscopy in these two studies was 0.71 (95\% confidence interval (Cl) 0.44 to 0.89$)$ and $0.95(95 \% \mathrm{Cl}$ 0.84 to 0.99 ), respectively, which means that of all women with unresectable disease at laparotomy, $71 \%$ to $95 \%$ were thought to have unresectable disease at laparoscopy. Of those thought to have resectable disease at laparoscopy, $5 \%$ to $29 \%$ of women had unresectable disease at laparotomy. Fagotti 2004 did not include all women in the analysis because in 13 women it was not possible to diagnose the extensiveness of disease at laparoscopy. The values given in the study of Fagotti 2004 were therefore based on only $80 \%$ of included women, resulting in overestimation of sensitivity and specificity. Furthermore, $25 \%$ of included women in these two studies had laparoscopy before interval debulking surgery or because of recurrent disease.

In all studies, women received a laparotomy when the laparoscopy had a negative index test result (laparoscopy suggested optimal resectable disease). In total, 683 women had no macroscopic residual tumour after primary debulking surgery. However, in total 87 women had suboptimal debulking $(>1 \mathrm{~cm}$ residual tumour deposits) after primary debulking surgery, despite the laparoscopy indicating resectable disease. These women could have been treated with NACT initially.

Not all studies used the same cut-off value to express a successful debulking result. Therefore, we use two figures to show the different outcome values; any macroscopically visible disease and $>1 \mathrm{~cm}$ residual disease. In Figure 6 the data show the included studies with a macroscopic complete debulking result after primary debulking surgery, meaning no residual tumour tissue visible. In Figure 7, the data show included studies with an optimal debulking result, meaning residual tumour $<1 \mathrm{~cm}$. Note that one study used residual tumour $<0.5 \mathrm{~cm}$ as the cut-off value for optimal debulking result and was therefore not included in the figures (Vergote 1998). Negative predictive values (NPV) ranged from $54 \%$ to $96 \%$ for macroscopic complete debulking, with a median of 81 (interquartile range (IQR) 72 to 91 ). For optimal debulking $(<1$ $\mathrm{cm}$ residual disease) the NPV ranged from $69 \%$ to $100 \%$, with a median of 92 (IQR 86 to 97). Figure 8 and Figure 9 show the NPV's of the included studies with their respective $95 \% \mathrm{Cls}$. In more recent studies with larger study populations, NPV result is better. For example, Vizzielli 2016 with a sample size of 555 women undergoing primary debulking surgery with a NPV of $90 \%$ for optimal debulking and a NPV of $75 \%$ for macroscopic complete debulking and Rutten 2016 describes a randomised controlled trial with a sample size of 201 and finds a NPV of $84 \%$ for optimal primary debulking and a NPV of $57 \%$ for macroscopic complete debulking.

We tested for heterogeneity of all included studies with the Cochrane Q-test, with an $\mathrm{R}^{2}=56 \%$ and a $\mathrm{P}<0.001$ for the macroscopic complete debulking group and an $\mathrm{L}^{2}=76 \%$ and a $\mathrm{P}$ $<0.001$ for the optimal debulking group $(<1 \mathrm{~cm}$ residual disease). Based on these test results, we decided not to perform a metaanalysis or pool the data.

As expected, the studies showing a high percentage of test-negative results of the laparoscopy had a higher NPV (Figure 10 and Figure 11). The percentage of test-positives (those women who were thought to have too extensive disease to have optimal primary debulking surgery at laparoscopy and started with NACT) ranged between $16 \%$ and $73 \%$ and test-negatives ranged between $27 \%$ to $84 \%$ per study (Figure 12). 
Figure 6. Absolute numbers of all women receiving laparoscopy before PDS included in analysis, women who received the reference standard, and the false negative and true negative test results for a macroscopic complete debulking surgery result $(0 \mathrm{~cm}$ residual disease) after primary debulking surgery.

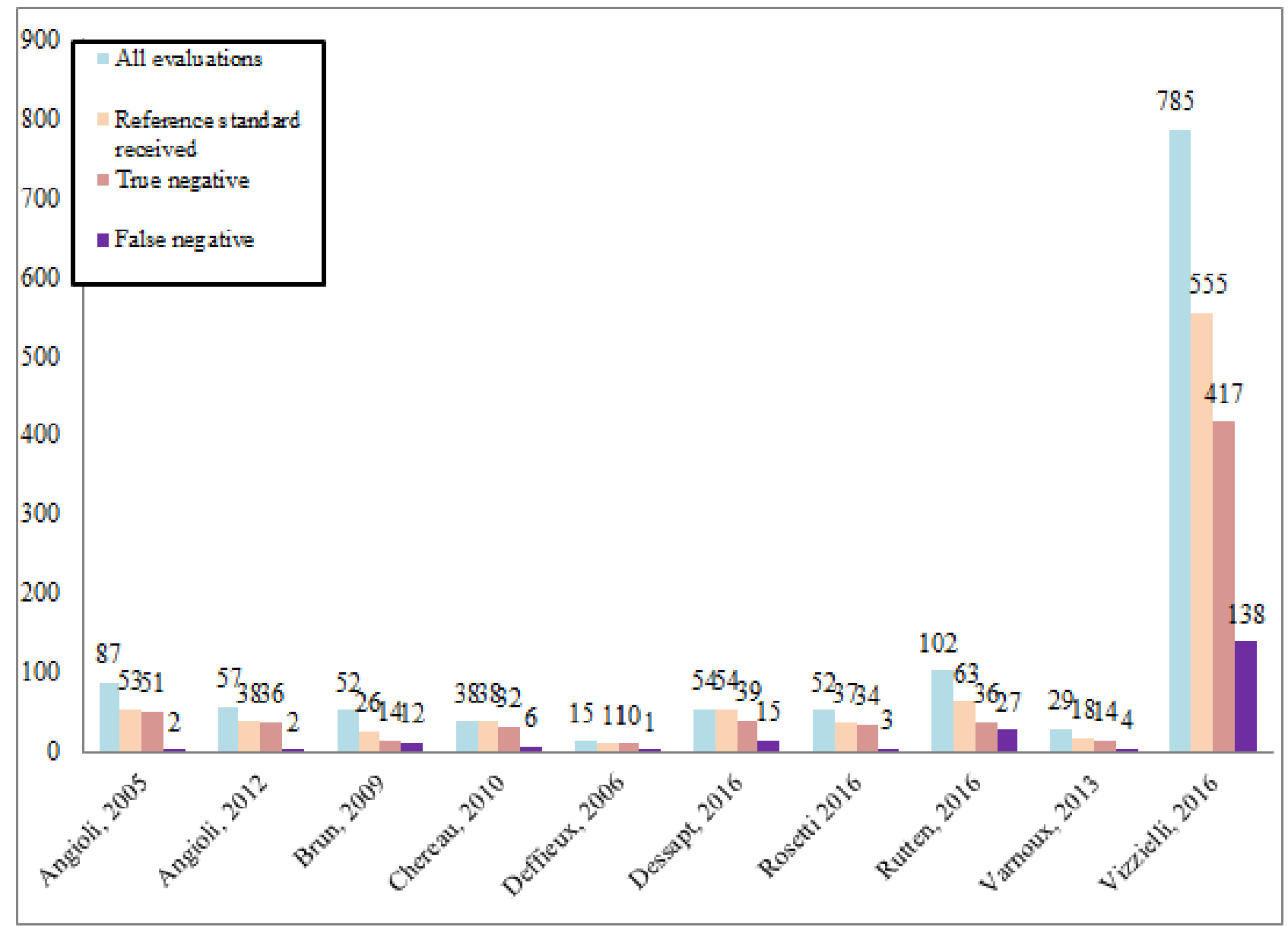


Figure 7. Absolute numbers of all women receiving laparoscopy before PDS included in analysis, women who received the reference standard, and the false negative and true negative test results for an optimal debulking surgery result ( $<1 \mathrm{~cm}$ residual tumour) after primary debulking surgery.All but four studies used residual tumour tissue $<1 \mathrm{~cm}$ as a cut-off definition for an optimal debulking result. Vergote 1998 used RT $<0.5 \mathrm{~cm}$ as a cut-off value and was therefore not used in this figure.

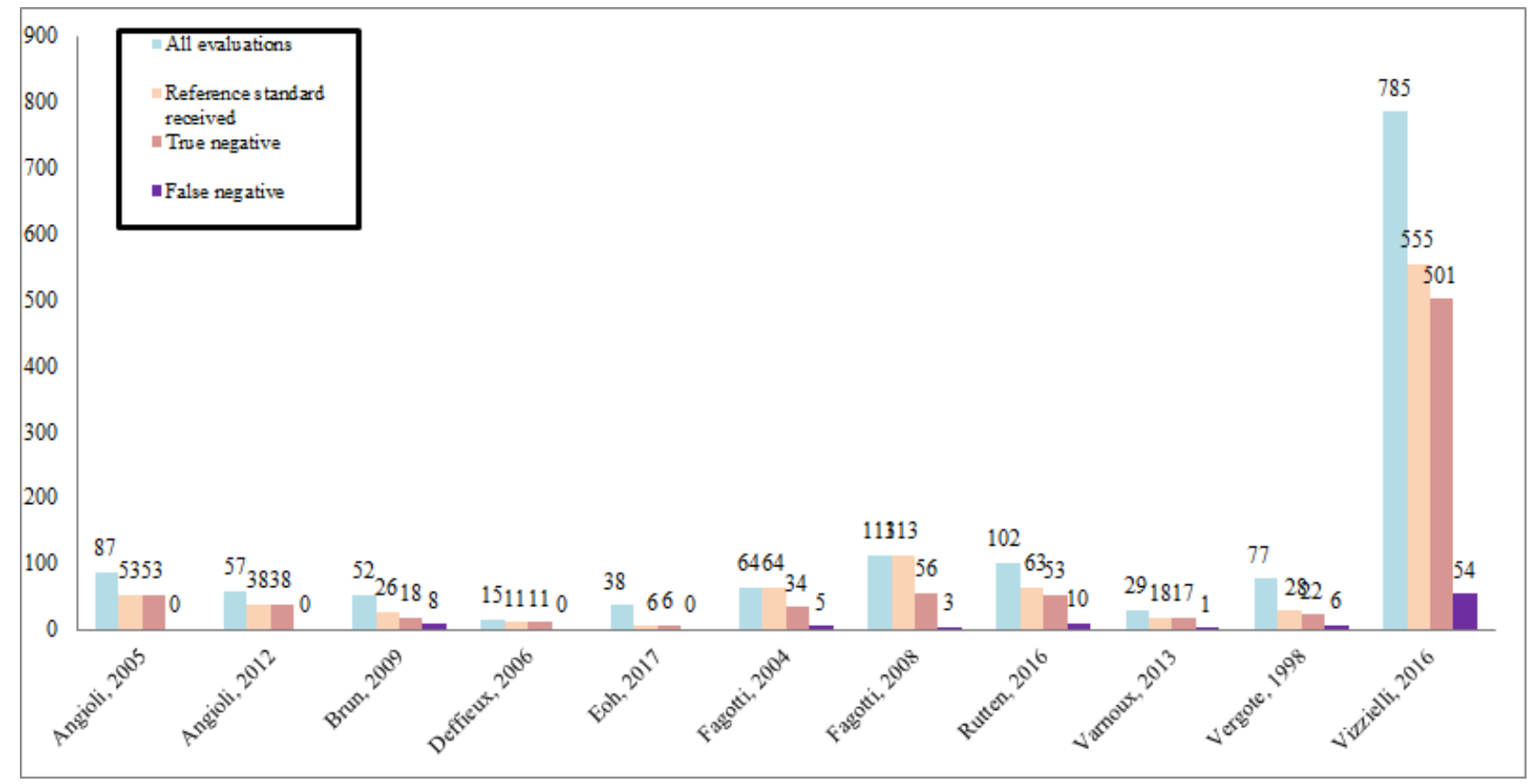


Figure 8. Negative predictive values and their $95 \% \mathrm{Cl}$ for complete debulking $(\mathrm{RT}=0 \mathrm{~cm})$ result after primary debulking surgery for each study.

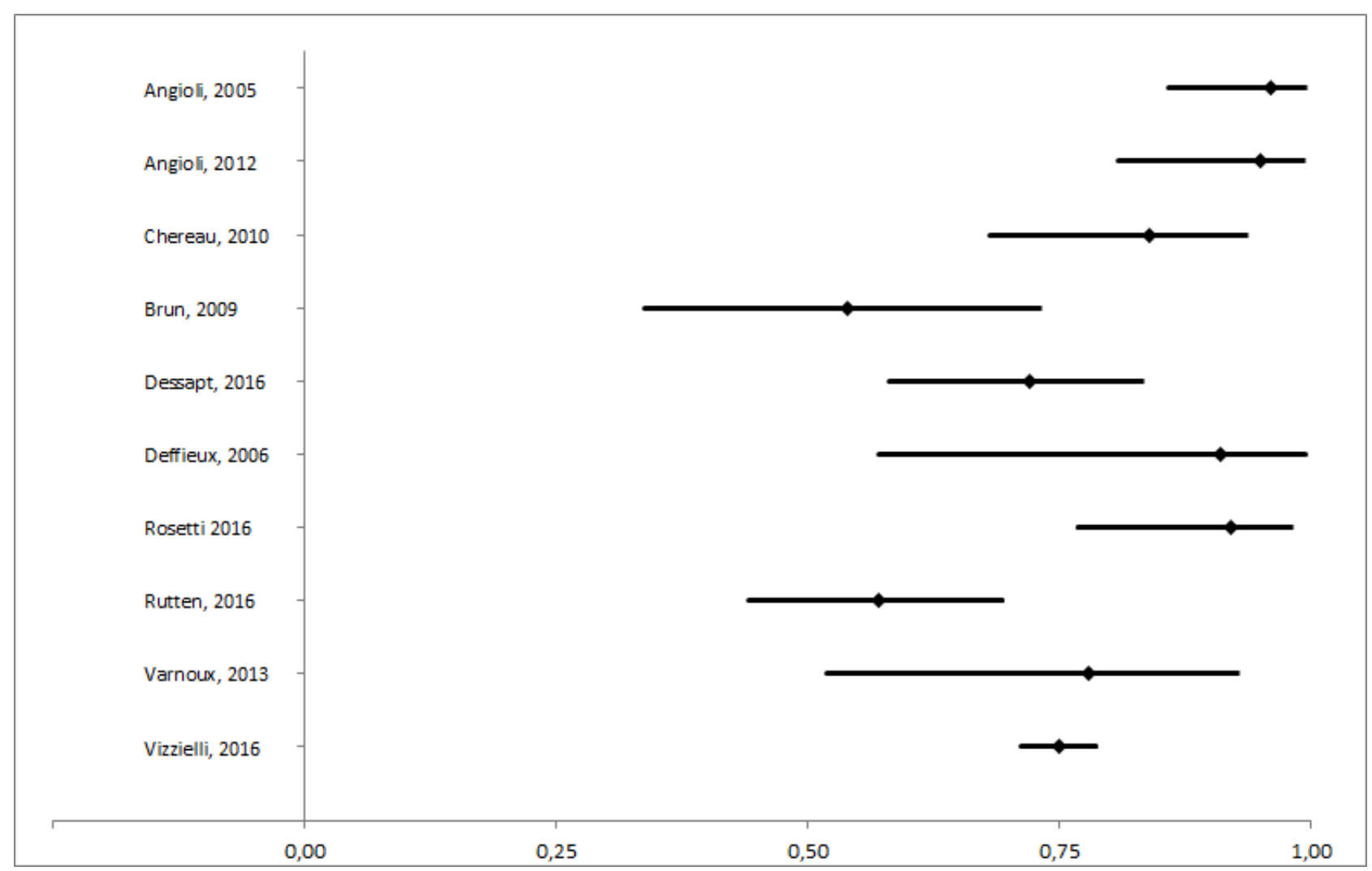


Figure 9. Negative predictive values and their $95 \% \mathrm{Cl}$ for optimal debulking $(\mathrm{RT}<1 \mathrm{~cm})$ result after primary debulking surgery for each study.

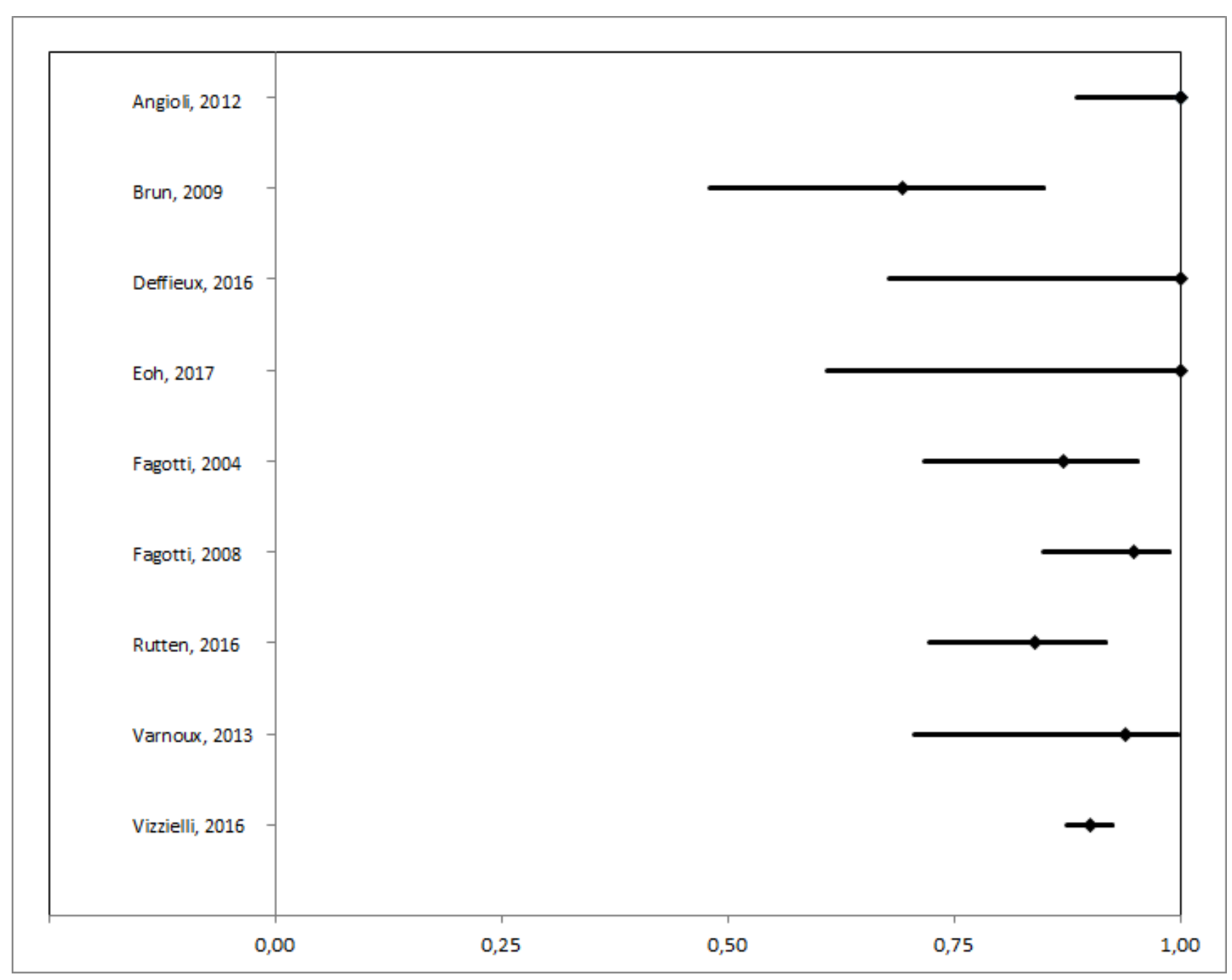


Figure 10. Percentage of test negative results and NPV of each included study, outcome macroscopic complete $(0 \mathrm{~cm}$ residual tumour).

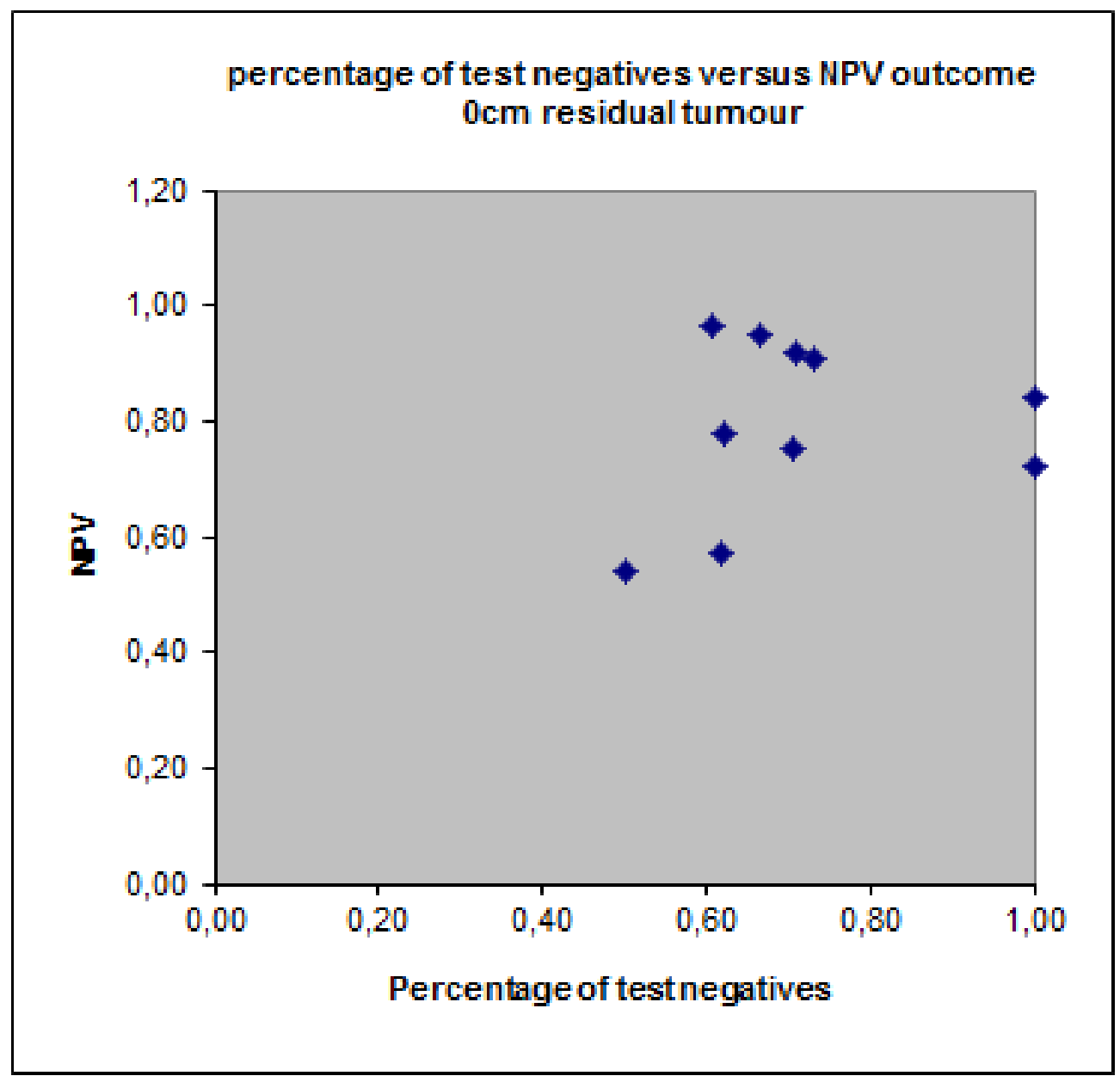


Figure 11. Percentage of test negative results and NPV of each included study, outcome $<1 \mathrm{~cm}$ residual tumour.

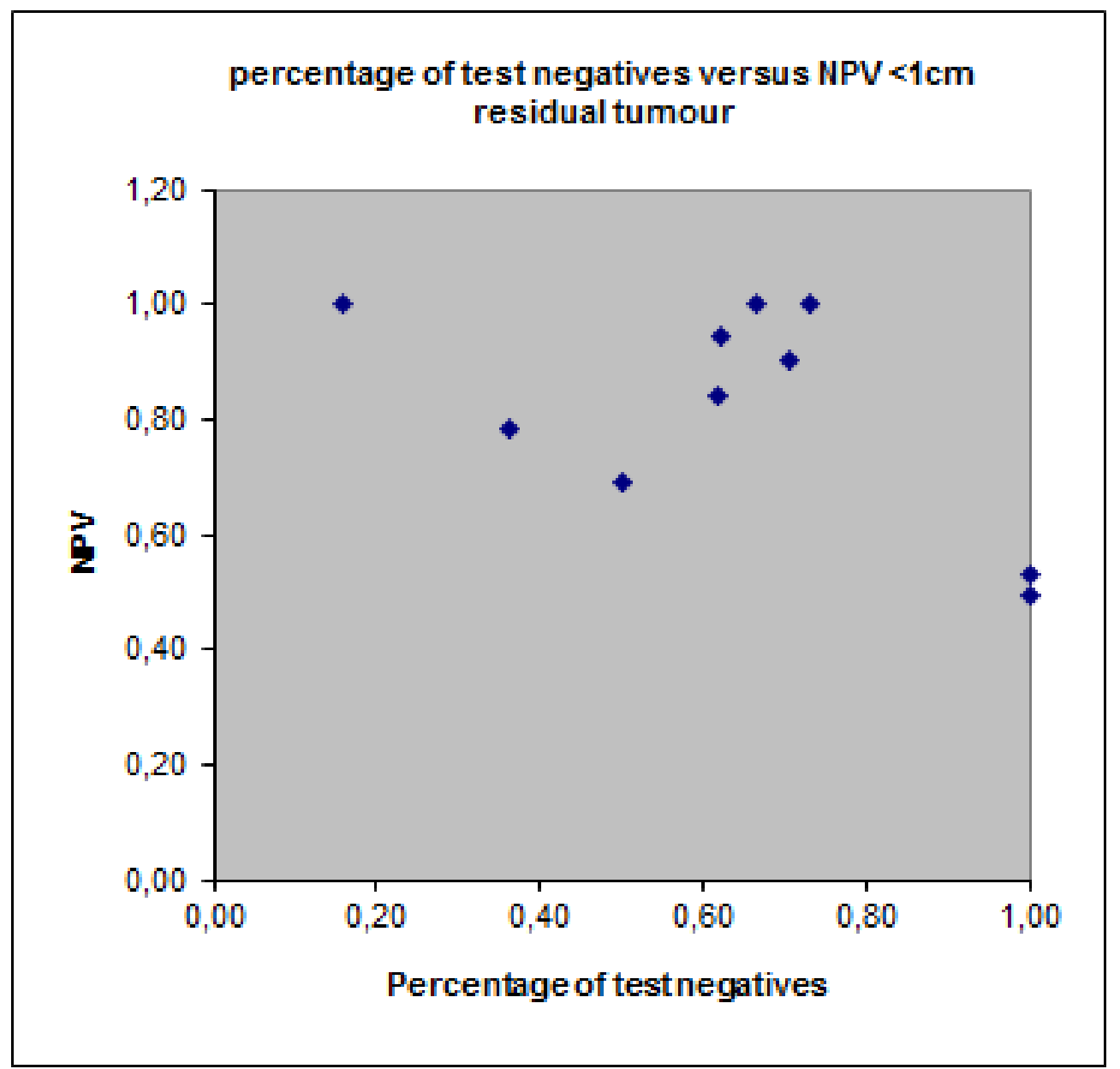

Figure 12. Percentage of women per study with a negative and positive index test result. The percentage of positive index test results varied between $\mathbf{2 7} \%$ and $84 \%$. Only Fagotti 2004 and Fagotti 2008 validated these results. Both studies found no false positives. In the study of Fagotti 2004, 13 women could not be evaluated by laparoscopy.

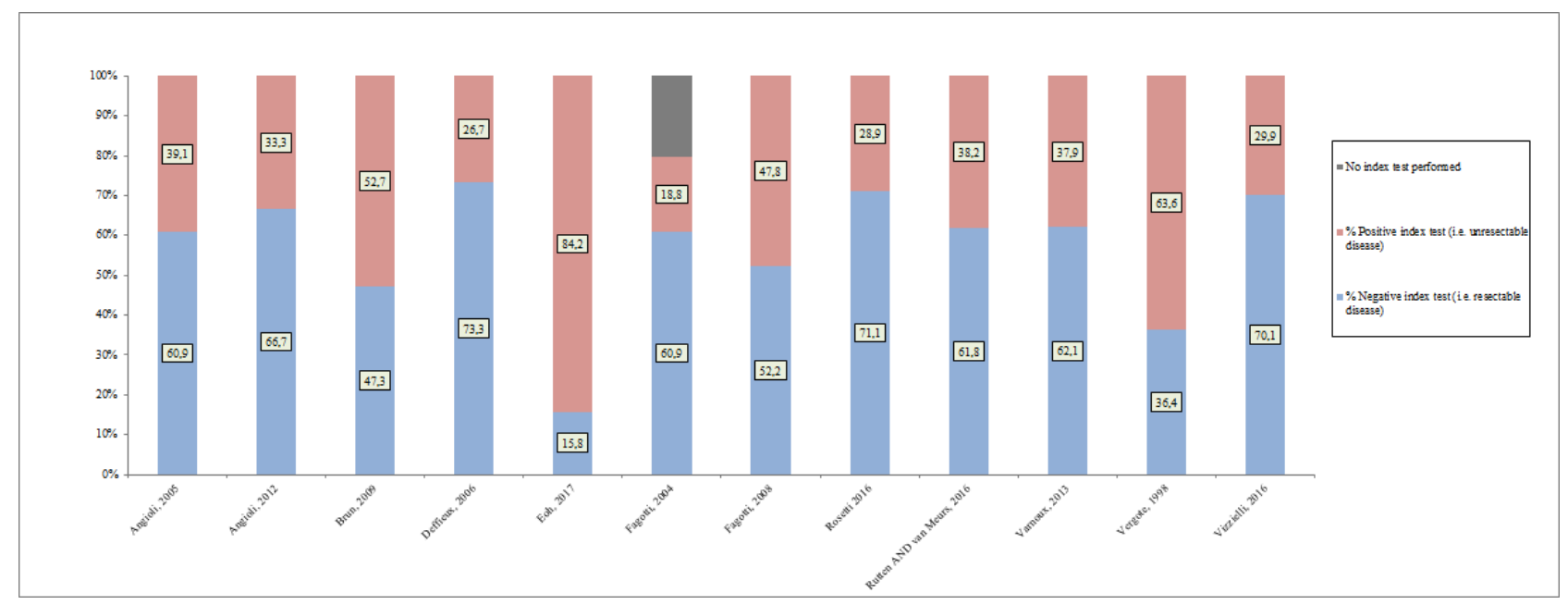

Eight studies we identified by the search, used a cut-off value of test-positivity derived from a prediction model using diagnostic criteria for extensiveness of disease diagnosed with a laparoscopy
(Brun 2008; Chéreau 2010; Eoh 2017; Fagotti 2008; Fagotti 2013; Petrillo 2015; Vizzielli 2014; Vizzielli 2016). Fagotti 2006 developed a prediction model using a laparoscopy-based score using the cohort 
of Fagotti 2004. In this prediction model, peritoneal carcinomatosis, diaphragmatic disease, mesenteric disease, omental disease, stomach infiltration, bowel infiltration and liver metastases were used as diagnostic criteria. Presence of the disease was scored with two points and the total score was used to calculate the Predictive Index Value (PIV $\geq 8$ ). This prediction model was externally validated by Brun 2008; Chéreau 2010; Eoh 2017; Fagotti 2008; and Varnoux 2013 (see Data and analyses). Fagotti 2008 validated the PIV $\geq 8$ model in a new and larger cohort; sensitivity in this study was 0.70 $(95 \% \mathrm{Cl} 0.57$ to 0.82$)$ and specificity $1.00(95 \% \mathrm{Cl} .0 .94$ to 1.00$)$. Brun 2008 also performed an external validation of the prediction model and found a sensitivity of $0.46(95 \% \mathrm{Cl} 0.29$ to 0.63$)$ and a specificity of 0.89 ( $9 \% \mathrm{Cl} 0.65$ to 0.99$)$. Results from the study of Brun 2008 could lead to an over- or underestimation since only 26 of 55 women received a laparotomy verifying the diagnosis of the laparoscopy (see Data and analyses). The other four studies used the PIV of $\geq 8$ as a cut-off test for index test positivity (Chéreau 2010; Eoh 2017; Fagotti 2008; Varnoux 2013). NPV's of studies using PIV of $\geq 8$ as a cut-off ranged from 0.54 to 0.84 for complete debulking result (no macroscopic residual tumour) and 0.69 to 1.00 for an optimal debulking result (residual tumour $<1 \mathrm{~cm}$ ). Compared to studies not using PIV of $\geq 8$ as a cut-off, NPV's ranged higher, from 0.57 to 0.96 and from 0.79 to 1.00 for complete (no macroscopic residual tumour) and optimal (residual tumour $<1 \mathrm{~cm}$ ) debulking result, respectively. Brun 2008 modified PIV $\geq 8$ model and created a modified score: PIV $\geq 4$ model. Validation of the modified score was described by Chéreau 2010 and Varnoux 2013. NPV's ranged from 0.78 to 1.00 .The additive value of the model appears limited.

One study evaluated the additional value of adding a laparoscopy to the diagnostic work-up compared to using only standard clinical or radiological work-up resulting in more women considered to have resectable disease, but who were found not to be operable at laparotomy than when only using clinical or /radiological evaluation (NPV 89\% versus 87\%) (Fagotti 2004).

\section{DISCUSSION}

\section{Summary of main results}

This review describes the added value of laparoscopy in diagnosing resectability of disease of women with ovarian cancer before primary debulking surgery. Laparoscopy can aid in the prediction of primary debulking surgery with $>1 \mathrm{~cm}$ tumour residue. As studies by Vergote 2010 and Kehoe 2015 did not show that treatment with neoadjuvant chemotherapy (NACT) gave a worse prognosis, false positive prediction with laparoscopy will not influence prognosis. Therefore, we are more interested in false negative prognosis as this will result in an unsuccessful and unnecessary debulking surgery.

We found 18 studies on 14 patient-cohorts describing the diagnostic accuracy of laparoscopy following standard diagnostic work-up planned for primary debulking surgery in women with advanced ovarian cancer, of which one was a randomised controlled trial.

In the included studies, between $16 \%$ and $73 \%$ of the women were considered to have too extensive disease to have a successful primary debulking surgery (i.e. index test positives). The remaining $27 \%$ to $84 \%$ of women were considered suitable for primary debulking surgery (i.e. index test negative) with expectation of achieving no macroscopic disease or optimal $(<1 \mathrm{~cm}$ residual disease) debulking result. At laparotomy, between $0 \%$ and $31 \%$ of women had $>1 \mathrm{~cm}$ residual tissue after primary debulking, suggesting that they could have been spared a laparotomy. The number of false positive laparoscopies; women who received NACT as primary treatment, but who would have undergone primary debulking surgery with $<1 \mathrm{~cm}$ residual tumour is unknown for most of the studies. Yet, because survival is not inferior to treatment with NACT, we are more interested in the false negative predicted women (Vergote 2010; Kehoe 2015). These are the women for whom laparoscopy could prevent unnecessary surgery and who might benefit from NACT initially, but had suboptimal primary debulking surgery.

Only two studies (Fagotti 2004; Fagotti 2008) avoided partial verification bias by performing a laparotomy in all of the included women. In these studies, no false positives were discovered at laparotomy, i.e. no women who could have had optimal debulking were thought to have suboptimally resectable disease at laparoscopy. With a sensitivity of 0.71 and 0.95 within these studies it is a promising test. However, these two studies were conducted in a heterogeneous population, including women receiving primary debulking surgery as well as interval debulking surgery. We were not able to analyse the results for the primary debulking surgery women separately. Furthermore, Fagotti 2004 did not include all women in their analysis, since in 13 cases the extensiveness of disease could not be evaluated at laparoscopy due to the presence of multiple and tenacious adherence hindering access to the abdominal and pelvic cavity. The values given in the study of Fagotti 2004 were therefore based on only $80 \%$ of included cases, resulting in overestimation of sensitivity and specificity. If these 13 women were added to the index test-positive group, sensitivity and specificity would be $0.78(95 \% \mathrm{Cl} 0.56$ to 0.93$)$ and $0.83(95 \% \mathrm{Cl}$ 0.68 to 0.93 ), respectively, resulting in more women not undergoing surgery who could have had optimal primary debulking surgery. When added to the group expected by laparoscopic assessment to have no macroscopic residual disease after debulking surgery, sensitivity decreased to $0.52(95 \% \mathrm{Cl} 0.31$ to 0.73$)$. Furthermore, $25 \%$ of included women in these two studies had laparoscopy before interval debulking surgery or because of recurrent disease (Data and analyses; Data table 1: Laparoscopy).

Negative predictive values (NPV) ranged from 0.54 to 0.96 for macroscopic complete debulking, which means that of every 100 women referred for primary debulking surgery after laparoscopy, between four and 46 will be left with visible residual tumour. NPV ranged from 0.69 to 1.00 for optimal debulking, which means that of every 100 women referred for surgery after laparoscopy, between zero and 31 will be left with $>1 \mathrm{~cm}$ residual tumour after primary debulking surgery. These women will undergo a primary debulking surgery that was intended to be avoided.

It is not possible to provide a pooled estimate of NPV, based on high heterogeneity. And only two studies provided data on sensitivity and specificity (Fagotti 2004; Fagotti 2008). Nevertheless, all studies report an added value of the diagnostic laparoscopy, although, importantly, this was without reporting increased risk of complications. Some prediction models were described and validated, however none of these models improved the predictive value compared to the subjective interpretation of the gynaecological oncologist performing the primary debulking surgery. 


\section{Strengths and weaknesses of the review}

This review is an updated systematic review on the accuracy of a diagnostic laparoscopy in the work-up of women suspected of advanced ovarian cancer. We performed an extensive search addressing all available databases. However, we found wide heterogeneity within the reported studies, which precludes performing a meta-analysis and correction for factors leading to bias.

Possible factors for heterogeneity were the reason for performing laparoscopy (standard versus only when in doubt after standard diagnostic work-up), different exclusion criteria (for example American Society of Anesthesiologists (ASA) classification of 3) and the different use of endpoint used after primary debulking surgery (i.e. no macroscopic, $<0.25 \mathrm{~cm},<0.5 \mathrm{~cm}$ and $<1 \mathrm{~cm}$ residual tumour tissue).

Unfortunately, only in two studies was the reference standard performed in all women (Fagotti 2004; Fagotti 2008). Therefore, the data could not be pooled. In addition, we were not able to perform a sensitivity analysis to correct for this form of bias due to this small number of studies. Furthermore, the only two studies avoiding verification bias conducted their studies in a heterogeneous population, without presenting the results of the woman having primary debulking surgery women separately. Therefore, it is not clear if their results would have been the same in a more homogeneous population. However, all studies show the same positive effect of laparoscopy in the different populations.

Finally, we judged the methodological quality with QUADAS-2. This is the most recent available tool for assessing methodological quality of diagnostic accuracy studies. Signaling questions concerning quality of included studies were added or removed to adjust the quality tool to make it suitable for this specific review. The overview of study quality shows clearly that all of the studies suffered from some kind of bias or applicability concern (Figure 5), except for one (Vizzielli 2016).

\section{Applicability of findings to the review question}

The diagnostic performance of an laparoscopy may be of added value to the standard diagnostic work-up. Based on the results of the studies described in this review, laparoscopy could be of benefit, and could be included as a standard procedure in clinical practice. When at laparoscopy the disease was judged too extensive, this was confirmed by laparotomy in two studies. However, when at laparoscopy the disease was judged as not too extensive for an optimal debulking result, there will be women who will have suboptimally resected disease (i.e. $>1 \mathrm{~cm}$ residual tumour) at primary debulking surgery. This is because not all tumour deposition can be visualised by laparoscopy as there is variability in what is considered resectable and which procedures are performed during laparotomy (Vergote 2010).

In some clinics, laparoscopy is already a standard intervention in the diagnostic process of women with advanced ovarian cancer. Women, who are diagnosed by laparoscopy with unresectable disease, will be treated with NACT. However, even though some women, who could be debulked to $<1 \mathrm{~cm}$ residual disease might not have primary surgery if they were assessed laparoscopically, this will not influence overall survival as NACT and interval debulking surgery is not deemed inferior to primary debulking surgery followed by chemotherapy (Kehoe 2015; Vergote 2010). Yet, the results of the study by Rutten 2016 estimate a reduction in primary debulking surgery leaving $>1 \mathrm{~cm}$ residual tumour from $39 \%$ to $10 \%$.

\section{AUTHORS' CONCLUSIONS}

\section{Implications for practice}

Laparoscopy may be a helpful diagnostic tool in predicting the extent of residual disease after primary debulking surgery. Two studies found that no women who were thought to have suboptimally resectable disease by laparoscopy-achieved optimal debulking. This suggests that laparoscopy would not misdirect women from primary surgery when they might benefit. Some women undergo suboptimal primary debulking surgery after laparoscopic assessment, yet the amount of women with suboptimal primary debulking surgery decreases. Therefore, laparoscopy aids in the selection of women whom are likely to benefit from primary debulking surgery. However, due to the large heterogeneity pooling of the data was not possible and careful interpretation of the study result is essential.

Based on findings at laparoscopy, women are unlikely to be directed away from primary surgery when optimal debulking is possible and suboptimal primary surgery $(>1 \mathrm{~cm}$ residual tumour) may be prevented for some women. Use of a prediction model does not increase the sensitivity and will result in more women with suboptimal primary debulking surgery. Based on this review, laparoscopy adds to the accuracy of clinical and radiological diagnostic work-up alone.

\section{Implications for research}

Future research should focus on selection criteria used at laparoscopy and careful selection of women who might benefit of an extra intervention. Some women are clearly fit for optimal primary debulking and others are clearly unfit; these women could be spared the invasive laparoscopy and medical costs could be reduced. However, the group of women for whom it is uncertain if primary debulking surgery is a good option should receive a laparoscopy. Selection criteria for these women should be developed and selection criteria on which to decide debulking surgery will be unsuccessful should be universal and investigated in a prospective trial.

\section{ACKNOWLEDGEMENTS}

We thank Jo Morrison for clinical expertise, Gail Quinn and Clare Jess for editorial assistance and Jo Platt from the Cochrane Gynaecological Cancer Review Group for her help in the search for trials for inclusion in this review. We would also like to thank the Cochrane Diagnostic Test Accuracy editorial team for their expertise.

This project was supported by the National Institute for Health Research, via Cochrane Infrastructure funding to the Cochrane Gynaecological, Neuro-oncology and Orphan Cancer Group. The views and opinions expressed therein are those of the authors and do not necessarily reflect those of the Systematic Reviews Programme, NIHR, NHS or the Department of Health. 


\section{R E F E R E N C E S}

\section{References to studies included in this review}

Angioli 2005 \{published and unpublished data\}

Angioli R, Palaia I, Zullo MA, Muzii L, Manci N, Calcagno M, et al. Diagnostic open laparoscopy in the management of advanced ovarian cancer. Gynecologic Oncology 2006;100(3):455-61.

\section{Angioli 2013 \{published data only\}}

Angioli R, Plotti F, Capriglione S, Aloisi A, Montera R, Luvero D, et al. Can the preoperative HE4 level predict optimal cytoreduction in patients with advanced ovarian carcinoma?. Gynecologic Oncology 2013;128(3):579-83.

\section{Brun 2008 \{published and unpublished data\}}

Brun JL, Rouzier R, Uzan S, Darai E. External validation of a laparoscopic-based score to evaluate resectability of advanced ovarian cancers: clues for a simplified score. Gynecologic Oncology 2008;110(3):354-9.

\section{Brun 2009 \{published and unpublished data\}}

Brun JL, Rouzier R, Selle F, Houry S, Uzan S, Darai E. Neoadjuvant chemotherapy or primary surgery for stage III/IV ovarian cancer: contribution of diagnostic laparoscopy. BMC Cancer 2009;9:171.

\section{Chéreau 2010 \{published data only\}}

Chéreau E, Ballester M, Selle F, Cortez A, Daraï E, Rouzier R. Comparison of peritoneal carcinomatosis scoring methods in predicting resectability and prognosis in advanced ovarian cancer. American Journal of Obstetrics and Gynecology 2010/02/02;202(2):178.e1-178.e10.

\section{Deffieux 2006 \{published and unpublished data\}}

Deffieux X, Castaigne D, Pomel C. Role of laparoscopy to evaluate candidates for complete cytoreduction in advanced stages of epithelial ovarian cancer. International Journal of Gynecological Cancer 2006;16 Suppl 1:35-40.

\section{Dessapt 2016 \{published data only\}}

Dessapt AL, Huchon C, Ngo C, Bats AS, Bensaid C, Lecuru F. Is complete cytoreductive surgery feasible in this patient with ovarian cancer?. Surgical Oncology 2016;25(3):326-31.

\section{Eoh 2017 \{published data only\}}

Eoh KJ, Yoon JW, Lee JY, Nam EJ, Kim S, Kim SW, et al. A novel algorithm for the treatment strategy for advanced epithelial ovarian cancer: consecutive imaging, frailty assessment, and diagnostic laparoscopy. BMC Cancer 2017;17(1):481. [DOI: 10.1186/s12885-017-3476-1]

\section{Fagotti 2004 \{published and unpublished data\}}

Fagotti A, Fanfani F, Ludovisi M, Lo Voi R, Bifulco G, Testa AC, et al. Role of laparoscopy to assess the chance of optimal cytoreductive surgery in advanced ovarian cancer: a pilot study. Gynecologic Oncology 2005;96(3):729-35.

\section{Fagotti 2008 \{published data only\}}

Fagotti A, Ferrandina G, Fanfani F, Garganese G, Vizzielli G, Carone V, et al. Prospective validation of a laparoscopic predictive model for optimal cytoreduction in advanced ovarian carcinoma. American Journal of Obstetrics \& Gynecology 2008;199(6):642-6.

\section{Fagotti 2013 \{published data only\}}

Fagotti A, Vizzielli G, Fanfani F, Costantini B, Ferrandina G, Gallotta V, et al. Introduction of staging laparoscopy in the management of advanced epithelial ovarian, tubal and peritoneal cancer: impact on prognosis in a single institution experience. Gynecologic Oncology 2013;131(2):341-6.

\section{Petrillo 2015 \{published data only\}}

Petrillo M, Vizzielli G, Fanfani F, Gallotta V, Cosentino F, Chiantera V, et al. Definition of a dynamic laparoscopic model for the prediction of incomplete cytoreduction in advanced epithelial ovarian cancer: proof of a concept. Gynecologic Oncology 2015;139(1):5-9.

\section{Rosetti 2016 \{published data only\}}

Rossetti D, Vitale SG, Gulino FA, Rapisarda AM, Valenti G, Zigarelli M, et al. Laparoendoscopic single-site surgery for the assessment of peritoneal carcinomatosis resectability in patients with advanced ovarian cancer. European Journal of Gynaecological Oncology j2016;37(5):671-3.

\section{Rutten 2016 \{published data only\}}

Rutten MJ, van Meurs HS, van de Vrie R, Gaarenstroom KN, Naaktgeboren CA, van Gorp T, et al. Laparoscopy to predict the result of primary cytoreductive surgery in patients with advanced ovarian cancer: a randomized controlled trial. Journal of Clinical Oncology 2016;35(6):613-21.

\section{Varnoux 2013 \{published data only\}}

Varnoux C, Huchon C, Bats AS, Bensaid C, Achouri A, Nos C, et al. Diagnostic accuracy of hand-assisted laparoscopy in predicting resectability of peritoneal carcinomatosis from gynecological malignancies. European Journal of Surgical Oncology 2013;39(7):774-9.

\section{Vergote 1998 \{published data only\}}

Vergote I, De Wever I, Tjalma W, Van Gramberen M, Decloedt J, Van Dam P. Neoadjuvant chemotherapy or primary debulking surgery in advanced ovarian carcinoma: a retrospective analysis of 285 patients. Gynecologic Oncology 1998;71(3):431-6.

\section{Vizzielli 2014 \{published data only\}}

Vizzielli G, Costantini B, Tortorella L, Petrillo M, Fanfani F, Chiantera V, et al. Influence of intraperitoneal dissemination assessed by laparoscopy on prognosis of advanced ovarian cancer: an exploratory analysis of a single-institution experience. Annals of Surgical Oncology 2014;21(12):3970-7.

\section{Vizzielli 2016 \{published data only\}}

Vizzielli G, Costantini B, Tortorella L, Pitruzzella I, Gallotta V, Fanfani F, et al. A laparoscopic risk-adjusted model to predict major complications after primary debulking surgery in ovarian cancer: A single-institution assessment. Gynecologic Oncology 2016;142(1):19-24 


\section{References to studies excluded from this review}

Andikyan 2015 \{published data only\}

Andikyan V, Kim AJ, Sierra T, Gretz HF, fZakashansky K, Segna RA, et al. Role of laparoscopy in determining optimal cytoreduction in patients with ovarian, fallopian tube and primary peritoneal cancer. Gynecologic Oncology 2015;Conference: 46th Annual Meeting on Women's Cancer of the Society of Gynecologic Oncology, SGO 2015 Chicago, IL United States. Conference Start: 20150328 Conference End: 20150331. Conference Publication:103.

\section{Batka 1993 \{published data only\}}

Batka M, Graf AH, Steiner H, Staudach A. Laparotomy vs. pelviscopy in adnexa processes--preoperative assessment, therapy planning and histology [German]. GynakologischGeburtshilfliche Rundschau 1993;33 Suppl 1:41-3.

\section{Bresson 2014 \{published data only\}}

Bresson L, Puga M, Cheurfa N, Merlot B, Narducci F, Leblanc E. Laparoscopic tips and tricks to evaluate peritoneal carcinosis index in ovarian cancer. Gynecological Surgery 2014; Conference: 23rd Annual Congress of the European Society of Gynaecological Endoscopy, ESGE 2014 Brussels Belgium. Conference Start: 20140924 Conference End: 20140927. Conference Publication:(var.pagings):39-40.

\section{Bresson 2016 \{published data only\}}

Bresson L, Allard-Duclercq C, Narducci F, Tresch E, Lesoin A, Ahmeidi A, et al. Single-port or classic laparoscopy compared withlLaparotomy to assess the peritoneal cancer Index in primary advanced epithelial ovarian cancer. Journal of Minimally Invasive Gynecology 2016/03/31;23(5):825-32.

Bristow 2006 \{published and unpublished data\}

Bristow RE. Predicting "unresectable" ovarian cancer: Taking aim at a moving target. Gynaecologic Oncology 2006;100:449-50.

Bruhat 1981 \{published data only\}

Bruhat MA, Dal Soglio I, Mage G, Manhes H. Coelioscopy and ovarian cancer. Gynecologie 1981;32:191-6.

\section{Brun 2009a \{published data only\}}

Brun J, Rouzier R, Uzan S, Darai E. External validation of a laparoscopic-based score to evaluate resectability of advanced ovarian cancers: Clues for a simplified score. International Journal of Gynecology and Obstetrics 2009;Conference: 19th FIGO World Congress of Gynecology and Obstetrics Cape Town South Africa. Conference Start: 20091004 Conference End: 20091009. Conference Publication::S135.

\section{Buist 2015 \{published data only\}}

Buist MR, van de Vrie R, Rutten MJ, van Meurs HS, Gaarenstroom KJ, Van Gorp T, et al. Laparoscopy to predict the result of primary cytoreductive surgery in advanced ovarian cancer patients (LapOvCa-trial): a multicentre randomized controlled study. Conference abstract ESGO 2015. International Journal of Gynecological Cancer 2015;25(9):102-3.
Burmich, 2013 \{published data only\}

Burmich KS, Dronov AI, Kovalskaya IA, Nastashenko IL, Zemskov SV. Role of staging laparoscopy in patients with intraabdominal malignancies. Surgical Endoscopy and other Interventional Techniques 2012;Conference: 20th International Congress of the European Association for Endoscopic Surgery, EAES 2012 Brussels Belgium. Conference Start: 20120620 Conference End: 20120623. Conference Publication:(var.pagings):S69.

Cusido, 2012 \{published data only\}

Cusido M, Amselem D, Vazquez A, Fabregas R Fargas F. Role of laparoscopy in advanced ovarian cancer. Gynecological surgery 2012; Conference: 21st Annual Congress ESGE Paris France. Conference Start: 20120911 Conference End: 20120914. Conference Publication(var.pagings):S133.

Dagnini 1987 \{published data only\}

Dagnini G, Marin G, Caldironi MW, Piccigallo E, Miola E. Laparoscopy in staging, follow-up, and restaging of ovarian carcinoma. Gastrointestinal Endoscopy 1987;33(2):80-3.

Fago-Olsen, 2014 \{published data only\}

Fago-Olsen CL, Ottesen B, Kehlet $\mathrm{H}$, Antonsen SL, Christensen IJ, Markauskas A, et al. Differences in regional diagnostic strategies and in intended versus actual firstline treatment of patients with advanced ovarian cancer in Denmark. International Journal of Gynecological Cancer May 18, 2014;24(7):1195-205.

Fagotti 2006 \{published data only\}

Fagotti A, Ferrandina G, Fanfani F, Ercoli A, Lorusso D, Rossi M, et al. A laparoscopy-based score to predict surgical outcome in patients with advanced ovarian carcinoma: a pilot study. Annals of Surgical Oncology 2006;13(8):1156-61.

Fagotti 2013a \{published data only\}

Fagotti A, Vizzielli G, Fanfani F, Costantini B, Ferrandina G, Gallotta V, et al. Introduction of staging laparoscopy in the management of advanced epithelial ovarian, tubal and peritoneal cancer: Impact on prognosis in a single institution experience. International Journal of Gynecological Cancer 2013; Conference: 18th International Meeting of the European Society of Gynaecological Oncology, ESGO 2013 Liverpool United Kingdom. Conference Start: 20131019 Conference End: 20131022. Conference Publication:555.

Fagotti 2014 \{published data only\}

Fagotti A, Vizzielli G, Fanfani F, Costantini B, Ferrandina G, Gallotta V, et al. Introduction of Staging Laparoscopy in the Management of Advanced Epithelial Ovarian, Tubal and Peritoneal Cancer: Impact on Prognosis in a Single Institution Experience. Obstetrical \& Gynecological Survey 2014;69(3):144-6.

Fagotti MITO 2013 \{published data only\}

Fagotti A, Vizzielli G, De laco P, Surico D, Buda A, Mandato VD, et al. A multicentric trial (Olympia-MITO 13) on the accuracy of laparoscopy to assess peritoneal spread in ovarian cancer. American Journal of Obstetrics and Gynecology July 22, 2013;209(5):462.e1-462.e11. 


\section{Gouy 2013 \{published data only\}}

Gouy S, Belghiti J, Uzan C, Canlorbe G, Gauthier T, Morice P. Accuracy and reproducibility of the peritoneal cancer index in advanced ovarian cancer during laparoscopy and laparotomy. International Journal of Gynecological Cancer July 19, 2013;23(9):1699-703.

\section{Gurrea 2010 \{published data only\}}

Gurrea M, Fuster S, Rodriguez E, Ruiz F, Domingo S, Pellicer A. Inclusion of diagnostic laparoscopy in the advanced ovarian cancer work algorithm. Gynecological Surgery 2010;Conference: 19th Annual Congress of the European Society for Gynaecological Endoscopy, ESGE Barcelona Spain. Conference Start: 20100929 Conference End: 20101002. Conference Publication:S41.

\section{Huchon 2015 \{published data only\}}

Huchon C, Dessapt A, Chammings F, Fournier L, Le FrereBelda MA, Bensaid C, et al. Can we perform cytoreductive surgery for this ovarian cancer?. International Journal of Gynecological Cancer 2015; Conference: 19th International Meeting of the European Society of Gynaecological Oncology, ESGO 2015 Nice France. Conference Start: 20151024 Conference End: 20151027. Conference Publication(var.pagings):1388.

\section{Hynninen 2013 \{published data only\}}

Hynninen J, Lavonius M, Oksa S, Grenman S, Carpen O, Auranen A. Is perioperative visual estimation of intraabdominal tumor spread reliable in ovarian cancer surgery after neoadjuvant chemotherapy?. Gynecologic Oncology 2013;128(2):229-32.

\section{Kobal 2012 \{published data only\}}

Kobal B, Cvjeticanin B, Barbic M, Meglic L, Jakimovska M. Laparoscopy in evaluation of optimal resectability in advanced ovarian cancer. Gynecological Surgery 2012;Conference: 21st Annual Congress ESGE Paris France. Conference Start: 20120911 Conference End: 20120914. Conference Publication:S22.

\section{Kornovski 2016 \{published data only\}}

Kornovski J, Ismail E, Stoilov S, Ivanov S. The role of laparoscopy in the case of suspected advanced ovarian cancer (ascites, CA-125). Akusherstvo i Ginekologiia 2016;55(Suppl 1 Pt 1):29-37.

Lamela 2013 \{published data only\}

Lamela EM, Jesus MV, Manuela LL, Yolanda EL, Almudena MM, Luis PA. Laparoscopy in ovarian cancer. Gynecological surgery 2013; Conference: 22nd Annual Congress of the European Society of Gynaecological Endoscopy, ESGE 2013 Berlin Germany. Conference Start: 20131016 Conference End: 20131019. Conference Publication:S22.

Martín-Cameán 2016 \{published data only\} Martín-Cameán M, Delgado-Sánchez E, Piñera A, Diestro MD, De Santiago J, Zapardiel I. The role of surgery in advanced epithelial ovarian cancer. Ecancermedicalscience 2016;10:666.
Molero Vilchez 2011 \{published data only\}

Molero V, J.Martinez L, E.Exposito Lucena, Y.Gallego Pastor, E.Lorente Ramos, R.Martin Marino, A. Contribution of the laparoscopyc technique in the ovarian cancer. Gynecological Surgery 2011; Conference: 20th Annual Congress ESGE London United Kingdom. Conference Start: 20110921 Conference End: 20110924. Conference Publication(var.pagings):S175-S176.

Molero Vilchez 2012 \{published data only\}

Molero Vilchez, J.Martinez Lamela, E.Sancho Garcia, S.Prieto Alonso, J. L.Exposito Lucena, Y.Gallego Pastor, E.Salazar Arquero, F. J. Acceptable indications of laparoscopy in the ovarian cancer. Gynecological Surgery 2012;Conference: 21st Annual Congress ESGE Paris France. Conference Start: 20120911 Conference End: 20120914. Conference Publication(var.pagings):S86.

\section{Nezhat 2010 \{published data only\}}

Nezhat FR, DeNoble SM, Liu CS, Cho JE, Brown DN, Chuang L, et al. The safety and efficacy of laparoscopic surgical staging and debulking of apparent advanced stage ovarian, fallopian tube, and primary peritoneal cancers. Journal of the Society of Laparoendoscopic Surgeons 2010;14(2):155-68.

\section{Nick 2014 \{published data only\}}

Nick AM, Ramirez PT, Rangel KM, Schmeler KM, Soliman PT, Burzawa JK, et al. Launching personalized surgical therapy for advanced ovarian cancer. Gynecologic Oncology 2014/03/22; Conference: 45th Annual Meeting on Women's Cancer of the Society of Gynecologic Oncology, SGO 2014 Tampa, FL United States. Conference Start: 20140322 Conference End: 20140325 . Conference Publication(var.pagings):28.

\section{Nick 2015 \{published data only\}}

Nick, AM, Coleman RL, Ramirez PT, Schmeler KM, Soliman PT, Lu KH, et al. Personalized surgical therapy for advanced ovarian cancer. Gynecologic Oncology 2015;Conference: 46th Annual Meeting on Women's Cancer of the Society of Gynecologic Oncology, SGO 2015 Chicago, IL United States. Conference Start: 20150328 Conference End: 20150331. Conference Publication(var.pagings):10.

\section{Nick 2016 \{published data only\}}

Nick AM, Coleman RL, Ramirez PT, Lu KH, Schmeler KM, Burzawa JK, et al. Personalized surgical therapy for advanced ovarian cancer: R0 resection after neoadjuvant chemotherapy is associated with decreased event-free survival compared with primary cytoreductive surgery. Gynecologic Oncology 2016; Conference: 47th Annual Meeting on Women's Cancer of the Society of Gynecologic Oncology, SGO 2016 San Diego, CA United States. Conference Start: 20160319 Conference End: 20160322. Conference Publication(var.pagings):181.

\section{Nick 2016a $\{$ published data only\}}

Nick AM, Ganeshan D, lyer R, Bhosale P, Munsell MF, Schmeler KM, et al. Personalizing surgical therapy for advanced ovarian cancer: $\mathrm{CT}$ imaging may not predict disease resectability. Gynecologic Oncology 2016;Conference: 47th Annual Meeting on Women's Cancer of the Society of 
Gynecologic Oncology, SGO 2016 San Diego, CA United States. Conference Start: 20160319 Conference End: 20160322. Conference Publication: 160 .

\section{Onda 2016 \{published data only\}}

Onda T, Satoh T, Saito T, Kasamatsu T, Nakanishi T, Nakamura K, et al. Japan Clinical Oncology, Group. Comparison of treatment invasiveness between upfrontdebulking surgery versus interval debulking surgeryfollowing neoadjuvant chemotherapy for stage III/IVovarian, tubal, and peritoneal cancers in a phase IIIrandomised trial: Japan Clinical Oncology Group StudyJCOG0602. European Journal of Cancer 2016;64:22-31.

\section{Quaranta 2014 \{published data only\}}

Quaranta D, Lambaudie E, Heinnemann M, Houvenaeghel G, Chereau E. Evaluation of single-port laparoscopy for peritoneal carcinomatosis assessment in advanced ovarian cancer. European Journal of Obstetrics, Gynecology, and Reproductive Biology 2014;181:60-5.

\section{Rutten 2012 \{published data only\}}

Rutten MJ, Gaarenstroom KN, Van Gorp T, van Meurs HS, Arts HJ, Bossuyt PM, et al. Laparoscopy to predict the result of primary cytoreductive surgery in advanced ovarian cancer patients (LapOvCa-trial): a multicentre randomized controlled study. BMC Cancer 2012;12:31.

\section{Taskiran 2016 \{published data only\}}

Taskiran C, Misirlioglu S, Yildiz Oguz S, Karatas F, Bostanci E, Kerem $\mathrm{M}$, et al. Does scoring systems really predict resectability or should we define new algorithm for advanced stage epithelial ovarian cancer, Conference abstract. International Journal of Gynecological Cancer 2016;778:Conference abstract.

\section{Vergote 2003 \{published data only\}}

Vergote I. Controversies in surgery in ovarian cancer - What is its real role?. European Journal of Cancer, Supplement 2003;1:115-25.

\section{Additional references}

\section{Bristow 2002}

Bristow RE, Tomacruz RS, Armstrong DK, Trimble EL, Montz FJ. Survival effect of maximal cytoreductive surgery for advanced ovarian carcinoma during the platinum era: a meta-analysis. Journal ofClinical Oncology 2002;20(5):1248-59. [MEDLINE: 11870167]

\section{Chi 2004}

Chi DS, Abu-Rustum NR, Sonoda Y, Awtrey C, Hummer A, Venkatraman ES, et al. Ten-year experience with laparoscopy on a gynecologic oncology service: analysis of risk factors for complications and conversion to laparotomy. American Journal of Obstetrics and Gynecology 2004;191(4):1138-45. [PUBMED: 15507933 ]

\section{Du Bois 2009}

Du Bois A, Reuss A, Pujade-Lauraine E, Harter P, RayCoquard I, Pfisterer J. Role of surgical outcome as prognostic factor in advanced epithelial ovarian cancer: a combined exploratory analysis of 3 prospectively randomized phase 3 multicenter trials: by the Arbeitsgemeinschaft Gynaekologische Onkologie Studiengruppe Ovarialkarzinom (AGO-OVAR) and the Groupe d'Investigateurs Nationaux Pour les Etudes des Cancers de l'Ovaire (GINECO). Cancer 2009;115(6):1234-44. [MEDLINE: 19189349]

\section{Eisenkop 1998}

Eisenkop SM, Friedman RL, Wang HJ. Complete cytoreductive surgery is feasible and maximizes survival in patients with advanced epithelial ovarian cancer: a prospective study. Journal ofGynaecologic Oncology 1998;62(2):103-8. [MEDLINE: 9600815]

\section{Elattar 2011}

Elattar A, Bryant A, Winter-Roach Brett A, Hatem M, Naik R. Optimal primary surgical treatment for advanced epithelial ovarian cancer. Cochrane Database of Systematic Reviews 2011, Issue 8. [DOI: 10.1002/14651858.CD007565.pub2]

\section{Espada 2013}

Espada M, Garcia-Flores JR, Jimenez, M, Alvarez-Moreno E, De Haro M, Gonzalez-Cortijo L, et al. Diffusion-weighted magnetic resonance imaging evaluation of intra-abdominal sites of implants to predict likelihood of suboptimal cytoreductive surgery in patients with ovarian carcinoma. European Radiology 2013;23(9):2636-42. [DOI: 10.1007/ s00330-013-2837-7]

\section{Gallardo-Rincón 2016}

Gallardo-Rincón D, Espinosa-Romero R, Muñoz WR, Mendoza-Martínez R, Villar-Álvarez SD, Oñate-Ocaña L, et al. Epidemiological overview, advances in diagnosis, prevention, treatment and management of epithelial ovarian cancer in Mexico. Salud Publica deMexico 2016;58(2):302-8. [ISSN: 1606-7916 ]

\section{Gerestein 2009}

Gerestein CG, van der Spek DW, Eijkemans MJ, Bakker J, Kooi GS, Burger CW. Prediction of residual disease after primary cytoreductive surgery for advanced-stage ovarian cancer: accuracy of clinical judgment. International Journal of Gynecological Cancer 2009;19(9):1511-5. [MEDLINE: 19955927]

\section{Globocan 2012}

Ferlay J, Soerjomataram I, Ervik M, Dikshit R, Eser S, Mathers C, et al. Cancer Incidence and Mortality Worldwide: IARC CancerBase No. 11 v1.1. Available from: http://globocan.iarc.fr accessed on 16/01/2015.

\section{Handbook for DTA Reviews}

Deeks JJ, Wisniewski S, Davenport C. Chapter 4: Guide to the contents of a Cochrane Diagnostic Test Accuracy Protocol. In: Deeks JJ, Bossuyt PM, Gatsonis C. Cochrane Handbook for Systematic Reviews of Diagnostic Test Accuracy Version 1.0.0. The Cochrane Collaboration 13th September 2013;1:http:// srdta.cochrane.org/. [http://methods.cochrane.org/sdt/ handbook-dta-reviews] 


\section{Higgins 2002}

Higgins JP, Thompson SG. Quantifying heterogeneity in a metaanalysis. Statistics in Medicine 2002;21(11):1539-58. [PUBMED: 12111919]

\section{Hoogendam 2017}

Hoogendam JP, Roze JF, van de Wetering FT, Spijker R, Verleye L, Vlayen J, et al. Positron emission tomography (PET) and magnetic resonance imaging (MRI) for assessing tumour resectability in advanced epithelial ovarian, fallopian tube and/ or primary peritoneal cancer. Cochrane Database of Systematic Reviews 2017, Issue 3. [DOI: 10.1002/14651858.CD012567]

\section{Kehoe 2015}

Kehoe S, Hook J, Nankivell M, Jayson GC, Kitchener H, Lopes T, et al. Primary chemotherapy versus primary surgery for newly diagnosed advanced ovarian cancer (CHORUS): an openlabel, randomised, controlled, non-inferiority trial. Lancet 2015;386(9990):249-57. [DOI: 10.1016/s0140-6736(14)62223-6]

\section{Makar 2016}

Makar AP, Trope CG, Tummers P, Denys H, Vandecasteele K. Advanced ovarian cancer: primary or interval debulking? Five categories of patients in view of the results of randomized trials and tumor biology: primary debulking surgery and interval debulking surgery for advanced ovarian cancer. Oncologist 2016;21(6):745-54. [DOI: 10.1634/theoncologist.2015-0239]

\section{Michielsen 2017}

Michielsen K, Dresen R, Vanslembrouck R, De Keyzer F, Amant F, Mussen E, et al. Diagnostic value of whole body diffusionweighted MRI compared to computed tomography for preoperative assessment of patients suspected for ovarian cancer. European Journal of Cancer 2017;83:88-98. [DOI: 10.1016/ j.ejca.2017.06.010]

\section{Munkarah 2004}

Munkarah AR, Coleman RL. Critical evaluation of secondary cytoreduction in recurrent ovarian cancer. Gynecologic Oncology 2004;95(2):273-80. [PUBMED: 15491746]

\section{Review Manager 5.3 [Computer program]}

The Nordic Cochrane Centre, The Cochrane Collaboration. Review Manager (RevMan) [Computer program]. Version 5.3. Copenhagen. The Nordic Cochrane Centre, The Cochrane Collaboration, 2014.

\section{Rutter 2001}

Rutter CM, Gatsonis CA. A hierarchical regression approach to meta-analysis of diagnostic test accuracy evaluations. Statistics in Medicine 2001;20(19):2865-84. [PUBMED: 11568945]

\section{SAS/STAT Software [Computer program]}

Cary, NC, USA. SAS/STAT Software. Version Version 9.4 of the SAS system for Windows. Cary, NC, USA, Copyright (c) 2016 by SAS Institute Inc.

\section{Siegel 2012}

Siegel R, Naishadham D, Jemal A. Cancer statistics, 2012. CA: A Cancer Journal for Clinicians 2012;62(1):10-29.

\section{Vergote 2010}

Vergote I, Tropé CG, Amant F, Kristensen GB, Ehlen T, Johnson N, et al. Neoadjuvant chemotherapy or primary surgery in stage IIIC or IV ovarian cancer. New England Journal of Medicine 2010;363:943-53. [MEDLINE: 20818904]

\section{Vergote 2013}

Vergote I, du Bois A, Amant F, Heitz F, Leunen K, Harter P. Neoadjuvant chemotherapy in advanced ovarian cancer: On what do we agree and disagree?. Gynecologic Oncology 2013;128(1):6-11. [PUBMED: 23006973]

\section{Whiting 2006}

Whiting PF, Weswood ME, Rutjes AW, Reitsma JB, Bossuyt PN, Kleijnen J. Evaluation of QUADAS, a tool for the quality assessment of diagnostic accuracy studies. BMC Medical Research Methodology 2006;6:9. [PUBMED: 16519814]

\section{Whiting 2011}

Whiting PF, Rutjes AW, Westwood ME, Mallett S, Deeks JJ, Reitsma JB, et al. QUADAS-2: a revised tool for the quality assessment of diagnostic accuracy studies. Annals of Internal Medicine 2011;155(8):529-36. [PUBMED: 22007046]

\section{Wright 2016}

Wright, AA, Bohlke K, Armstrong DK, Bookman MA, Cliby WA, Coleman RL, et al. Neoadjuvant chemotherapy for newly diagnosed, advanced ovarian cancer: Society of Gynecologic Oncology and American Society of Clinical Oncology Clinical Practice Guideline. Journal of Clinical Oncology 01 Oct 2016;34(28):3460-73. [DOI: 10.1200/JCO.2016.68.6907]

\section{References to other published versions of this review Rutten 2012}

Rutten MJ, Leeflang MM, Kenter GG, Mol BW, Buist M. Laparoscopy for diagnosing resectability of disease in patients with advanced ovarian cancer. Cochrane Database of Systematic Reviews 2012, Issue 4. [DOI: 10.1002/14651858.CD009786]

\section{Rutten 2014}

Rutten MJ, Leeflang MM, Kenter GG, Mo, BW, Buist M. Laparoscopy for diagnosing resectability of disease in patients with advanced ovarian cancer. Cochrane Database of Systematic Reviews 2014, Issue 2. [DOI: 10.1002/14651858.CD009786.pub2]

\section{CHARACTERISTICS OF STUDIES}

Characteristics of included studies [ordered by study ID] 
Angioli 2005

\section{Study characteristics}

\section{Patient sampling}

Patient characteristics and setting
Retro- or prospective enrolment not known.

\section{Sample size: 87 women}

Mean age: 58 years (range 19 to 79 )

Presentation: women with primary ovarian cancer FIGO Stage IIIC/IV, good nutrition status, $\mathrm{WHO}<2$, no contraindications for surgery, evaluation for optimal primary debulking surgery (residual tumour $=0$ )

Diagnostics before index test: physical/gynaecological examination, ultrasonography, CA-125, CT abdomen/pelvis, thorax X-ray/CT

Kind of surgery: PDS 53; IDS 25: No debulking surgery: 9

Setting: Department of gynaecology, University hospital Rome, Italy

Index tests

Open diagnostic laparoscopy; examination of the whole abdominal cavity, biopsies for frozen section, performed by gynaecological oncologist. If judged resectable direct debulking

Cut-off test-positivity: prediction of complete absence of disease after debulking

Complications of index test: trocar metastasis 2 cases (6\%), intraoperative complication $1(3 \%)$

Target condition and reference standard(s)

Target condition: possibility of leaving no macroscopic disease at debulking surgery

Criteria for target condition: extensive peritoneal carcinomatosis/involvement of bowel mesentery/bulky disease diaphragm/ multiple liver metastases/heavily bleeding tumoral tissue Reference standard: laparotomy. Test operators: gynaecological oncologist. Percentage of women reference standard performed: $61 \%$ unresectable disease at laparotomy: 2

Flow and timing

Time between reference standard and Index test: 0 days.

Comparative

Notes

Eighty-seven women had a laparoscopy, 53 were indicated to be operable. Of these, 51 had operable disease at laparotomy and 2 not. The other 34 women were treated with NACT and 25 received an interval debulking surgery after 3 courses of chemotherapy.

\section{Methodological quality}

\begin{tabular}{llll}
\hline Item & Authors' judgement & Risk of bias & Applicability concerns \\
\hline
\end{tabular}

\section{DOMAIN 1: Patient Selection}

Was a consecutive or random sample of patients Yes enrolled?

\begin{tabular}{ll}
\hline Did the study avoid inappropriate exclusions? & Yes \\
\hline $\begin{array}{l}\text { Were the patients suspected of advanced ovarian } \\
\text { cancer by conventional diagnostic work-up? }\end{array}$ & Yes \\
\hline
\end{tabular}


Angioli 2005 (Continued)

Were patients planned for primary debulking surgery after conventional diagnostic work-up?

\section{DOMAIN 2: Index Test Diagnostic open laparoscopy}

Were the index test results interpreted without Yes knowledge of the results of the reference standard?

Were the same clinical data available when test No results were interpreted as would be available when the test is used in practice?

Did the study provide a clear definition of what No was considered to be a "positive "result for the index test?

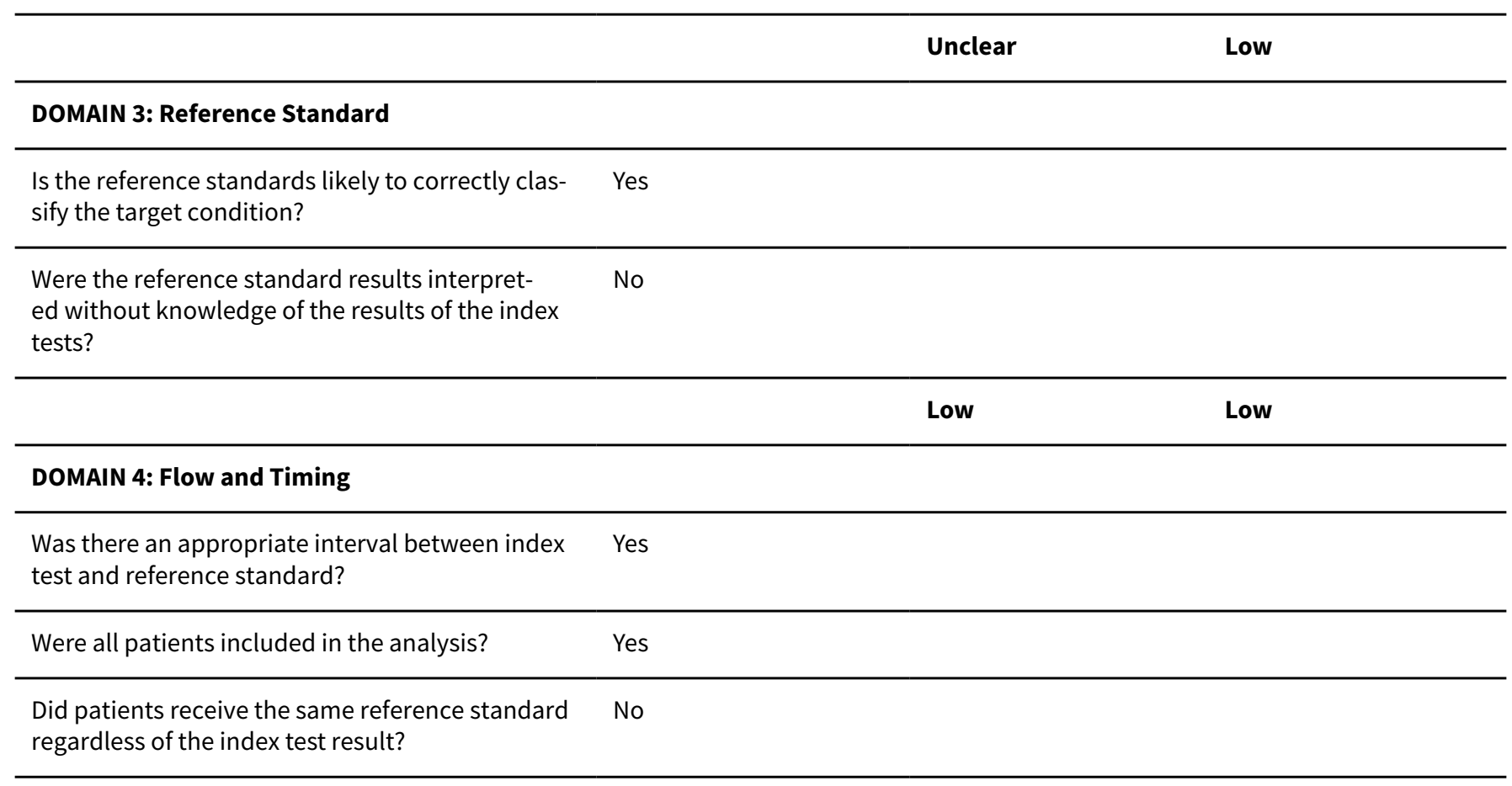

High

\section{Angioli 2013}

\section{Study characteristics}

Patient sampling Prospective study design.

\footnotetext{
Patient characteristics and setting
}

\section{Sample size: 57}

Diagnostics before index test: not mentioned 
Presentation: consecutive women affected by suspicious advanced ovarian cancer (FIGO stage III-IV)

Kind of surgery: PDS 38

Setting: the Department of Gynecology of Campus Biomedico of Rome, Italy

Index tests

Diagnostic open laparoscopy. women who were judged resectable were given PDS, and those who were judged as irresectable were given NACT.

Cut-of test-positivity: prediction of complete absence of disease after debulking surgery.

Complications of index tests: were not mentioned.

Target condition and reference standard(s)
Target condition: the possibility of optimal debulking surgery.

Criteria for target condition: extended visceral peritoneal metastases, large involvement of upper abdomen, extended small bowel involvement, multiple liver metastases, heavily bleeding tumour tissue.

Test operators: not mentioned

Percentage of women in whom reference standard is performed: $66.7 \%$ Unresectable disease at laparotomy: $94.7 \%$.

Flow and timing Reference standard performed after index test, time between treatment is 0 days.

\section{Comparative}

Notes

Fifty-seven laparoscopic evaluations were made; 38 women were judged resectable and received PDS, 36 women had no residual tumour tissue after surgery and 2 women had residual tumour tissue $<1 \mathrm{~cm}$ in diameter after surgery. 19 women were judged irresectable by S-LSP and received NACT followed by IDS.

\section{Methodological quality}

\begin{tabular}{lll}
\hline Item Authors' judgement & Risk of bias & $\begin{array}{l}\text { Applicability con- } \\
\text { cerns }\end{array}$
\end{tabular}

\section{DOMAIN 1: Patient Selection}

Was a consecutive or random sample of patients en- Yes rolled?

\begin{tabular}{ll}
\hline Did the study avoid inappropriate exclusions? & Yes \\
\hline $\begin{array}{l}\text { Were the patients suspected of advanced ovarian can- } \\
\text { cer by conventional diagnostic work-up? }\end{array}$ & Yes
\end{tabular}

Were patients planned for primary debulking surgery Yes after conventional diagnostic work-up?

\begin{tabular}{lll}
\hline Low & Low \\
\hline
\end{tabular}


Angioli 2013 (Continued)

\section{DOMAIN 2: Index Test Diagnostic open laparoscopy}

Were the index test results interpreted without knowl- Yes edge of the results of the reference standard?

If a threshold was used, was it pre-specified? No

Were the same clinical data available when test re- Yes sults were interpreted as would be available when the test is used in practice?

Did the study provide a clear definition of what was No considered to be a "positive "result for the index test?

\section{Unclear}

Low

\section{DOMAIN 3: Reference Standard}

Is the reference standards likely to correctly classify

Yes

the target condition?

Were the reference standard results interpreted with- Unclear

out knowledge of the results of the index tests?

\begin{tabular}{lll}
\hline Low & Low \\
\hline
\end{tabular}

\section{DOMAIN 4: Flow and Timing}

Was there an appropriate interval between index test Yes and reference standard?

\begin{tabular}{ll}
\hline Were all patients included in the analysis? & Yes \\
\hline $\begin{array}{l}\text { Did patients receive the same reference standard re- } \\
\text { gardless of the index test result? }\end{array}$ & No \\
\hline
\end{tabular}

High

\section{Brun 2008}

\section{Study characteristics}

\begin{tabular}{ll}
\hline Patient sampling & Prospective study. \\
\hline Patient characteristics and setting & Sample size: 55 women \\
& Diagnostics before index test: physical/gynaecological examination, \\
abdominal ultrasound, CA-125, \\
CT abdomen/pelvis, thorax X-ray/CT, routine blood test. \\
Mean age: 61 years; (range 21 to 88 ) \\
Presentation: women suspected of ovarian cancer FIGO III-IVwithout \\
contraindication for surgery \\
Kind of surgery: 26 women PDS \\
Setting: hospital Tenon, France.
\end{tabular}


Brun 2008 (Continued)

Index tests
Diagnostic laparoscopy; examination of uterus and ovaries, peritoneal surfaces, paracolic gutters, small bowel and mesentery, liver surface, omentum, diaphragm, large bowel

Cut-off test-positivity: PIV of 8 or more

Complications of index test: none reported.
Target condition and reference standard(s)

\section{Flow and timing}

Target condition: residual disease of more than $1 \mathrm{~cm}$ after surgery Criteria for target condition: no extensive peritoneal carcinomatosis/ involvement of bowel mesentery/bulky disease diaphragm/unresectable upper abdomen metastases Reference standard: laparotomy.

Test operators: gynaecological oncologist

Percentage of women reference standard performed: 26/55

Unresectable disease at laparotomy: 8 (of 26 operated) (29 NACT).

Comparative

Notes

Retrospective external validation of the prediction model of Fagotti 2006. This was done in the same population as described in Brun 2009.

\section{Methodological quality}

\begin{tabular}{llll}
\hline Item & Authors'judgement & Risk of bias & $\begin{array}{l}\text { Applicability con- } \\
\text { cerns }\end{array}$ \\
\hline
\end{tabular}

\section{DOMAIN 1: Patient Selection}

\begin{tabular}{ll}
\hline Was a consecutive or random sample of patients enrolled? & Unclear \\
\hline Did the study avoid inappropriate exclusions? & Unclear \\
\hline $\begin{array}{ll}\text { Were the patients suspected of advanced ovarian cancer by } \\
\text { conventional diagnostic work-up? }\end{array}$ & Yes \\
\hline
\end{tabular}

Were patients planned for primary debulking surgery after Yes

conventional diagnostic work-up?

Unclear

Low

\section{DOMAIN 2: Index Test Diagnostic open laparoscopy}

Were the index test results interpreted without knowledge of Yes the results of the reference standard?

If a threshold was used, was it pre-specified? Yes

Were the same clinical data available when test results were Yes interpreted as would be available when the test is used in practice?

Did the study provide a clear definition of what was consid- Yes ered to be a "positive "result for the index test?

Low Low 
Brun 2008 (Continued)

DOMAIN 3: Reference Standard

Is the reference standards likely to correctly classify the tar- Yes get condition?

Were the reference standard results interpreted without No knowledge of the results of the index tests?

\section{Low}

Low

\section{DOMAIN 4: Flow and Timing}

Was there an appropriate interval between index test and Yes reference standard?

\begin{tabular}{ll}
\hline Were all patients included in the analysis? No & No \\
\hline
\end{tabular}

Did patients receive the same reference standard regardless No of the index test result?

\section{High}

\section{Brun 2009}

\section{Study characteristics}

\begin{tabular}{|c|c|}
\hline Patient sampling & Retrospective study. \\
\hline \multirow[t]{4}{*}{ Patient characteristics and setting } & $\begin{array}{l}\text { Sample size: } 55 \text { women } \\
\text { Mean age: } 62 \text { years (range } 21 \text { to } 88 \text { ) } \\
\text { Presentation: women with primary ovarian cancer FIGO stage III/IV, no con- } \\
\text { traindication for surgery or malnutrition, evaluation for PDS }\end{array}$ \\
\hline & $\begin{array}{l}\text { Diagnostics before index test: physical/gynaecological examination, CA-125, CT } \\
\text { abdomen/pelvis, thorax X-ray/CT, routine blood test }\end{array}$ \\
\hline & Kind of surgery: PDS 26; IDS 26: No debulking surgery 3 \\
\hline & Setting: Department of gynaecology, hospital Tenon, Paris, France. \\
\hline
\end{tabular}

Index tests

Open diagnostic laparoscopy performed by 7 surgeons, 3 gynaecological oncologists, 4 non-gynaecological surgeons. Frozen section of tumour/metastasis. In case of operability direct debulking by laparotomy

Cut-off test-positivity: absence of visible residual tumour was considered feasible

Complications of index test: 1 trocar metastasis occurred in PDS group (2\%)

\footnotetext{
Target condition and reference standard(s)
}

Target condition: macroscopic residual tumour.

Criteria for target condition: extensive peritoneal carcinomatosis/involvement of bowel mesentery/bulky disease diaphragm/unresectable upper abdomen metastases.

Reference standard: laparotomy.

Test operators: gynaecological oncologists and general gynaecologists. 
Brun 2009 (Continued)

Percentage of women in whom reference standard performed: $47 \%$

Unresectable disease at laparotomy: 12

Flow and timing

Time between reference standard and Index test: 0 days

Comparative

\section{Notes}

Same population as Brun 2008. Fifty-two women had a diagnostic laparoscopy; 26 of these women were considered suitable for laparotomy. However, 8 had more than $1 \mathrm{~cm}$ of residual disease left after laparotomy. The other 26 women received NACT and interval debulking surgery. Debulking only when absence of visible residual tumour was considered feasible.

\section{Methodological quality}

\begin{tabular}{llll}
\hline Item & Authors' judgement & Risk of bias & Applicability concerns \\
\hline
\end{tabular}

\section{DOMAIN 1: Patient Selection}

Was a consecutive or random sample of patients Unclear enrolled?

Did the study avoid inappropriate exclusions? Unclear

Were the patients suspected of advanced ovarian Yes

cancer by conventional diagnostic work-up?

Were patients planned for primary debulking Yes surgery after conventional diagnostic work-up?

\begin{tabular}{lll}
\hline & Unclear & Low \\
\hline DOMAIN 2: Index Test Diagnostic open laparoscopy &
\end{tabular}

\section{DOMAIN 2: Index Test Diagnostic open laparoscopy}

Were the index test results interpreted without knowledge of the results of the reference standard?

\section{If a threshold was used, was it pre-specified? Unclear}

Were the same clinical data available when test Yes results were interpreted as would be available when the test is used in practice?

Did the study provide a clear definition of what Yes was considered to be a "positive "result for the index test?

\section{Unclear}

\section{DOMAIN 3: Reference Standard}

Is the reference standards likely to correctly clas- Yes sify the target condition? 
Brun 2009 (Continued)

Were the reference standard results interpreted without knowledge of the results of the index tests?

Low

Low

\section{DOMAIN 4: Flow and Timing}

Was there an appropriate interval between index Yes

test and reference standard?

\begin{tabular}{ll}
\hline Were all patients included in the analysis? & Unclear \\
\hline $\begin{array}{l}\text { Did patients receive the same reference standard } \\
\text { regardless of the index test result? }\end{array}$ & No
\end{tabular}

High

\section{Chéreau 2010}

\section{Study characteristics}

\begin{tabular}{ll}
\hline Patient sampling & Retrospective study design. \\
\hline Patient characteristics and setting & Sample size: 61 \\
& Diagnostics before index test: not described \\
& Mean age: 57 years \\
& Presentation: women who underwent surgery for ovarian cancer. \\
& Kind of surgery: PDS 44 women, IDS 17 women \\
& Setting: Department of Gynecology and Obstetrics, Tenon Hospital, \\
Paris, France.
\end{tabular}

Index tests

Thirty-eight women received standard laparoscopy followed by a primary debulking surgery. The findings described during laparoscopy were used to compute a Fagotti- and a modified-Fagotti score.

Cut-of test-positivity: PIV $\geq 8$

Complications of index tests: not mentioned.

\footnotetext{
Target condition and reference standard(s)
}

Target condition: possibility of leaving no macroscopic disease at debulking surgery

Criteria for target condition: not mentioned

Reference standard: laparotomy

Test operators: not mentioned

Percentage of women in whom reference standard is performed: $100 \%$ 
Chéreau 2010 (Continued)

Unresectable disease at laparotomy: $20 \%$

Flow and timing

Reference standard performed after index test, time between treatment not mentioned.

Comparative

Notes

This study included FIGO stage I-IV. Sub-analysis were performed using only FIGO stage III to IV. 38 women received a laparoscopy. Thirty-two women had no residual disease after primary debulking surgery.

\section{Methodological quality}

\begin{tabular}{llll}
\hline Item Authors' judgement & Risk of bias & $\begin{array}{l}\text { Applicability con- } \\
\text { cerns }\end{array}$
\end{tabular}

\section{DOMAIN 1: Patient Selection}

\begin{tabular}{ll}
\hline Was a consecutive or random sample of patients enrolled? & Unclear \\
\hline Did the study avoid inappropriate exclusions? & Yes \\
\hline $\begin{array}{l}\text { Were the patients suspected of advanced ovarian cancer by } \\
\text { conventional diagnostic work-up? }\end{array}$ & Yes \\
\hline $\begin{array}{l}\text { Were patients planned for primary debulking surgery after } \\
\text { conventional diagnostic work-up? }\end{array}$ & Yes
\end{tabular}

\begin{tabular}{llll}
\hline & Unclear & High \\
\hline
\end{tabular}

\section{DOMAIN 2: Index Test Diagnostic open laparoscopy}

Were the index test results interpreted without knowledge of Yes the results of the reference standard?

If a threshold was used, was it pre-specified? Unclear

Were the same clinical data available when test results were Yes interpreted as would be available when the test is used in practice?

Did the study provide a clear definition of what was consid- Yes ered to be a "positive "result for the index test?

Unclear

Low

\section{DOMAIN 3: Reference Standard}

Is the reference standards likely to correctly classify the target Yes condition?

Were the reference standard results interpreted without knowledge of the results of the index tests?

\begin{tabular}{lll}
\hline Low & Low \\
\hline
\end{tabular}


Chéreau 2010 (Continued)

DOMAIN 4: Flow and Timing

Was there an appropriate interval between index test and ref- Unclear erence standard?

Were all patients included in the analysis? Yes

Did patients receive the same reference standard regardless

of the index test result?

Deffieux 2006

\section{Study characteristics}

Patient sampling

Patient characteristics and setting
Cross-sectional study, enrolment not reported.

\section{Sample size: 15 women}

Mean age: 54 years (range 37 to 75 )

Presentation: women with primary ovarian cancer FIGO stagellIC/IV suspected of peritoneal carcinomatosis and in whom preoperative evaluation was unsatisfactory to define the possibility of achieving a complete debulking, no massive disease at diaphragm/xiphoid or liver pedicle, planned for PDS

Diagnostics before index test: physical/gynaecological examination, CT abdomen/pelvis, thorax X-ray/CT,

Kind of surgery: PDS 11; IDS 0 No debulking surgery 4

Setting: Department of gynaecology, hospital Tenon, Paris, France

Index tests

Open diagnostic laparoscopy; examination of the whole abdomen, focus on involvement of small bowel, liver pedicle and upper right diaphragmatic dome. Cut-off test-positivity: having one or more of the criteria for unresectability

Complications of index test: none

Target condition and reference standard(s)

Target condition: unresectable carcinomatosis

Criteria for target condition: involvement of bowel mesentery/bulky disease diaphragm/massive involvement of liver pedicle

Reference standard: laparotomy.

Test operators: not reported

Percentage of women in whom reference standard performed:73\%

Unresectable disease at laparotomy: 1

Flow and timing

Time between reference standard and index test: 0 day. 
Deffieux 2006 (Continued)

Notes
Fifteen women underwent diagnostic laparoscopy, of these 11 were considered operable. Ten of the women were indeed successfully operated and one had too extensive disease. The other four women were treated with NACT.

\section{Methodological quality}

\begin{tabular}{llll}
\hline Item Authors' judgement & Risk of bias & $\begin{array}{l}\text { Applicability con- } \\
\text { cerns }\end{array}$ \\
\hline
\end{tabular}

\section{DOMAIN 1: Patient Selection}

\section{Was a consecutive or random sample of patients en- Unclear} rolled?
Did the study avoid inappropriate exclusions?
Unclear

Were the patients suspected of advanced ovarian can- Yes

cer by conventional diagnostic work-up?

\section{Were patients planned for primary debulking surgery Yes}

after conventional diagnostic work-up?

\begin{tabular}{lcc}
\hline & Unclear & Low \\
\hline DOMAIN 2: Index Test Diagnostic open laparoscopy &
\end{tabular}

DOMAIN 2: Index Test Diagnostic open laparoscopy

Were the index test results interpreted without knowl- Yes edge of the results of the reference standard?

\begin{tabular}{ll}
\hline If a threshold was used, was it pre-specified? & Yes \\
\hline $\begin{array}{l}\text { Were the same clinical data available when test re- } \\
\text { sults were interpreted as would be available when the }\end{array}$ & Yes \\
test is used in practice? & \\
\hline
\end{tabular}

Did the study provide a clear definition of what was Yes considered to be a "positive "result for the index test?

\begin{tabular}{lcc}
\hline & Low & Low \\
\hline DOMAIN 3: Reference Standard &
\end{tabular}

\section{DOMAIN 3: Reference Standard}

Is the reference standards likely to correctly classify

the target condition?

Were the reference standard results interpreted with- No

out knowledge of the results of the index tests?

\begin{tabular}{lll}
\hline Low & Low \\
\hline
\end{tabular}

\section{DOMAIN 4: Flow and Timing}

Was there an appropriate interval between index test Yes and reference standard?

Were all patients included in the analysis? 
Deffieux 2006 (Continued)

Did patients receive the same reference standard re-

No gardless of the index test result?

High

\section{Dessapt 2016}

\section{Study characteristics}

\begin{tabular}{ll}
\hline Patient sampling & Retrospective study design. \\
\hline Patient characteristics and setting & Sample size: 123 \\
& Diagnostics before index test: physical and gynaecological examination, \\
& CA-125, albumin, CT chest/abdomen/pelvis, nutritional assessment. \\
& Mean age: 62.5 years \\
& $\begin{array}{l}\text { Presentation: women with advanced epithelial cancer of the ovary, tube, or } \\
\text { peritoneum. }\end{array}$ \\
& Kind of surgery: PDS: 54, IDS: 69 \\
& Setting: Women's Oncologic Surgery Center of the Georges Pompidou \\
& Teaching Hospital, Paris, France. \\
& $\begin{array}{l}\text { Standard staging laparoscopy. Each abdominal en pelvic sector was ex- } \\
\text { plored systematically. The PCl score was determined. }\end{array}$ \\
Index tests & $\begin{array}{l}\text { Cut-of test-positivity: prediction of complete absence of disease after de- } \\
\text { bulking surgery. }\end{array}$ \\
Complications of index tests: not mentioned.
\end{tabular}

Target condition and reference standard(s)

Target condition: possibility of leaving no macroscopic disease at debulking surgery.

Criteria for target condition: massive involvement of the hepatic pedicle, bowel involvement requiring extensive small-bowel resection, need for more than two gastrointestinal resections and/or mesenteric resection, suprarenal lymphadenopathy and massive involvement of the retroperitoneum.

Reference standard: laparotomy

Test operators: not mentioned

Percentage of women in whom reference standard is performed: $100 \%$

Unresectable disease at laparotomy: $22.8 \%$ (28 women).

Flow and timing

Reference standard performed after index test, time between treatment not mentioned.

\section{Comparative}


Dessapt 2016 (Continued)

Methodological quality

\begin{tabular}{llll}
\hline Item Authors' judgement & Risk of bias & $\begin{array}{l}\text { Applicability con- } \\
\text { cerns }\end{array}$ \\
\hline
\end{tabular}

\section{DOMAIN 1: Patient Selection}

Was a consecutive or random sample of patients en- Yes rolled?

\begin{tabular}{ll}
\hline Did the study avoid inappropriate exclusions? & Yes \\
\hline
\end{tabular}

Were the patients suspected of advanced ovarian can- Yes

cer by conventional diagnostic work-up?

Were patients planned for primary debulking surgery Yes

after conventional diagnostic work-up?

\begin{tabular}{lcc}
\hline & Low & Low \\
\hline DOMAIN 2: Index Test Diagnostic open laparoscopy & &
\end{tabular}

Were the index test results interpreted without knowl- Yes

edge of the results of the reference standard?

If a threshold was used, was it pre-specified?

No

Were the same clinical data available when test re- Yes

sults were interpreted as would be available when the

test is used in practice?

Did the study provide a clear definition of what was Yes

considered to be a "positive "result for the index test?

Unclear Low

DOMAIN 3: Reference Standard

Is the reference standards likely to correctly classify Yes

the target condition?

Were the reference standard results interpreted with- Unclear out knowledge of the results of the index tests?

Low Low

\section{DOMAIN 4: Flow and Timing}

Was there an appropriate interval between index test Unclear and reference standard?

$\begin{array}{ll}\text { Were all patients included in the analysis? } & \text { Yes } \\ \begin{array}{l}\text { Did patients receive the same reference standard re- } \\ \text { gardless of the index test result? }\end{array} & \text { No }\end{array}$

\section{High}




\section{Study characteristics}

\begin{tabular}{|c|c|}
\hline Patient sampling & Retrospective study design. \\
\hline \multirow[t]{6}{*}{ Patient characteristics and setting } & Sample size: 38 \\
\hline & Mean age: 50.8 years ( range: 27 to 69 ) \\
\hline & $\begin{array}{l}\text { Presentation: all patients diagnosed with epithelial ovarian cancer, } \\
\text { stage IIIC/IV. }\end{array}$ \\
\hline & $\begin{array}{l}\text { Diagnostics before index test: chest radiography, pelvic ultrasonogra- } \\
\text { phy, CT-scan and CA-125. }\end{array}$ \\
\hline & $\begin{array}{l}\text { Kind of surgery: } 6 \text { patients received diagnostic laparoscopy (DLS) fol- } \\
\text { lowed by primary debulking surgery (PDS). } 32 \text { patients received DLS fol- } \\
\text { lowed by NACT. }\end{array}$ \\
\hline & Setting: Unclear \\
\hline \multirow[t]{4}{*}{ Index tests } & $\begin{array}{l}\text { Diagnostic laparoscopy. The Fagotti score (PIV 8) was determined and } \\
\text { used to predict resectability. }\end{array}$ \\
\hline & Cut-off test-positivity:Patients in whom Fagotti score $\geq 8$ underwent \\
\hline & $\begin{array}{l}\text { NACT. Patients considered with a resectable disease (PIV }<8 \text { ) were oper- } \\
\text { ated by laparotomy. }\end{array}$ \\
\hline & Complications of index tests: not mentioned. \\
\hline
\end{tabular}

Target condition and reference standard(s)

Target condition: the possibility of optimal debulking surgery $(<1 \mathrm{~cm})$.

Criteria for target condition: Fagotti score $<8$

Reference standard: laparotomy

Test operators: gynaecological oncologist

Percentage of patients in whom reference standard is performed: $16 \%$

Unresectable disease at laparotomy: $0 \%$

Flow and timing

Reference standard performed after index test, time between treatment is 0 days.

\section{Comparative}

Notes

Thirty-eight laparoscopic evaluations were made. Six patients whom scored PIV $<8$ received PDS. All six patients whom received PDS had an optimal debulking rate $(100 \%)$. Thirty-two patients received NACT after a PIV score $\geq 8$ at laparoscopic evaluation.

\section{Methodological quality}

\begin{tabular}{llll}
\hline Item & Authors' judgement & Risk of bias & \multicolumn{1}{l}{$\begin{array}{l}\text { Applicability con- } \\
\text { cerns }\end{array}$}
\end{tabular}

\section{DOMAIN 1: Patient Selection}

Was a consecutive or random sample of patients en- Unclear rolled?

Did the study avoid inappropriate exclusions?

Unclear 
Eoh 2017 (Continued)

Were the patients suspected of advanced ovarian cancer Yes by conventional diagnostic work-up?

Were patients planned for primary debulking surgery after Yes conventional diagnostic work-up?

Unclear

Low

\section{DOMAIN 2: Index Test Diagnostic open laparoscopy}

Were the index test results interpreted without knowledge Yes

of the results of the reference standard?

If a threshold was used, was it pre-specified?

Were the same clinical data available when test results

Did the study provide a clear definition of what was con- Yes sidered to be a "positive "result for the index test?

Low

Low

\section{DOMAIN 3: Reference Standard}

Is the reference standards likely to correctly classify the Yes target condition?

Were the reference standard results interpreted without No

knowledge of the results of the index tests?

Low

Low

\section{DOMAIN 4: Flow and Timing}

Was there an appropriate interval between index test and Yes reference standard?

Were all patients included in the analysis?

Yes

Did patients receive the same reference standard regard- No

less of the index test result?

High

Fagotti 2004

\section{Study characteristics}

\begin{tabular}{ll}
\hline Patient sampling & Prospective study. \\
\hline Patient characteristics and setting & Sample size: 64 women \\
& Mean age: 57.4 years $(+/-12.7)$
\end{tabular}


Fagotti 2004 (Continued)

Presentation: women undergoing surgery for a suspected advanced ovarian or peritoneal cancer, exclusion advanced ASA or very large mass reaching xiphoid/ occupying the abdominal wall or cavity. Included also if on radiologic and clinical criteria suspected of unresectable disease.

Diagnostics before index test: physical/gynaecological examination, ultrasonography, CA-125, CT abdomen/pelvis, thorax X-ray/CT

Kind of surgery: all women received explorative laparotomy. Performed before: PDS 42; IDS 19: recurrence: 3 .

Index tests

Open diagnostic laparoscopy, investigating frozen pelvis, omental cake, diaphragmatic or peritoneal extensive carcinomatosis, tumour diffusion to the large and small curvature of the stomach, large and/or small bowel mesentery disease, spleen and/or liver metastases, bulky lymph nodes.

Cut-off test-positivity: absence of criteria for unresectability

Complications of index test: none

Target condition and reference standard(s)

Target condition: resectability of tumour residual of less than $1 \mathrm{~cm}$ not possible Criteria for target condition: extensive peritoneal carcinomatosis/involvement of bowel mesentery/bulky disease diaphragm/ portal triad disease/unresectable upper abdominal metastasis

Reference standard: explorative laparotomy.

Test operators: not reported percentage of women

Reference stand performed: $100 \%$

Unresectable disease at laparotomy: 23

Flow and timing

Time between reference standard and index test: 0 days.

Comparative

Notes

Not only women planned for primary surgery, but also planned for IDS or secondary surgery because of recurrence. After inclusion and laparotomy FIGO I to

II, III to IV 9 to 42, respectively, 6 benign, 7 other tumour

\section{Methodological quality}

\begin{tabular}{llll}
\hline Item & Authors' judgement & Risk of bias & Applicability concerns \\
\hline
\end{tabular}

DOMAIN 1: Patient Selection

Was a consecutive or random sample of patients Yes enrolled?

\begin{tabular}{llll}
\hline Did the study avoid inappropriate exclusions? & Yes & \\
\hline $\begin{array}{l}\text { Were the patients suspected of advanced ovarian } \\
\text { cancer by conventional diagnostic work-up? }\end{array}$ & Yes & & \\
\hline $\begin{array}{l}\text { Were patients planned for primary debulking } \\
\text { surgery after conventional diagnostic work-up? }\end{array}$ & No & Low High \\
\hline
\end{tabular}


Fagotti 2004 (Continued)

\section{DOMAIN 2: Index Test Diagnostic open laparoscopy}

Were the index test results interpreted without knowledge of the results of the reference standard?

\begin{tabular}{ll}
\hline If a threshold was used, was it pre-specified? Yes \\
\hline
\end{tabular}

Were the same clinical data available when test Yes results were interpreted as would be available when the test is used in practice?

\begin{tabular}{lll}
\hline & Low & Low \\
\hline
\end{tabular}

\section{DOMAIN 3: Reference Standard}

Is the reference standards likely to correctly clas- Yes sify the target condition?

Were the reference standard results interpret- No ed without knowledge of the results of the index tests?

\begin{tabular}{ll}
\hline DOMAIN 4: Flow and Timing & Low \\
\hline Was there an appropriate interval between index & Yes \\
test and reference standard? & No \\
\hline $\begin{array}{l}\text { Were all patients included in the analysis? } \\
\text { Did patients receive the same reference standard }\end{array}$ \\
\begin{tabular}{l} 
regardless of the index test result? \\
\hline
\end{tabular}
\end{tabular}

Low

\section{Fagotti 2008}

\section{Study characteristics}

$$
\text { Patient sampling }
$$

Patient characteristics and setting
Prospective study.

Sample size: 113 women

Diagnostics before index test: physical/gynaecological examination, CA-125, CT abdomen/pelvis, thorax X-ray/CT, Performance status Mean age: 59 years (range 34 to 81 )

Presentation: women suspected of advanced primary ovarian cancer Kind of surgery: primary (91) or interval debulking (22) surgery

Setting: Division of Gynaecologic Oncology, University hospital, Rome, Italy 
Fagotti 2008 (Continued)

Index tests
Eight laparoscopic features investigated as potential indicators of surgical outcome; presence of ovarian masses, omental cake, peritoneal carcinomatosis, diaphragmatic carcinosis, mesenteric retraction, bowel infiltration, stomach infiltration, liver metastases.

Cut-off test-positivity: PIV 8 or more ( based on presence of criteria)

Complications of index test: none
Target condition: possibility of leaving less than $1 \mathrm{~cm}$ macroscopic disease at debulking surgery

Criteria for target condition: no extensive peritoneal carcinomatosis/no involvement of bowel mesentery/no bulky disease diaphragm/no unresectable upper abdomen metastases, good performance status

Reference standard: laparotomy.

Test operators: gynaecological oncologist

Percentage of women in whom reference standard performed: $100 \%$

Unresectable disease at laparotomy: 50\%
Time between ref standard and index test not mentioned.

\section{Comparative}

$$
\text { Notes }
$$

Validation of prediction model developed by Fagotti 2006 in prospective cohort. Also women planned for IDS included in study. Primary and interval debulking women were not separately analysed.

\section{Methodological quality}

\begin{tabular}{llll}
\hline Item Authors' judgement & Risk of bias & $\begin{array}{l}\text { Applicability con- } \\
\text { cerns }\end{array}$
\end{tabular}

\section{DOMAIN 1: Patient Selection}

Was a consecutive or random sample of patients en- Yes rolled?

\begin{tabular}{lll}
\hline Did the study avoid inappropriate exclusions? & Yes & \\
\hline $\begin{array}{l}\text { Were the patients suspected of advanced ovarian can- } \\
\text { cer by conventional diagnostic work-up? }\end{array}$ & Yes & \\
\hline $\begin{array}{l}\text { Were patients planned for primary debulking surgery } \\
\text { after conventional diagnostic work-up? }\end{array}$ & No & High \\
\hline & & \\
\hline DOMAIN 2: Index Test Diagnostic open laparoscopy & & \\
\hline $\begin{array}{l}\text { Were the index test results interpreted without knowl- } \\
\text { edge of the results of the reference standard? }\end{array}$ & Yes \\
\hline If a threshold was used, was it pre-specified?
\end{tabular}




\section{Fagotti 2008 (Continued)}

Were the same clinical data available when test results were interpreted as would be available when the test is used in practice?

Did the study provide a clear definition of what was Yes considered to be a "positive "result for the index test? Yes

\begin{tabular}{lll}
\hline & Low & Low \\
\hline DOMAIN 3: Reference Standard & &
\end{tabular}

Is the reference standards likely to correctly classify Yes
the target condition?

Were the reference standard results interpreted with- Unclear

out knowledge of the results of the index tests?

\begin{tabular}{lll}
\hline DOMAIN 4: Flow and Timing & Low \\
\hline $\begin{array}{l}\text { Was there an appropriate interval between index test } \\
\text { and reference standard? }\end{array}$ & Yes \\
\hline Were all patients included in the analysis? & Yes \\
\hline $\begin{array}{l}\text { Did patients receive the same reference standard re- } \\
\text { gardless of the index test result? }\end{array}$ & Yes \\
\hline
\end{tabular}

Low

\section{Fagotti 2013}

\section{Study characteristics}

Patient sampling

Patient characteristics and setting
Retrospective study design.

Sample size: 300

Diagnostics before index test: complete physical and gynaecological examination, assessment of Ca-125 serum levels, ECOG performance status (ECOG-PS), chestabdominal-pelvic CT-scan and sonography.

Mean age: 59 years (range: 31 to 85 )

Presentation: women with primary advanced epithelial ovarian cancer. retrieved from the Catholic University of the Sacred Heart (CUSH) of Rome and Campobasso - Registry database.

Kind of surgery: 300 women received laparoscopic evaluation. 148 women received PDS and 120 women received NACT followed by IDS.

Setting: Division of Minimally Invasive Gynecological Surgery, St. Maria Hospital , Terni, Italy

Index tests
Staging laparoscopy (S-LSP). Each abdominal en pelvic sector was explored systematically. The Predictive Index Value (PIV) score was determined. 
Fagotti 2013 (Continued)

Cut-of test-positivity: PIV $\geq 8$

Complications of index tests: no complications related to surgical procedure were mentioned

Target condition and reference standard(s)
Target condition: possibility to predict optimal cytoreductive result after surgery.

Criteria for target condition: cumulative PIV score $\geq 8$

Reference standard: laparotomy

Test operators: not mentioned

Percentage of women in whom reference standard is performed: $49.3 \%$

Unresectable disease at laparotomy: $10.2 \%$

Target condition: possibility to predict optimal cytoreductive result after surgery

Criteria for target condition: cumulative PIV score $\geq 8$

Reference standard: laparotomy

Test operators: not mentioned

Percentage of women in whom reference standard is performed: $49.3 \%$

Unresectable disease at laparotomy: $10.2 \%$

Reference standard performed after index test, time between treatment is not mentioned.

Flow and timing

One hundred and forty-eight women received S-LPS followed by PDS attempt. Ninety-two women had no macroscopic residual tumour tissue after surgery and 41 women had residual tumour tissue $\leq 1 \mathrm{~cm}$ after surgery.

\section{Methodological quality}

Item Authors' judgement Risk of bias Applicability concerns

\section{DOMAIN 1: Patient Selection}

Was a consecutive or random sample of pa- $\quad$ Yes tients enrolled?

Did the study avoid inappropriate exclusions? Yes

Were the patients suspected of advanced ovar- Yes ian cancer by conventional diagnostic workup?

Were patients planned for primary debulking Yes surgery after conventional diagnostic work-up?

\begin{tabular}{lll}
\hline Low & Low \\
\hline
\end{tabular}

DOMAIN 2: Index Test Diagnostic open laparoscopy 
Fagotti 2013 (Continued)

Were the index test results interpreted without knowledge of the results of the reference standard?

If a threshold was used, was it pre-specified? Yes

Were the same clinical data available when test Yes results were interpreted as would be available when the test is used in practice?

Did the study provide a clear definition of what was considered to be a "positive "result for the index test?

Yes

\begin{tabular}{lcc}
\hline & Low & Low \\
\hline DOMAIN 3: Reference Standard & &
\end{tabular}

Is the reference standards likely to correctly Yes

classify the target condition?

Were the reference standard results interpret- Unclear ed without knowledge of the results of the index tests?

\section{DOMAIN 4: Flow and Timing}

Was there an appropriate interval between in- Unclear dex test and reference standard?

\begin{tabular}{ll}
\hline Were all patients included in the analysis? Yes \\
\hline
\end{tabular}

Did patients receive the same reference stan- No

dard regardless of the index test result?

High

\section{Petrillo 2015}

\section{Study characteristics}

Patient sampling Retrospective study design.

Patient characteristics and setting

Sample size: 234

Diagnostics before index test: not mentioned.

Mean age: 57 years (range: 25 to 84 )

Presentation: women submitted to staging laparoscopy and further laparotomic attempt of PDS.

Kind of surgery: PDS: 234 
Petrillo 2015 (Continued)

Setting: Gynaecologic Oncology Unit of the Catholic University of the sacred heart of Rome and Campobasso, Rome, Italy.

\section{Index tests}

Standard staging laparoscopy. Each abdominal en pelvic sector was explored systematically. The Predictive Index Value (PIV) score was determined.

Cut-of test-positivity: prediction of complete absence of disease after cytoreductive surgery

Complications of index tests: not mentioned.

\section{Target condition and reference standard(s)}

Target condition: residual disease of more than $1 \mathrm{~cm}$ after surgery

Criteria for target condition: mesenterial retraction and miliaric carcinomatosis on the serosa of the small bowel

Reference standard: laparotomy

Test operators: two experienced gynaecological oncologists

Percentage of women in whom reference standard is performed: $100 \%$

Unresectable disease at laparotomy: 19.2\% (45 women)

\section{Flow and timing}

Reference standard performed after index test, time between treatment not mentioned.

\section{Comparative}

Notes

Two hundred and thirty-four women received S-LPS and were judged suitable for PDS. 135 women had no macroscopic residual tumour tissue after surgery and 54 women had residual tumour tissue $\leq 1 \mathrm{~cm}$ after surgery.

\section{Methodological quality}

\begin{tabular}{llll}
\hline Item Authors' judgement & Risk of bias & \multicolumn{1}{l}{$\begin{array}{l}\text { Applicability con- } \\
\text { cerns }\end{array}$}
\end{tabular}

DOMAIN 1: Patient Selection

Was a consecutive or random sample of patients en- Yes rolled?

Did the study avoid inappropriate exclusions? Yes

Were the patients suspected of advanced ovarian cancer Yes by conventional diagnostic work-up?

Were patients planned for primary debulking surgery after Yes conventional diagnostic work-up?

\begin{tabular}{lll}
\hline Low & Low \\
\hline
\end{tabular}

\section{DOMAIN 2: Index Test Diagnostic open laparoscopy}

Were the index test results interpreted without knowledge Yes

of the results of the reference standard? 
Petrillo 2015 (Continued)

If a threshold was used, was it pre-specified? No

Were the same clinical data available when test results Yes were interpreted as would be available when the test is used in practice?

Did the study provide a clear definition of what was con- Yes

sidered to be a "positive "result for the index test?

Unclear

Low

\section{DOMAIN 3: Reference Standard}

Is the reference standards likely to correctly classify the Yes target condition?

Were the reference standard results interpreted without No knowledge of the results of the index tests?

Low

Low

\section{DOMAIN 4: Flow and Timing}

Was there an appropriate interval between index test and Unclear reference standard?

Were all patients included in the analysis? No

Did patients receive the same reference standard regard- No

less of the index test result?

High

Rosetti 2016

\section{Study characteristics}

Patient sampling Retrospective study.

Patient characteristics and setting

Sample size: 52

Diagnostics before index test: general and gynaecological examination, pelvic ultrasonography, CA-125, CT scan.

Mean age: 64 years (range: 54 to 77 )

Presentation: women found through clinical databases using the following diagnosis and procedures codes: epithelial ovarian cancer, NACT, diagnostic laparoscopic procedure, and debulking.

Kind of surgery: 15 NACT and IDS, 37 PDS

Setting: Papa Giovanni XXIII Hospital, Bergamo, Italy.

Index tests

An umbilical incision of $1.5 \mathrm{~cm}$ to $2.5 \mathrm{~cm}$ was performed and a multichannel single port was placed. The Fagotti score was determined and used to predict resectability. Patients in whom Fagotti score $>8$ under- 
Rosetti 2016 (Continued)

went NACT. Patients considered with a resectable disease were operated by laparotomy.

\section{Target condition and reference standard(s)}

Target condition: prediction of resectability to no macroscopic residual tumour

Criteria for target condition: Fagotti score $>8$

Reference standard: laparotomy

Test operators: not mentioned

Percentage of women in whom reference standard is performed: $72.5 \%$

Unresectable disease at laparotomy: $8.1 \%$

Flow and timing

Reference standard performed after index test, time between treatment not mentioned.

\section{Comparative}

Notes

Fifty-two women were included and received laparoscopy, 37 got PDS, 15 women got NACT. 34 patient had no macroscopic tumour after PDS.FIGO stage in not described. Short article.

\section{Methodological quality}

\begin{tabular}{llll}
\hline Item Authors' judgement & Risk of bias & \multicolumn{1}{c}{$\begin{array}{l}\text { Applicability con- } \\
\text { cerns }\end{array}$}
\end{tabular}

DOMAIN 1: Patient Selection

Was a consecutive or random sample of patients en- Unclear rolled?

Did the study avoid inappropriate exclusions? Yes

Were the patients suspected of advanced ovarian cancer Yes by conventional diagnostic work-up?

Were patients planned for primary debulking surgery after Unclear conventional diagnostic work-up?

\begin{tabular}{lll}
\hline Unclear & Low \\
\hline
\end{tabular}

DOMAIN 2: Index Test Diagnostic open laparoscopy

Were the index test results interpreted without knowledge Yes

of the results of the reference standard?

\begin{tabular}{ll}
\hline If a threshold was used, was it pre-specified? Yes \\
\hline
\end{tabular}

Were the same clinical data available when test results Yes were interpreted as would be available when the test is used in practice?

Did the study provide a clear definition of what was con- Yes sidered to be a "positive "result for the index test? 
Rosetti 2016 (Continued)

Low

Low

\section{DOMAIN 3: Reference Standard}

Is the reference standards likely to correctly classify the Yes

target condition?

Were the reference standard results interpreted without Yes

knowledge of the results of the index tests?

Low

Low

\section{DOMAIN 4: Flow and Timing}

\section{Was there an appropriate interval between index test and Unclear} reference standard?

\begin{tabular}{ll}
\hline Were all patients included in the analysis? Yes \\
\hline
\end{tabular}

Did patients receive the same reference standard regard- $\quad$ No less of the index test result?

High

\section{Rutten 2016}

\section{Study characteristics}

Patient sampling Randomised controlled study design.

Patient characteristics and setting Sample size: 201

Diagnostics before index test: medical history, physical and gynaecological examination, CA-125 and CEA, Risk of Malignancy Index score, CT abdomen, CT chest/X-ray chest, sonography pelvis.

Mean age: 64 years

Presentation: women between 18 to 80 years of age suspected of advanced stage ovarian cancer (FIGO stage IIB or higher)

Kind of surgery: PDS: 201

Setting: eight gynaecological cancer centres in the Netherlands.

Index tests

Participants were randomised to receive either an open laparoscopy before surgery or only primary debulking surgery. The whole abdomen was inspected systematically. If judged resectable, direct debulking was performed. If not, three cycles of NACT was given followed by an interval debulking.

Cut-of test-positivity: prediction of complete absence of disease after debulking surgery.

Complications of index tests: port-site metastasis in 3 cases (3\%) and a wound infection in 1 case $(1 \%)$.

Target condition and reference stan$\operatorname{dard}(\mathrm{s})$

Target condition: residual tumour of $>1 \mathrm{~cm}$ in maximum diameter after PDS. 
Rutten 2016 (Continued)

Criteria for target condition: extensive agglutinated intra-abdominal metastatic disease, extensive serosa invasion of the intestines and/or mesenterial deposits, and extensive (irresectable) peritoneal metastases at diaphragmatic level.

Reference standard: laparotomy

Test operators: gynaecological oncologists

Percentage of women in whom reference standard is performed: $100 \%$

Unresectable disease at laparotomy: 28.9\% (58 women).

Flow and timing

Reference standard performed after index test, time between treatment not mentioned.

Comparative

Notes
Sixty-three women received laparoscopy and primary debulking surgery, 36 women had no residual disease after PDS and 17 women had residual tumour tissue between $0.1 \mathrm{~cm}$ to $1 \mathrm{~cm}$ in diameter after surgery. Thirty-five women received laparoscopy followed by interval debulking surgery, 18 women had no residual tumour tissue and 9 women had residual tumour tissue between $0.1 \mathrm{~cm}$ to $1 \mathrm{~cm}$ in diameter after surgery. Ninety-three women received only PDS, 37 women had no residual disease after PDS and 17 women had residual tumour tissue between $0.1 \mathrm{~cm}$ to $1 \mathrm{~cm}$ in diameter after surgery. Five women received only IDS, 3 women had no residual disease after IDS and 1 patient had residual tumour tissue between $0.1 \mathrm{~cm}$ to $1 \mathrm{~cm}$ in diameter after surgery.

\section{Methodological quality}

\begin{tabular}{llll}
\hline Item Authors' judgement $\quad$ Risk of bias & Applicability concerns
\end{tabular}

\section{DOMAIN 1: Patient Selection}

Was a consecutive or random sample of Yes patients enrolled?

Did the study avoid inappropriate exclu- Yes sions?

Were the patients suspected of advanced Yes ovarian cancer by conventional diagnostic work-up?

\section{Were patients planned for primary de-

\section{DOMAIN 2: Index Test Diagnostic open laparoscopy}

Were the index test results interpreted without knowledge of the results of the reference standard?

\section{Yes}

If a threshold was used, was it pre-speci- Yes fied?

Were the same clinical data available when test results were interpreted as 
Rutten 2016 (Continued)

would be available when the test is used

in practice?

Did the study provide a clear definition

Yes

of what was considered to be a "positive

"result for the index test?

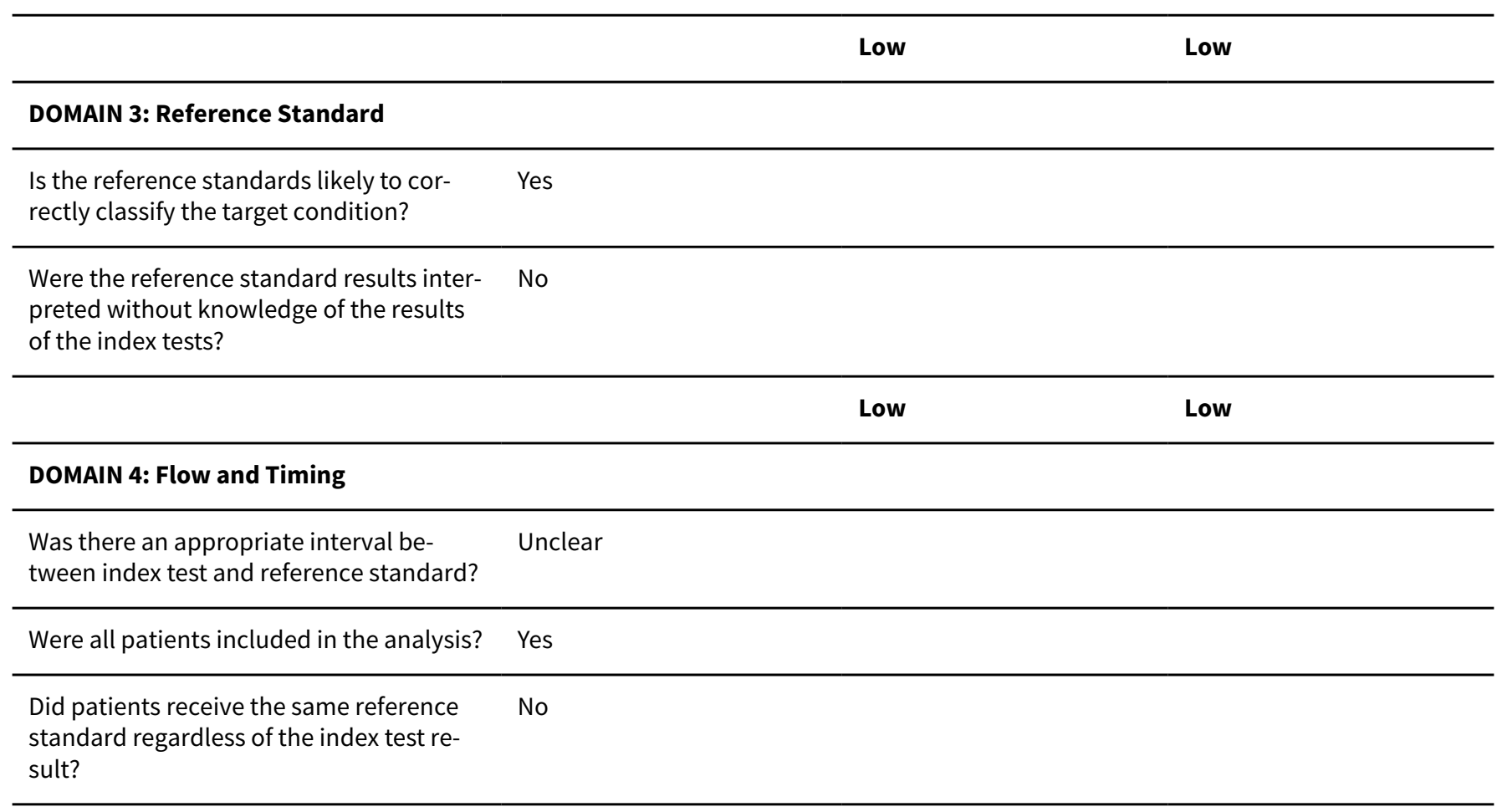

High

Varnoux 2013

\section{Study characteristics}

Patient sampling

Patient characteristics and setting
Retrospective study design.

Sample size: 28

Diagnostics before index test: physical and gynaecological examination, CA-125, CT chest/abdomen/pelvis

Mean age: 61.5 years (range: 32 to 82 )

Presentation: women above 18 years of age who were evaluated for resectability of an adnexal, peritoneal or gynaecological mass with peritoneal carcinomatosis using standard laparoscopy followed by hand-assisted laparoscopy.

Kind of surgery: PDS 13, IDS 15. Unfortunately it was not possible to analyse the primary debulking surgery group separately.

Setting: Women's Oncologic Surgery Center of the Georges Pompidou Teaching Hospital, Paris, France. 
Varnoux 2013 (Continued)

Index tests
Standard laparoscopy followed by hand-assisted laparoscopy using the Lapdisc $^{\circledR}$ device. If both laparoscopies judged resectable disease, debulking surgery was performed. If not, women were referred to the oncology department to receive NACT.

Cut-of test-positivity: prediction of complete absence of disease after debulking surgery.

Complications of index tests: no complications following Lapdisc ${ }^{\circledR}$ were reported.

\section{Target condition and reference standard(s)}

Target condition: possibility of leaving no macroscopic disease at debulking surgery.

Criteria for target condition: not mentioned.

Reference standard: laparotomy

Test operators: the same four senior surgeons or fellows

Percentage of women in whom reference standard was performed: $62.1 \%$ (18 women)

Unresectable disease at laparotomy: 5.6\% (1 patient).
Time between reference standard and Index test: 0 to 10 days.

\section{Comparative}

Notes

Twenty-nine laparoscopic evaluations were made in 28 women. Eighteen women were judged resectable and received debulking surgery, 14 women had no residual tumour tissue after surgery and 3 women had residual tumour tissue $<1 \mathrm{~cm}$ in diameter after surgery.

\section{Methodological quality}

\begin{tabular}{llll}
\hline Item & Authors' judgement & Risk of bias & Applicability concerns \\
\hline
\end{tabular}

\section{DOMAIN 1: Patient Selection}

Was a consecutive or random sample of patients Yes enrolled?

\begin{tabular}{lc}
\hline Did the study avoid inappropriate exclusions? & Yes \\
\hline $\begin{array}{l}\text { Were the patients suspected of advanced ovarian } \\
\text { cancer by conventional diagnostic work-up? }\end{array}$ & Yes \\
\hline $\begin{array}{l}\text { Were patients planned for primary debulking } \\
\text { surgery after conventional diagnostic work-up? }\end{array}$ & Yes \\
\hline
\end{tabular}

\begin{tabular}{lll}
\hline & Low & High \\
\hline DOMAIN 2: Index Test Diagnostic open laparoscopy & & \\
\hline
\end{tabular}

Were the index test results interpreted without knowledge of the results of the reference standard? 
Varnoux 2013 (Continued)

If a threshold was used, was it pre-specified? Yes

Were the same clinical data available when test Yes results were interpreted as would be available when the test is used in practice?

Did the study provide a clear definition of what No was considered to be a "positive "result for the index test?

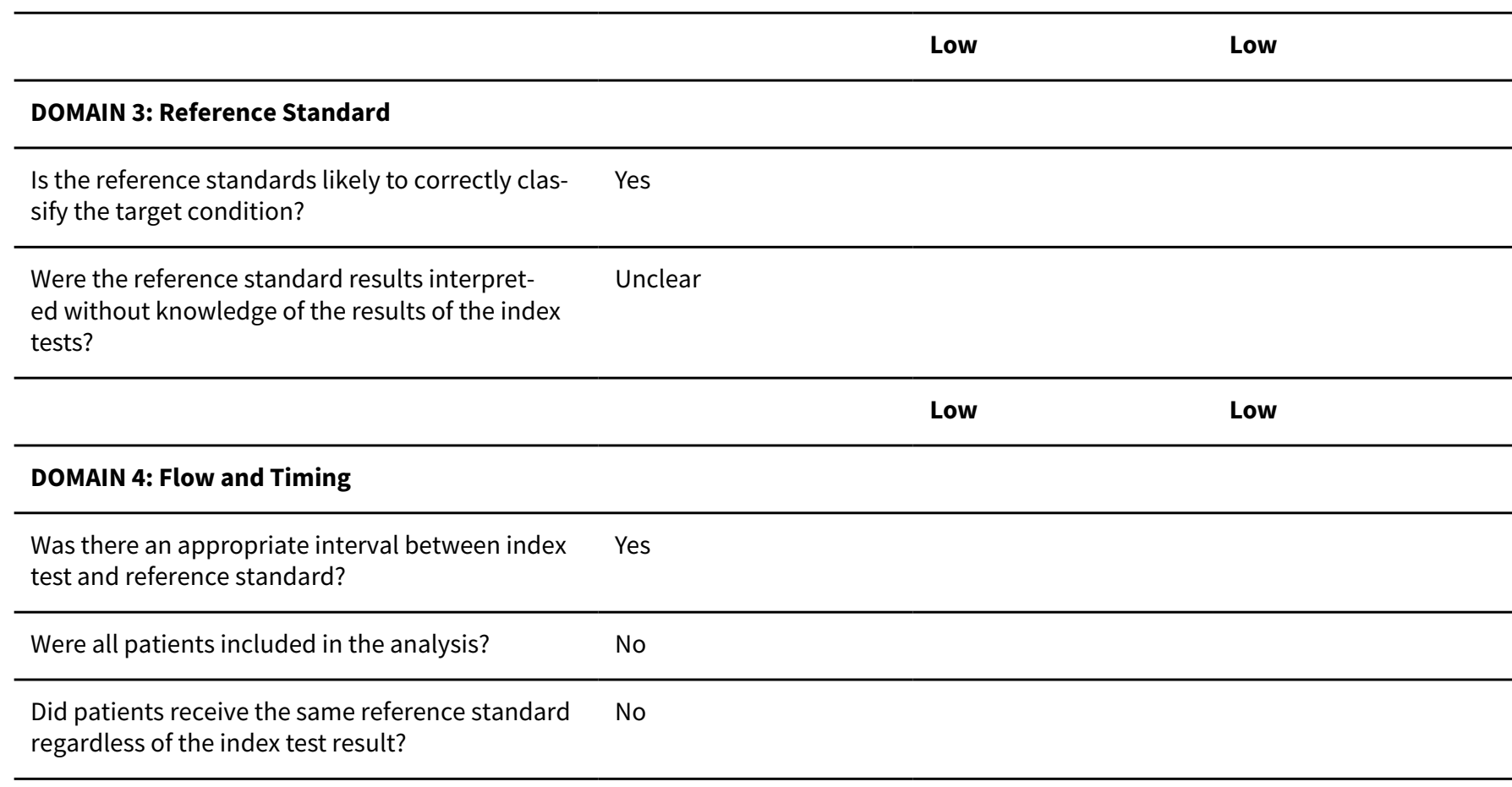

High

\section{Vergote 1998}

\section{Study characteristics}

Patient sampling Retrospective study design.

\section{Patient characteristics and setting}

Sample size: 77

Diagnostics before index test: radiological examination

Mean age: not mentioned

Presentation: women with obvious metastatic disease of ovarian cancer on radiological examination, planned for PDS

Kind of surgery: primary debulking in 28 women, IDS 31,18 no surgery

Setting: Division of Gynaecologic Oncology, University Hospital, Brussels, Belgium

Cut-off test-positivity: not reported 
Target condition: unresectability leaving more than $0.5 \mathrm{~cm}$ of residual tumour

Criteria for target condition: not mentioned

Reference standard: explorative laparotomy.

Test operators: not reported

Percentage of women in whom reference standard performed: $36 \%$ (28 women)

Unresectable disease at laparotomy: 21\% (6 women)

\section{Comparative}

Notes

Decision to give NACT or PDS in all women with advanced ovarian cancer, subgroup in paper about NACT or PDS retrospectively. Seventy-seven women had a diagnostic laparoscopy. Of these, 28 underwent a laparotomy and 21 had resectable disease. Forty-nine women received NACT and IDS.

\section{Methodological quality}

\begin{tabular}{llll}
\hline Item Authors'judgement & Risk of bias & $\begin{array}{l}\text { Applicability con- } \\
\text { cerns }\end{array}$
\end{tabular}

\section{DOMAIN 1: Patient Selection}

\begin{tabular}{lll}
\hline Was a consecutive or random sample of patients enrolled? & Yes \\
\hline Did the study avoid inappropriate exclusions? & No & Yes \\
\hline $\begin{array}{l}\text { Were the patients suspected of advanced ovarian cancer by } \\
\text { conventional diagnostic work-up? }\end{array}$ & Yes \\
\hline $\begin{array}{l}\text { Were patients planned for primary debulking surgery after } \\
\text { conventional diagnostic work-up? }\end{array}$ & Low \\
\hline
\end{tabular}

\section{DOMAIN 2: Index Test Diagnostic open laparoscopy}

Were the index test results interpreted without knowledge of Yes the results of the reference standard?

\begin{tabular}{ll}
\hline If a threshold was used, was it pre-specified? & No \\
\hline $\begin{array}{l}\text { Were the same clinical data available when test results were } \\
\text { interpreted as would be available when the test is used in }\end{array}$ & Yes \\
practice? &
\end{tabular}

Did the study provide a clear definition of what was consid- No ered to be a "positive "result for the index test? 
Vergote 1998 (Continued)

High

High

\section{DOMAIN 3: Reference Standard}

Is the reference standards likely to correctly classify the tar- Yes get condition?

Were the reference standard results interpreted without knowledge of the results of the index tests?

No

\begin{tabular}{l}
\hline DOMAIN 4: Flow and Timing \\
\hline $\begin{array}{l}\text { Was there an appropriate interval between index test and } \\
\text { reference standard? }\end{array}$
\end{tabular}
reference standard?

\begin{tabular}{ll}
\hline Were all patients included in the analysis? & Yes \\
\hline $\begin{array}{l}\text { Did patients receive the same reference standard regardless } \\
\text { of the index test result? }\end{array}$ & No \\
\hline
\end{tabular}

High

\section{Vizzielli 2014}

\section{Study characteristics}

\begin{tabular}{|c|c|}
\hline Patient sampling & Retrospective study design. \\
\hline \multirow[t]{6}{*}{ Patient characteristics and setting } & Sample size: 348 \\
\hline & $\begin{array}{l}\text { Diagnostics before index test: complete physical and gynaecological examination, } \\
\text { CA- } 125 \text { serum levels, CT-scan and ECOG performance status. }\end{array}$ \\
\hline & Mean age: 60 years (range: 25 to 85 ) \\
\hline & $\begin{array}{l}\text { Presentation: all women with FIGO stages IIIC and IV ovarian, fallopian tube, or pri- } \\
\text { mary peritoneal carcinoma who received primary treatment retrieved from the } \\
\text { Catholic University of the Sacred Heart (CUSH) of Rome and Campobasso - Registry } \\
\text { database. }\end{array}$ \\
\hline & Kind of surgery: 348 women were evaluated by a S-LSP; 165 women received PDS. \\
\hline & Setting: Division of Gynecologic Oncology of the Catholic University of Rome. \\
\hline \multirow[t]{3}{*}{ Index tests } & $\begin{array}{l}\text { Staging laparoscopy (S-LPS). Each abdominal en pelvic sector was explored system- } \\
\text { atically. The Predictive Index Value (PIV) score was determined. }\end{array}$ \\
\hline & Cut-of test-positivity: PIV $\geq 8$ \\
\hline & Complications of index tests: there were no complications described. \\
\hline
\end{tabular}

Target condition and reference standard(s) Target condition: suboptimal result after PDS

Criteria for target condition: extensive carcinosis on ileal/colonic loops and/or prohibitive number of implants and/or confluent disease and agglutinated bow- 
Vizzielli 2014 (Continued)

el/mesentery and/or disease involving the base of the mesentery and/or diaphragm bulky disease.

Reference standard: laparotomy

Test operators: the same surgical team, composed of at least two experienced surgeons with specific training in gynaecological oncology.

Percentage of women in whom reference standard was performed: $47.7 \%$

Unresectable disease at laparotomy: 9.1\%

Flow and timing

Reference standard performed after index test, time between treatment is not mentioned.

\section{Comparative}

\section{Notes}

Three hundred and forty-eight laparoscopic evaluations were made. One hundred and sixty-five women were judged resectable and received PDS, 102 women had no residual tumour tissue after surgery and 48 women had residual tumour tissue $<1$ $\mathrm{cm}$ in diameter after surgery. One-hundred and eighty-three women were judged irresectable by S-LSP and received NACT followed by IDS.

\section{Methodological quality}

\begin{tabular}{llll}
\hline Item & Authors' judgement & Risk of bias & Applicability concerns \\
\hline DOMAIN 1: Patient Selection & &
\end{tabular}

Was a consecutive or random sample of pa- Yes tients enrolled?

Did the study avoid inappropriate exclusions? Yes

Were the patients suspected of advanced Yes ovarian cancer by conventional diagnostic work-up?

Were patients planned for primary debulking Yes surgery after conventional diagnostic workup?

\begin{tabular}{lcc}
\hline & Low & Low \\
\hline DOMAIN 2: Index Test Diagnostic open laparoscopy &
\end{tabular}

Were the index test results interpreted with- Yes out knowledge of the results of the reference standard?

\begin{tabular}{ll}
\hline If a threshold was used, was it pre-specified? Yes \\
\hline
\end{tabular}

Were the same clinical data available when Yes test results were interpreted as would be available when the test is used in practice?

Did the study provide a clear definition of Yes what was considered to be a "positive "result for the index test? 
Vizzielli 2014 (Continued)

Low

Low

\section{DOMAIN 3: Reference Standard}

Is the reference standards likely to correctly Yes

classify the target condition?

Were the reference standard results interpret-

ed without knowledge of the results of the in-

dex tests?

No

\begin{tabular}{|c|c|c|}
\hline & Low & Low \\
\hline \multicolumn{3}{|l|}{ DOMAIN 4: Flow and Timing } \\
\hline $\begin{array}{l}\text { Was there an appropriate interval between in- } \\
\text { dex test and reference standard? }\end{array}$ & Unclear & \\
\hline Were all patients included in the analysis? & Yes & \\
\hline $\begin{array}{l}\text { Did patients receive the same reference stan- } \\
\text { dard regardless of the index test result? }\end{array}$ & No & \\
\hline
\end{tabular}

High

\section{Vizzielli 2016}

\section{Study characteristics}

Patient sampling Retrospective study design.

\section{Patient characteristics and setting}

\section{Sample size: 555}

Diagnostics before index test: women' history, physical examination, thorax-abdomen and pelvic CT-scan and staging laparoscopy (S-LPS)

Mean age: 59 years (range: 24 to 89 )

Presentation: all women with advanced epithelial ovarian cancer who underwent S-LPS followed by PDS retrieved from the Catholic University of the Sacred Heart

(CUSH) of Rome and Campobasso - Registry database.

Kind of surgery: 555 women received a staging laparoscopy (S-LPS) followed by a PDS.

Setting: Division of Gynecologic Oncology, Catholic University of the Sacred Heart, Rome, Italy.

Index tests

Staging laparoscopy (S-LPS). Each abdominal en pelvic sector was explored systematically. The Predictive Index Value (PIV) score was determined.

Cut-of test-positivity: PIV $\geq 8$

Complications of index tests: there were no complications described.

Target condition and reference standard(s) Target condition: suboptimal result after PDS


Vizzielli 2016 (Continued)

Criteria for target condition: not mentioned.

Reference standard: laparotomy

Test operators: experienced surgeons who had completed the training program in ovarian cancer surgery performed all surgical procedures. Each surgeon operates on at least 15 women with $A E O C$ per year, and his/her work is regularly peer reviewed.

Percentage of women in whom reference standard was performed: $100 \%$

Unresectable disease at laparotomy: 9.7\%

\section{Flow and timing}

Reference standard performed after index test, time between treatment is not mentioned.

\section{Comparative}

$\begin{array}{ll}\text { Notes } & \text { Seven hundred and eighty-five laparoscopic evaluations were made. Five } \\ & \text { hundred and fifty-five women were judged resectable and received PDS, } 417 \\ & \text { women had no residual tumour tissue after surgery and } 84 \text { women had residual } \\ \text { tumour tissue }<1 \mathrm{~cm} \text { in diameter after surgery. Two hundred and thirty women } & \text { were judged irresectable by S-LSP and received NACT followed by IDS. }\end{array}$

\section{Methodological quality}

\begin{tabular}{llll}
\hline Item & Authors' judgement & Risk of bias & Applicability concerns \\
\hline
\end{tabular}

DOMAIN 1: Patient Selection Was a consecutive or random sample of patients Yes
enrolled?

\begin{tabular}{ll}
\hline Did the study avoid inappropriate exclusions? & Yes \\
\hline $\begin{array}{l}\text { Were the patients suspected of advanced ovarian } \\
\text { cancer by conventional diagnostic work-up? }\end{array}$ & Yes \\
\hline $\begin{array}{l}\text { Were patients planned for primary debulking } \\
\text { surgery after conventional diagnostic work-up? }\end{array}$ & Yes \\
\hline
\end{tabular}

\section{DOMAIN 2: Index Test Diagnostic open laparoscopy}

Were the index test results interpreted without Yes knowledge of the results of the reference standard?

\begin{tabular}{ll}
\hline If a threshold was used, was it pre-specified? & Yes \\
\hline
\end{tabular}

Were the same clinical data available when test Yes results were interpreted as would be available when the test is used in practice?

Did the study provide a clear definition of what Yes was considered to be a "positive "result for the index test? 
Vizzielli 2016 (Continued)

Low

Low

\section{DOMAIN 3: Reference Standard}

Is the reference standards likely to correctly clas- Yes

sify the target condition?

Were the reference standard results interpret-

Unclear

ed without knowledge of the results of the index

tests?

Low

Low

\section{DOMAIN 4: Flow and Timing}

Was there an appropriate interval between index Unclear

test and reference standard?

Were all patients included in the analysis? Yes

Did patients receive the same reference standard Yes

regardless of the index test result?

Low

ASA: American Society of Anesthesiology

CA-125: cancer antigen 125

CT: computed tomography

IDS: interval debulking surgery

NACT: neoadjuvant chemotherapy

$\mathrm{PCl}$ : peritoneal cancer index

PDS: primary debulking surgery

PIV: Predictive Index Value

S-LP: staging laparoscopy

WHO: World Health Organization

Characteristics of excluded studies [ordered by study ID]

\begin{tabular}{ll}
\hline Study & Reason for exclusion \\
\hline Andikyan 2015 & Conference abstract \\
\hline Batka 1993 & Different outcome \\
\hline Bresson 2014 & Conference abstract \\
\hline Bresson 2016 & Case-control study \\
\hline Bristow 2006 & No original data shown \\
\hline Bruhat 1981 & No original data shown \\
\hline Brun 2009a & Conference abstract \\
\hline Buist 2015 & Conference abstract \\
\hline
\end{tabular}




\begin{tabular}{|c|c|}
\hline Study & Reason for exclusion \\
\hline Burmich, 2013 & Conference abstract \\
\hline Cusido, 2012 & Conference abstract \\
\hline Dagnini 1987 & Different outcome \\
\hline Fago-Olsen, 2014 & Different outcome: no data on evaluation of resectability \\
\hline Fagotti 2006 & Duplicate data, same cohort as Fagotti 2004 \\
\hline Fagotti 2013a & Conference abstract \\
\hline Fagotti 2014 & No original data: editorial comment \\
\hline Fagotti MITO 2013 & Different outcome \\
\hline Gouy 2013 & Different outcome \\
\hline Gurrea 2010 & Different outcome: no data about evaluation of resectability \\
\hline Huchon 2015 & Conference abstract \\
\hline Hynninen 2013 & Different outcome \\
\hline Kobal 2012 & Conference abstract \\
\hline Kornovski 2016 & No original data reported \\
\hline Lamela 2013 & Conference abstract \\
\hline Martín-Cameán 2016 & No original data, review \\
\hline Molero Vilchez 2011 & Conference abstract \\
\hline Molero Vilchez 2012 & Conference abstract \\
\hline Nezhat 2010 & Different outcome: no data about evaluation of resectability \\
\hline Nick 2014 & Conference abstract \\
\hline Nick 2015 & Conference abstract \\
\hline Nick 2016 & Conference abstract \\
\hline Nick 2016a & Conference abstract \\
\hline Onda 2016 & Different outcome \\
\hline Quaranta 2014 & Different outcome \\
\hline Rutten 2012 & $\begin{array}{l}\text { No original data, study protocol of the LapOvCa-trial by Rutten and colleagues, which is } \\
\text { included in this review }\end{array}$ \\
\hline Taskiran 2016 & Conference abstract \\
\hline
\end{tabular}




\section{A T A}

Presented below are all the data for all of the tests entered into the review.

Table Tests. Data tables by test

\begin{tabular}{lll}
\hline Test & No. of studies & No. of participants \\
\hline 1 Laparoscopy & 2 & 292 \\
\hline 2 PIV $\geq 8$ to diagnose unresectable disease with $>1 \mathrm{~cm}$ residual disease & 6 & 265 \\
\hline $\begin{array}{l}4 \text { Modified fagotti PIV }>4 \text { to diagnose unresectable disease with }>1 \mathrm{~cm} \text { residual } \\
\text { disease }\end{array}$ & 3 & 85 \\
\hline
\end{tabular}

Test 1. Laparoscopy.

Review: Laparoscopy for diagnosing resectability of disease in women with advanced ovarian cancer

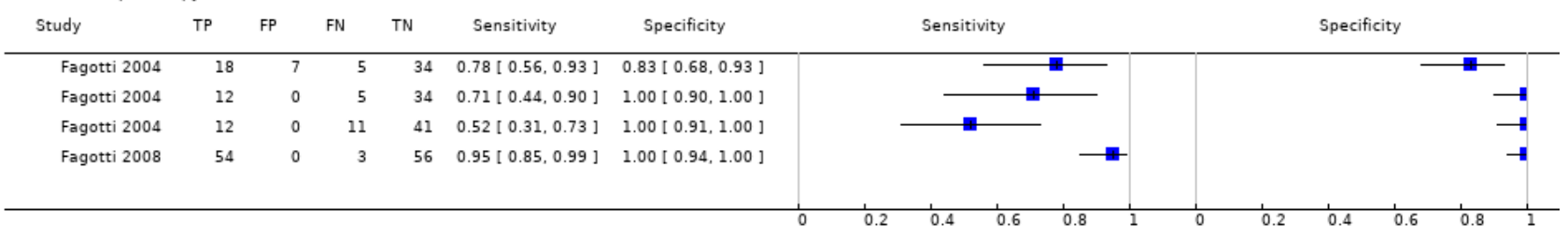

Test 2. PIV $\geq 8$ to diagnose unresectable disease with $>1 \mathrm{~cm}$ residual disease.

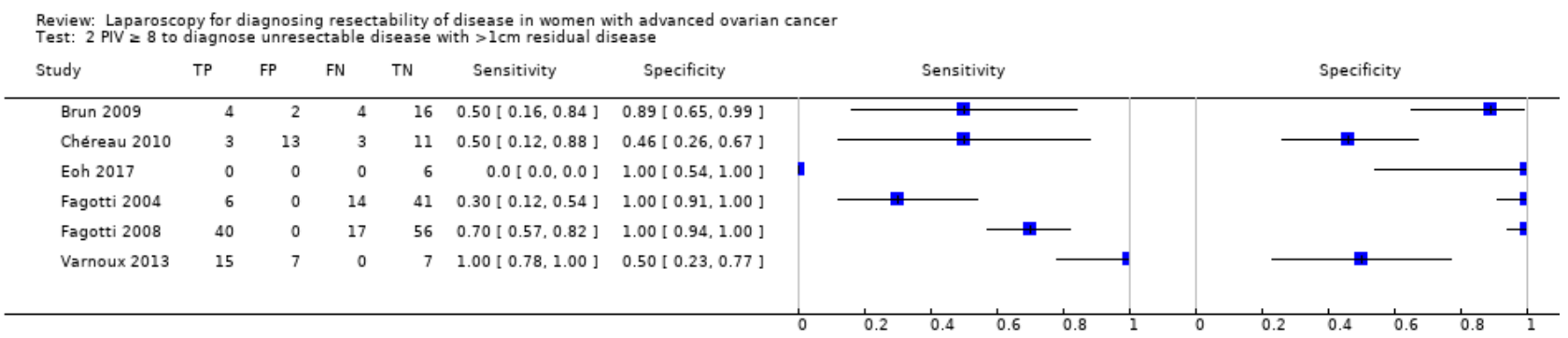


Test 4. Modified fagotti PIV >4 to diagnose unresectable disease with $>1 \mathrm{~cm}$ residual disease.

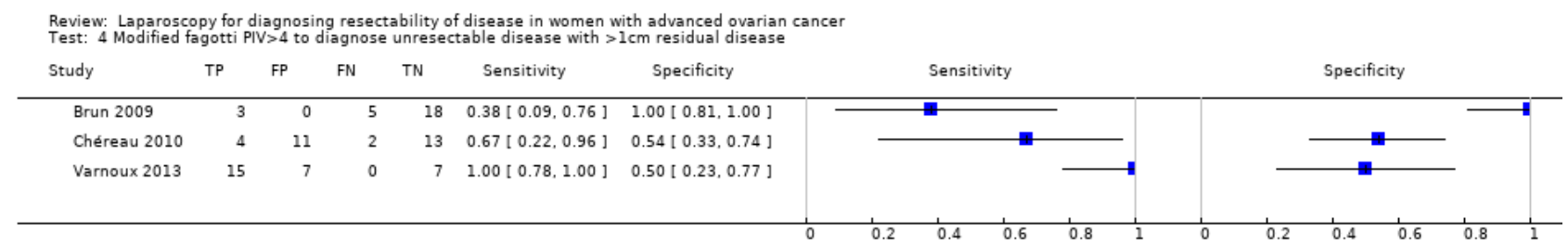

\section{APPENDICES}

\section{Appendix 1. MEDLINE search strategy}

1 exp Ovarian Neoplasms/

2 Fallopian Tube Neoplasms/

3 ((ovar ${ }^{\star}$ or fallopian tube ${ }^{\star}$ ) adj5 (cancer ${ }^{\star}$ or tumor* or tumour $^{\star}$ or adenocarcinoma ${ }^{\star}$ or carcino* or cystadenocarcinoma ${ }^{\star}$ or choriocarcinoma* or malignan* or neoplas* or metasta* or mass or masses)).tw,ot.

4 (thecoma* or luteoma*).tw,ot.

51 or 2 or 3 or 4

6 exp Laparoscopy/

7 laparoscop*.tw,ot.

8 celioscop ${ }^{*}$. tw,ot.

9 peritoneoscop ${ }^{*}$. tw,ot.

10 abdominoscop ${ }^{*}$.tw,ot.

116 or 7 or 8 or 9 or 10

125 and 11

13 exp animals/ not humans.sh.

1412 not 13

key:

tw,ot. $=$ textword, original title

\section{Appendix 2. EMBASE search strategy}

1 exp ovary tumor/

2 uterine tube tumor/

3 ((ovar $^{\star}$ or fallopian tube $)$ adj5 (cancer ${ }^{\star}$ or tumor $^{\star}$ or tumour $^{\star}$ or adenocarcinoma* or carcino* or cystadenocarcinoma* or malignan ${ }^{\star}$ or neoplas ${ }^{\star}$ or metasta* or mass or masses)).tw,ot.

4 (thecoma* or luteoma*).tw,ot.

51 or 2 or 3 or 4

6 exp laparoscopy/

7 laparoscop ${ }^{\star} . \mathrm{tw}, \mathrm{ot}$.

8 celioscop*.tw,ot.

9 peritoneoscop ${ }^{\star}$.tw,ot.

10 abdominoscop*.tw,ot.

116 or 7 or 8 or 9 or 10

125 and 11

13 (exp Animal/ or Nonhuman/ or exp Animal Experiment/) not Human/

1412 not 13

key: tw,ot $=$ textword, original title

\section{Appendix 3. CENTRAL search strategy}

\#1 MeSH descriptor Ovarian Neoplasms explode all trees

\#2 MeSH descriptor Fallopian Tube Neoplasms, this term only

\#3 ((ovar ${ }^{\star}$ or fallopian tube ${ }^{\star}$ ) near/5 (cancer ${ }^{\star}$ or tumor ${ }^{\star}$ or tumour ${ }^{\star}$ or adenocarcinoma* or carcino* or cystadenocarcinoma* or malignan ${ }^{\star}$ or neoplas* or metasta* or mass or masses))

\#4 thecoma* or luteoma* 
\#5 (\#1 OR \#2 OR \#3 OR \#4)

\#6 MeSH descriptor Laparoscopy explode all trees

\#7 laparoscop*

\#8 celioscop*

\#9 peritoneoscop*

$\# 10$ abdominoscop*

\#11 (\#6 OR \#7 OR \#8 OR \#9 OR \#10)

\#12 (\#5 AND \#11)

\section{Appendix 4. MEDION (http://www.mediondatabase.nt/)}

ICPC code for female genital system - "X"

\section{Appendix 5. Science Citation Index}

All citations found though the searches in MEDLINE, EMBASE and CENTRAL were checked in Science Citation Index for articles which cited these articles.

\section{Appendix 6. Quadas review question and inclusion criteria}

\begin{tabular}{lll}
\hline Category & Review Question & Inclusion Criteria \\
\hline Women & $\begin{array}{l}\text { Women with advanced stage ovarian cancer } \\
\text { who are thought to have resectable disease after } \\
\text { conventional diagnostic work-up }\end{array}$ & Women suspected of advanced stage ovarian cancer \\
&
\end{tabular}

Index test Additional open laparoscopy Diagnostic laparoscopy

Target Condition Non-resectable disease Non-resectable disease for which a definition is given

\begin{tabular}{lll}
\hline Reference standard & Laparotomy & Laparotomy \\
\hline Outcome & NA & Sufficient data to construct a $2 \times 2$ table \\
\hline Study Design & NA & Diagnostic cohort study \\
\hline
\end{tabular}

\section{Appendix 7. Quality indicator}

\begin{tabular}{lll}
\hline Risk of Bias & Applicabillity \\
\hline Quality indicator Notes & Quality indicator Notes \\
\hline
\end{tabular}


(Continued)

Domain 1 Patient Selection
Could the selection of women have introduced bias? (High/low/unclear)

\begin{tabular}{ll}
\hline 1. Was a con- & "Yes" if a consecutive or random \\
secutive or ran- & sample of women was enrolled \\
dom sample & "No" if a selected group of \\
of women en- & women was enrolled \\
rolled? & "Unclear" if there is insufficient \\
& information on enrollement
\end{tabular}

Are there concerns that the included women and settings do not match the review question? (High/low/unclear)
"Yes" if women were diagnosed by conventional diagnostic work-up with advanced stage ovarian can- cer
"No" if women included in the tri- al are diagnosed with low-stage disease (FIGO I or IIA) only. No high-stage disease women in the trial
"Unclear" if there is insufficient information on recruitment method, criteria for diagnosis of ovarian cancer

$\begin{array}{ll}\text { 2. Did the study } & \text { "Yes" if there were no inappropri- } \\ \text { avoid inappro- } & \text { ate exclusions } \\ \text { priate exclu- } & \text { "No" if there were inappropriate } \\ \text { sions? } & \begin{array}{l}\text { exclusions } \\ \text { "Unclear" if there is insufficient } \\ \text { information on exclusions }\end{array}\end{array}$

\section{Were the} women planned for primary debulking surgery after conventional diagnostic work-up?
"Yes" if the women were planned for primary debulking surgery after conventional diagnostic workup?

"No" if none of the women were planned for primary debulking surgery

"Unclear" if there is insufficient information
Domain 2

Index Test
Could the interpretation of the Index test have introduced bias? (High/low/unclear)
Are there concerns that the index test, its conduct or the interpretation differ from the review question? (High/low/unclear)
1. Were the index This will always be rated as test results interpreted without the knowledge of the results of the reference standard? dard yes, because the index test is performed before the reference stan-

1. Were the same clinical data available when test results were interpreted as would be available when the test is used in practice?

"Yes" if all usual clinical data (except laparotomy results) are available when the index test is interpreted, including details of physical examination, serum tumour markers, and ultrasound and $\mathrm{CT} / \mathrm{MRI}$ imaging. Also answer "yes" if one of the items is missing "No" if clinical information (as mentioned by "yes") was not available to the gynaecologist "Unclear" if insufficient information is reported.

"Yes" if a clear description is giv-

2.Did the study provide a clear definition of what was considered to be a 'positive' result for the index test? en about when the index test is positive or negative. (e.g. what the cut-off for too extensive abdominal disease was)

"No" if there is no clear description of what is classified as too extensive disease or not "Unclear" if there is insufficient information within the paper to determine whether or not a de- 


\section{Domain 3}

Reference

Standard
Could the interpretation of the reference standard have introduced bias?
(High/low/unclear)

Are there concerns that the target condition as defined by the reference standard does not match the question? (High/low/unclear)

$\begin{array}{ll}\text { 1. Is the refer- } & \text { "Yes" if the reference standard is } \\ \text { ence standard } & \text { laparotomy. } \\ \text { likely to } & \text { "No" if the reference standard } \\ \text { correctly classify } & \text { used is not the one defined in the } \\ \text { the target condi- } & \begin{array}{l}\text { protocol } \\ \text { tion? }\end{array} \\ & \text { "Unclear" if the information is in- } \\ \text { sufficient }\end{array}$

1.Did the study provide a clear definition of what was considered to be a 'positive' result for the reference standard?

\author{
"Yes" if a clear description is giv- \\ en about when the reference stan- \\ dard is positive or negative. (e.g. \\ what the cut-off at laparotomy is \\ for too extensive abdominal dis- \\ ease was) \\ "No" if there is no clear descrip- \\ tion of what is classified as too ex- \\ tensive disease or not \\ "Unclear" if there is insufficient \\ information within the paper to \\ determine whether or not a de- \\ fined threshold was used to a pos- \\ itive test result
}

\section{Were the ref- "Yes" if the report stated that the erence standard reference test is performed by in- results interpret- dividuals who did not perform the ed without the index test knowledge of the "No" if the reference test were results of the in- done by the same person per- dex test? forming the index test "Unclear" if not reported.}

Domain 4 Flow and Timing
Could the patient flow have introduced bias?

(High/low/unclear)

$\begin{array}{ll}\begin{array}{l}\text { 1. Is the time pe- } \\ \text { riod between ref- }\end{array} & \begin{array}{l}\text { Yes" if the time period between } \\ \text { the index test }\end{array} \\ \text { erence standard } & \text { and reference standard is not } \\ \text { and index test } & \text { longer than } 3 \text { weeks } \\ \text { short enough to } & \text { "No" if the time period is more } \\ \text { be reasonably } & \text { than 3weeks for an unacceptable } \\ \text { sure that the tar- } & \text { high proportion of women } \\ \text { get condition did } & \text { "Unclear" if the information on } \\ \text { not change be- } & \text { the timing of tests is not provided } \\ \text { tween the two } & \end{array}$

tween the two tests?

2. Did all women receive the same reference standard?

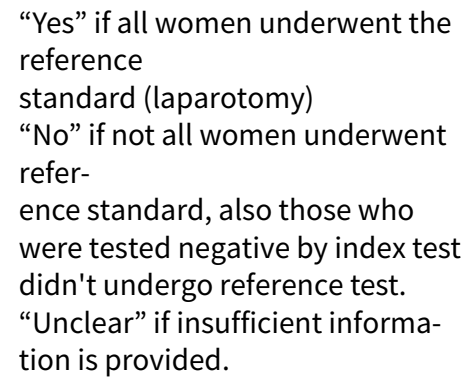

"Yes" if all women underwent the reference standard (laparotomy) "No" if not all women underwent reference standard, also those who were tested negative by index test didn't undergo reference test. "Unclear" if insufficient information is provided. 
(Continued)
3. Were all
"Yes" if for all women entered
women included in the study are included in the
in the analysis? analysis
"No" if not all the women in the
study are included in the analysis
"Unclear" if it is not clear whether
all women were accounted for

\section{WHAT'S NEW}

\begin{tabular}{lll}
\hline Date & Event & Description \\
\hline 10 October 2018 & $\begin{array}{l}\text { New citation required but conclusions } \\
\text { have not changed }\end{array}$ & $\begin{array}{l}\text { New studies included that strengthen the previously reported } \\
\text { conclusions. }\end{array}$ \\
\hline 4 October 2018 & New search has been performed & $\begin{array}{l}\text { Full update of the review. We updated the background with re- } \\
\text { cent literature. We added 11 new studies to the results. }\end{array}$ \\
\hline
\end{tabular}

\section{CONTRIBUTIONS OF AUTHORS}

Drafting the protocol: MJ Rutten, MM Leeflang, GG Kenter, BWJ Mol, MR Buist. Developing the search strategy: MJ Rutten, MM Leeflang, GG Kenter, BWJ Mol, MR Buist. Searching for trials: MJ Rutten, R van de Vrie and JD Asseler. Obtaining copies of trials: MJ Rutten and R van de Vrie. Selecting trials for inclusion: MJ Rutten, MR Buist, R van de Vrie and JD Asseler. Extracting data: MJ Rutten, MR Buist, R van de Vrie and JD Asseler. Carrying out analysis: MJ Rutten, R van de Vrie and MM Leeflang. Interpreting the analysis: R van de Vrie, MJ Rutten, JD Asseler, MM Leeflang, GG Kenter, BWJ Mol, MR Buist. Drafting the final review: R van de Vrie, MJ Rutten, JD Asseler, MM Leeflang, GG Kenter, BWJ Mol, MR Buist. Updating the review: R van de Vrie, MJ Rutten, JD Asseler, MM Leeflang, GG Kenter, BWJ Mol, MR Buist. R van de Vrie took the lead in rewriting the protocol. MJ Rutten is the primary author of the previous publication of the review Rutten 2014.

\section{DECLARATIONS OF INTEREST}

RV: none known

MJR: none known

JDA: none known

MMGL: none known

GGK: none known

BWJM: none known

MB: none known

\section{SOURCES OF SUPPORT}

\section{Internal sources}

- Academic Medical Center Amsterdam, Netherlands.

\section{External sources}

- No sources of support supplied

\section{DIFFERENCES BETWEEN PROTOCOLAND REVIEW}

We removed the subheading "Secondary objectives" because there were limited data on variation in test accuracy according to FIGO stage (FIGO stage IIB until IV or only stage IIIC and IV), and who performed the laparoscopy, a general gynaecologist or gynaecologist-oncologist.

Because definition of test positive, that is unresectable disease, is based on a judgement rather than measurement, we thought different thresholds would be used to define test positivity. Therefore, we planned to analyse and summarise the data using a hierarchical summary receiver operating characteristic (HSROC) model (Rutter 2001). However, because of the few studies we retrieved and the high heterogeneity, data could not be pooled and no meta-analyses were performed. 
In the updated version of this review we made subgroups for outcome macroscopic complete primary debulking surgery $(0 \mathrm{~cm})$ and optimal primary debulking surgery $(<1 \mathrm{~cm})$.

\section{INDEX TERMS}

\section{Medical Subject Headings (MeSH)}

*Laparoscopy; Chemotherapy, Adjuvant; Laparoscopes; Neoplasm, Residual; Ovarian Neoplasms [drug therapy] [pathology] [*surgery]; Randomized Controlled Trials as Topic; Tumor Burden; Validation Studies as Topic

\section{MeSH check words}

Female; Humans 